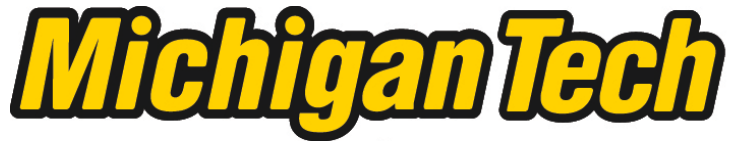 \\ Michigan Technological University Create the Future Digital Commons @ Michigan Tech
}

Dissertations, Master's Theses and Master's Reports - Open

Dissertations, Master's Theses and Master's

Reports

2014

\section{AN INVESTIGATION OF VARIABLE VALVE TIMING EFFECTS ON HCCI ENGINE PERFORMANCE}

Hrishikesh Abhay Saigaonkar

Michigan Technological University

Follow this and additional works at: https://digitalcommons.mtu.edu/etds

Part of the Mechanical Engineering Commons Copyright 2014 Hrishikesh Abhay Saigaonkar

\section{Recommended Citation}

Saigaonkar, Hrishikesh Abhay, "AN INVESTIGATION OF VARIABLE VALVE TIMING EFFECTS ON HCCI ENGINE PERFORMANCE", Master's Thesis, Michigan Technological University, 2014.

https://doi.org/10.37099/mtu.dc.etds/835

Follow this and additional works at: https://digitalcommons.mtu.edu/etds

Part of the Mechanical Engineering Commons 
AN INVESTIGATION OF VARIABLE VALVE TIMING EFFECTS ON HCCI ENGINE

PERFORMANCE

By
Hrishikesh Abhay Saigaonkar

A THESIS

Submitted in partial fulfillment of the requirements for the degree of MASTER OF SCIENCE

In Mechanical Engineering

MICHIGAN TECHNOLOGICAL UNIVERSITY

2014

(c) 2014 Hrishikesh Abhay Saigaonkar 

This thesis has been approved in partial fulfillment of the requirements for the Degree of MASTER OF SCIENCE in Mechanical Engineering.

Department of Mechanical Engineering-Engineering Mechanics

Thesis Advisor: Dr. Mahdi Shahbakhti

Committee Member: Dr. Jeffrey Naber

Committee Member: Dr. Sunil Mehendale

Department Chair: Dr. William Predebon 



\section{Dedication}

\section{To those willing to take the road less traveled...}

Twenty years from now you will be more disappointed by the things that you didn't do than by the ones you did do, so throw off the bowlines, sail away from safe harbor, catch the trade winds in your sails. Explore, Dream, Discover.

-Mark Twain 



\section{Contents}

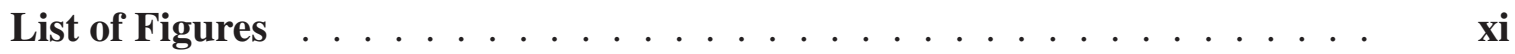

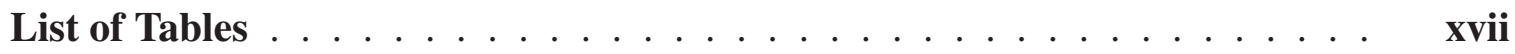

Acknowledgments $\ldots \ldots \ldots \ldots \ldots \ldots \ldots \ldots \ldots \ldots \ldots \ldots \ldots \ldots$ xxii

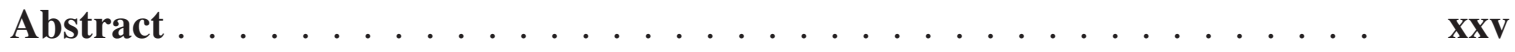

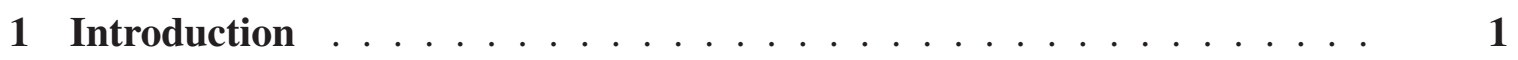

1.1 What is HCCI and why is it needed? . . . . . . . . . . . . 1

1.2 Promises and challenges $\ldots \ldots \ldots \ldots \ldots \ldots \ldots$

$1.3 \mathrm{HCCI}$ combustion chemistry $\ldots \ldots \ldots \ldots \ldots \ldots$

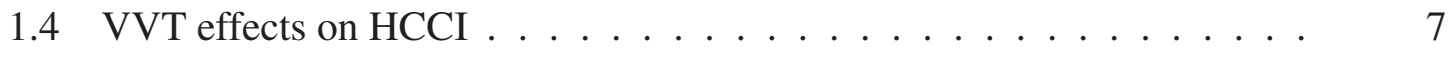

1.5 Scope and organization of thesis $\ldots \ldots \ldots \ldots \ldots$

2 Experimental HCCI Engine Setup $\ldots \ldots \ldots \ldots \ldots \ldots$

2.1 Engine experimental setup $\ldots \ldots \ldots \ldots \ldots \ldots \ldots$

2.2 Experimental measurement of valve profiles $\ldots \ldots \ldots \ldots \ldots$

2.2.0.1 Valve profile measurement procedure . . . . . . 16 
2.3 Compression ratio increase . . . . . . . . . . . . . 19

2.3.1 Piston to valve clearance . . . . . . . . . . . . . 21

2.3.2 Volume measurements ............... 22

2.3.3 Piston selection ...................... 25

2.4 Controllable air heater . . . . . . . . . . . . . . . . 28

2.5 MTU Supercharging Station . . . . . . . . . . . . . 30

2.5.1 Supercharger testing results . . . . . . . . . . . . 34

3 Sequential Combustion Modeling of HCCI Engines with Variable Valve

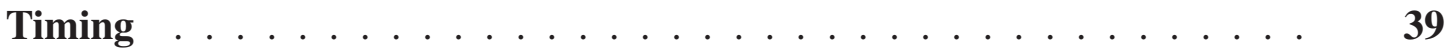

3.1 SMRH Description . . . . . . . . . . . . . . 43

3.1.1 Step 1: 1-D HCCI engine model for conditions at IVC . . . . 45

3.1.2 Step 2: Multi zone modelling (IVC-EVO) . . . . . . . . . 46

3.1.2.1 Multi zone modeling and heat transfer correlations . . 48

3.1.3 Step 3: Exhaust stroke gas flow and RGF model (EVO-EVC) . . 51

3.1.3.1 Determination of $T_{e v c} \ldots \ldots \ldots 51$

3.1.3.2 Flow through Exhaust Valves .......... 52

3.1.4 Step 4: Multi zone modelling in CHEMKIN-PRO (Stage II) . . 54

3.2 Results and Discussion ...................... 56

3.2.1 Model Validation . . . . . . . . . . . . . 56

3.2.2 Results for impact of valve timings on HCCI combustion . . . . 59

3.2.2.1 Effect of IVC variations . . . . . . . . . . 60 


\subsubsection{Effect of EVO variations on HCCI combustion . . . 70}

3.2.3 Virtual Engine Test Bed for Controller Design . . . . . . . . . . 77

4 Summary and Conclusion . . . . . . . . . . . . . . . 85

4.1 Summary of thesis contributions ............... 86

4.2 Future Work . . . . . . . . . . . . . . . . 87

References ......................... 89

A Calculations for cam timing determination . . . . . . . . . . 101

B MSc Publications . . . . . . . . . . . . . . . . . . . . . 104

C Thesis files summary . . . . . . . . . . . . . . 105

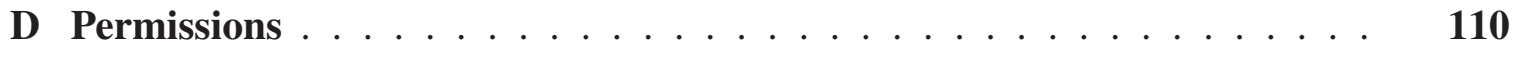




\section{List of Figures}

1.1 Background of main VVT strategies for HCCI combustion. . . . . . . . 8

1.2 Thesis organization $\ldots \ldots \ldots \ldots \ldots$

2.1 Schematic of the HCCI engine setup . . . . . . . . . . . 12

2.2 Experimental HCCI engine setup along with the supercharging station . 13

2.3 (a): Lift measurement at the valve; (b): Overview of the valve profile measurement setup . . . . . . . . . . . . . . 16

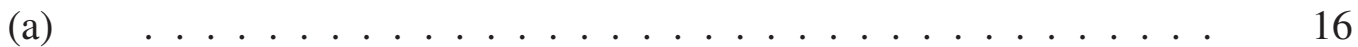

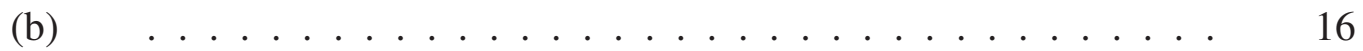

2.4 Piston stop for measuring TDC crank angle . . . . . . . . . . 17

2.5 (a): Intake and exhaust valve profiles for park position and completely phased position; (b): Valve timing diagram for the GM Ecotec LHU engine.

Dotted line near the base indicates the lift $(1 \mathrm{~mm})$ at which valve opening and closing crank angles are measured. . . . . . . . . . . . . 20

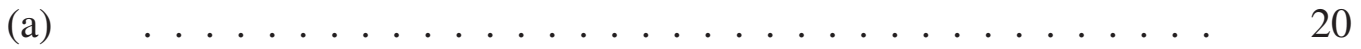

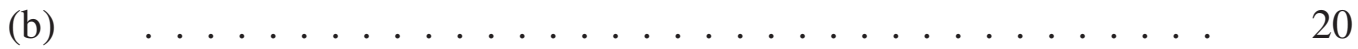


2.6 Measured piston to valve clearance, using the same reference point at which valve lifts are measured . . . . . . . . . . . . . 21

2.7 Experimental measurement of compression ratio . . . . . . . . 23

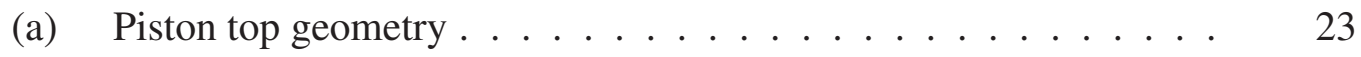

(b) Cylinder head dome volume ............... 23

2.8 Figure showing different sections for which volume measurements are

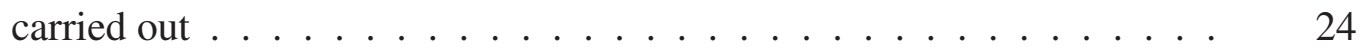

2.9 Stock and new piston top designs . . . . . . . . . . . . . 26

2.10 Design specifications for the increased CR piston from Wiseco . . . . . 27

2.11 Enclosure for housing Omega controller and SSR with heat sink . . . $\quad 29$

2.12 Designed LabView interface to control air heater . . . . . . . . . . . . 29

2.13 Figure showing the supercharger test setup . . . . . . . . . . . 31

2.14 Design details of the intake plenum for carrying supercharged air . . . . 33

2.15 Performance map of the Eaton M62 supercharger[1] . . . . . . . . . . . 34

2.16 Test setup for boost pressure measurement . . . . . . . . . . 35

2.17 Mapping of E-motor speed as a function of input voltage (0-10V) to the

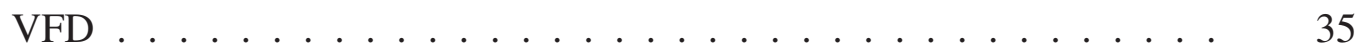

2.18 Test result for boost pressure from the supercharger for 5V input to VFD 36

2.19 Filtered pressure trace with engine motoring at $1500 \mathrm{rpm}$ and supercharger speeds of (a) $3600 \mathrm{rpm}$ and (b) $2700 \mathrm{rpm} \ldots \ldots$. . . . . . . . . . 37

3.1 Simulation models for HCCI combustion modeling available in literature $\quad 40$ 
3.2 Simulation path for the SMRH modeling platform. The path includes four steps shown by circled numbers. . . . . . . . . . . . .

3.3 Single cylinder HCCI engine model in GT - POWER ${ }^{\circledR} \quad \ldots \ldots$. . . 45

3.4 Zone temperature distribution inside a cylinder . . . . . . . . . . . . 47

3.5 Pressure trace validation for the engine operating condition corresponding to case ain Table $3.1 \ldots \ldots \ldots \ldots$

3.6 Pressure trace validation for the engine operating condition corresponding to case bin Table $3.1 \ldots \ldots \ldots \ldots \ldots$

3.7 Pressure trace validation for the engine operating condition corresponding to case cin Table $3.1 \ldots \ldots \ldots \ldots \ldots$

3.8 Intake valve profile variations in this study . . . . . . . . . . . 60

3.9 Exhaust valve profile variations in this study . . . . . . . . . 60

3.10 Variation in in-cylinder gas pressure as a function of intake valve phasing

3.11 Variation in in-cylinder gas temperature as a function of intake valve

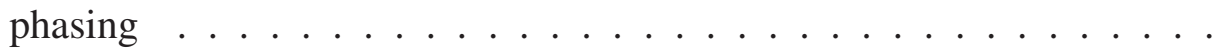

3.12 Variations of combustion metrics (CA10, CA50 and BD) for changes in

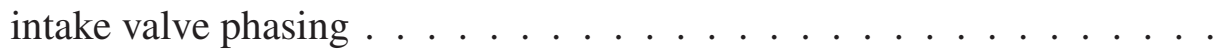

3.13 Impact of intake valve phasing on (a): in-cylinder gas temperature at IVC due to presence of RGF, (b): RGF quantity, (c): temperature of trapped residual gases. . . . . . . . . . . . . . . . 
3.14 Close-up view of in-cylinder gas temperatures history before start of

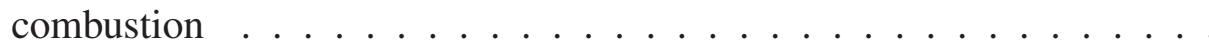

3.15 Variation of IMEP and indicated thermal efficiency $\left(\eta_{\mathrm{th}, \mathrm{i}}\right)$ as a function of intake valve timing $\ldots \ldots \ldots \ldots \ldots$

3.16 Net heat release rate (NHRR) as a function of changing intake valve timing

3.17 Impact of intake valve timing on Carbon monoxide $(\mathrm{CO})$ concentration and maximum gas temperature $\left(\mathrm{T}_{\max }\right)$ averaged including all ten zones . . .

3.18 Unburned hydrocarbons ( $\mathrm{uHC}$ ) concentration and maximum zone averaged gas temperature $\left(\mathrm{T}_{\max }\right)$ as a function of intake valve timing $\ldots \ldots$.

3.19 Zone temperature versus CAD for $\mathrm{IVC}=-140^{\circ} \mathrm{aTDC}_{\mathrm{f}}$ showing peak temperature above $1500 \mathrm{~K}$ for zone $\# 7 \ldots \ldots \ldots$

3.20 $\mathrm{CO}$ and $\mathrm{CO}_{2}$ variation versus crank angle for $\mathrm{IVC}=-140^{\circ} \mathrm{aTDC}$ f showing late oxidation of $\mathrm{CO}$ to $\mathrm{CO}_{2}$, leading to low $\mathrm{CO}$ concentration for this operating point $\ldots \ldots \ldots \ldots \ldots$

3.21 Variation of in-cylinder gas pressure vs. CAD as a function of exhaust valve

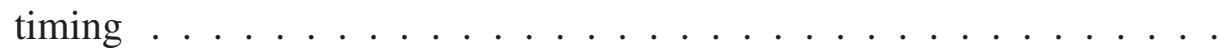

3.22 Variation of in-cylinder gas temperature vs. CAD as a function of exhaust valve timing

3.23 Effect of phasing exhaust valve timing on combustion metrics including

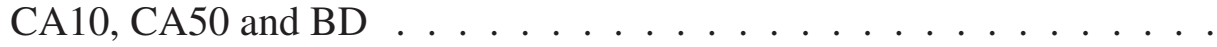


3.24 Effect of phasing EVO timing on (a): gas temperature at IVC, (b): RGF quantity, (c): temperature of trapped residual gases. . . . . . . . . .

3.25 Variation of IMEP and indicated thermal efficiency $\left(\eta_{\mathrm{th}, \mathrm{i}}\right)$ as a function of exhaust valve phasing . . . . . . . . . . . . .

3.26 Net heat release rate (NHRR) versus CAD as a function of exhaust valve

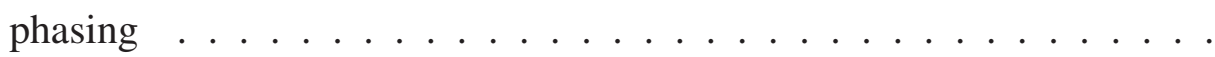

3.27 $\mathrm{CO}$ emissions and maximum zone averaged gas temperature as a function

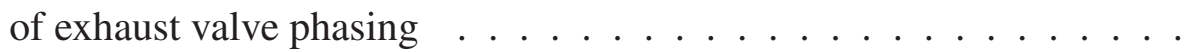

$3.28 \mathrm{uHC}$ emissions and maximum zone averaged gas temperature as a function

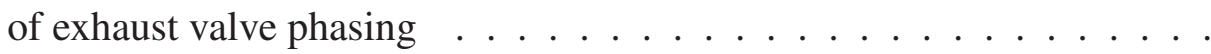

3.29 Schematic of SMRH based virtual engine test bed for HCCI combustion controller design . . . . . . . . . . . . . . . . . .

3.30 Contour plot of engine indicated thermal efficiency $\left(\eta_{\text {th,i }}\right)$ as a function of valve timing for the constant loadcase study. (IMEP $=5.5 \pm 0.2$ bar) . . .

3.31 Raw emission index (REI) contour plot as a function of valve timings for the constant loadcase study. (IMEP $=5.5 \pm 0.2$ bar $) \ldots \ldots . . . .$.

3.32 CA50 contour plot as a function of valve timings for the constant loadcase study. $(\mathrm{IMEP}=5.5 \pm 0.2$ bar $) \ldots \ldots \ldots \ldots$

3.33 $\mathrm{T}_{\mathrm{ivc}-\bmod }$ contour plot as a function of valve timings for the constant loadcase study. $($ IMEP $=5.5 \pm 0.2$ bar $) \ldots \ldots . . . .$. 
3.34 Contour plot of fuel efficiency and emissions (FEE) index for the constant loadcase study. $($ IMEP $=5.5 \pm 0.2$ bar $) \ldots \ldots$. . . . . . . . 82

3.35 Contour plot of fuel efficiency and emissions (FEE) index for the constant fuelcase study. $\left(\dot{\mathrm{m}}_{\mathrm{f}}=0.3752 \mathrm{~kg} / \mathrm{hr}\right) \ldots \ldots . \ldots . \ldots 8$ 


\section{List of Tables}

2.1 Engine specifications (GM Ecotec LHU A20NFT) . . . . . . . . . . 12

2.2 Valve timing data for the Ecotec LHU engine . . . . . . . . . . . 19

2.3 Measurements for engine combustion chamber volume . . . . . . . 25

2.4 Air heater specifications $[2] \ldots \ldots \ldots \ldots \ldots$

2.5 E-motor specifications mentioned on the physical motor . . . . . . . 31

2.6 E-motor insulation classes by NEMA [3] . . . . . . . . . . . . 32

2.7 VFD specifications . . . . . . . . . . . . . . 32

3.1 Engine operating conditions of the experimental data [4] used to validate $\mathrm{SMRH} \ldots \ldots \ldots \ldots \ldots \ldots \ldots \ldots$

3.2 Zone mass distribution for SMRH. This mass distribution is based on the results in [5] and is modified suitably. . . . . . . . . . . .

3.3 Constants used in the Woschni correlation for multi zone modeling in

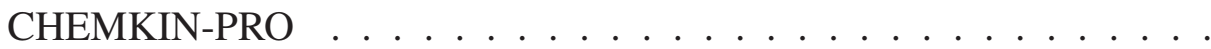

3.4 Ricardo single cylinder engine specifications . . . . . . . . . . 
3.5 Comparison between experimental (Exp.) and simulated (Sim.) combustion phasing, IMEP, indicated thermal efficiency $\left(\eta_{\mathrm{th}, \mathrm{i}}\right)$ and $\mathrm{CO}$ emission ............................... 59

C.1 Experimental data files . . . . . . . . . . . . . . 105

C.2 Matlab script files for HCCI simulation . . . . . . . . . . . . 106

C.3 GT-POWER ${ }^{\circledR}$ and CHEMKIN ${ }^{\circledR}$ - PRO files . . . . . . . . . . . 106

C.4 Matlab figure (.fig) files for Chapter $2 \ldots \ldots$. . . . . . . 106

C.5 Image files for Chapter $2 \ldots \ldots \ldots$. . . . . . . . . 107

C.6 Matlab figure (.fig) files for Chapter $3 \ldots \ldots$. . . . . . . 108

C.7 Visio figures . . . . . . . . . . . . . . . . . . 109 


\section{Nomenclature}

$\mathrm{CO}_{2}$ Carbon Dioxide

$\mathrm{N}_{2} \quad$ Nitrogen

$\Phi \quad$ Equivalence ratio [-]

$\rho \quad$ Density $\left[\frac{\mathrm{kg}}{\mathrm{m}^{3}}\right]$

$C_{D} \quad$ Discharge coefficient [-]

$C_{p} \quad$ Constant-pressure specific heat capacity $\left[\frac{\mathrm{kJ}}{\mathrm{kg} . \mathrm{K}}\right]$

$C_{v} \quad$ Constant-volume specific heat capacity $\left[\frac{\mathrm{kJ}}{\mathrm{kg} . \mathrm{K}}\right]$

$C A_{X} \quad$ Crank angle for $\mathrm{X} \%$ burnt fuel [CAD aTDC]

$k \quad$ Ratio of specific heat capacities [-]

L Instantaneous cylinder height [m]

$L_{v} \quad$ Exhaust valve axial lift [m] 


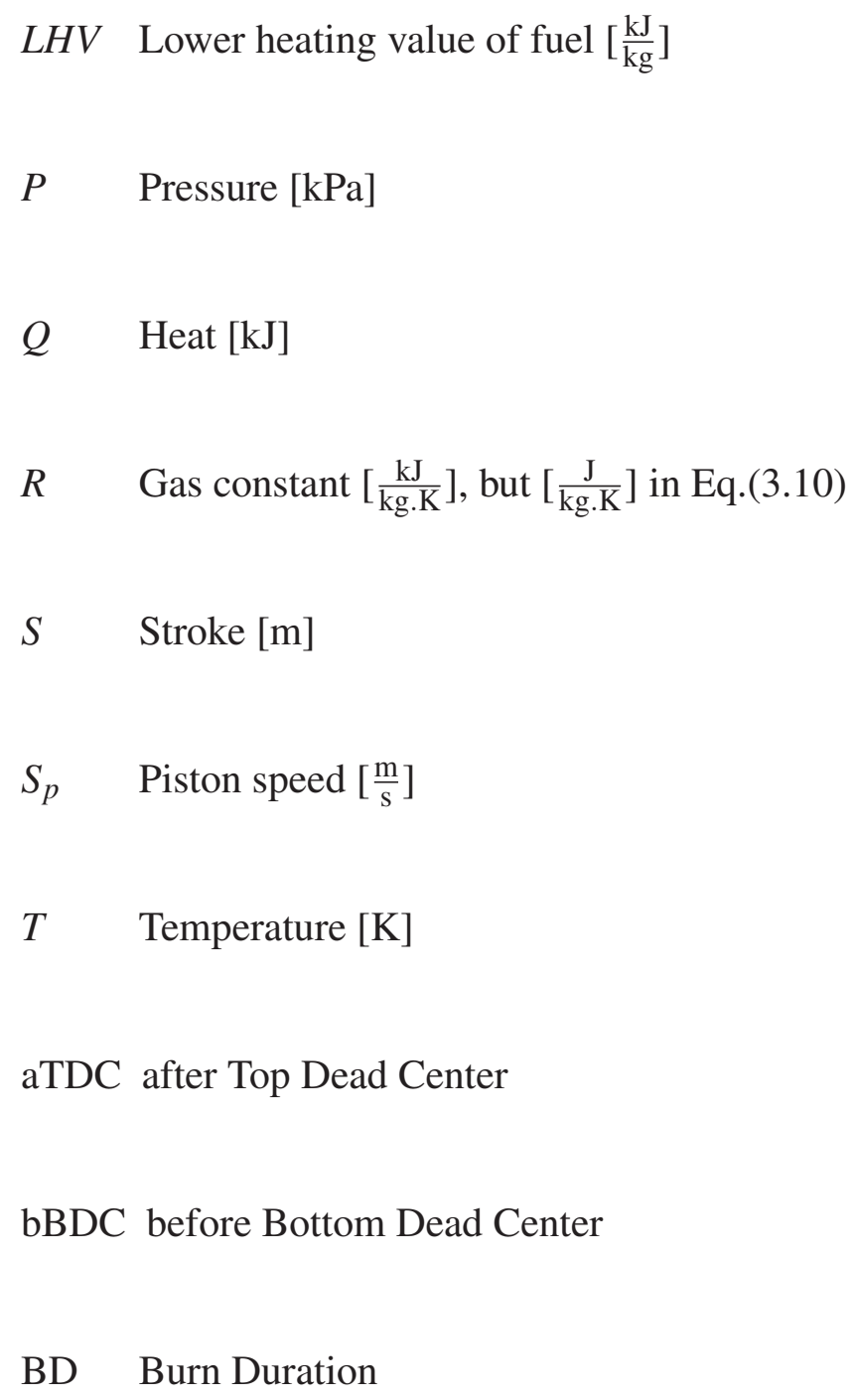


ETC Exothermal Center

EVC Exhaust Valve Closing

EVO Exhaust Valve Opening

HCCI Homogeneous Charge Compression Ignition

IVC Intake Valve Closing

IVO Intake Valve Opening

LES Lotus Engine Simulation

MTU Michigan Technological University

NVO Negative Valve Overlap

ON Octane Number

PFI Port Fuel Injection

PM Particulate Matter

PVO Positive Valve Overlap

RGF Residual Gas Fraction

RPM Revolution per Minute

SMRH Sequential Model for Residual affected HCCI 
SOC Start of Combustion

TKM Thermo Kinetic Model

uHC unburned Hydrocarbons

VCR Variable Compression Ratio

VVT Variable Valve Timing 


\section{Acknowledgments}

I consider this work to be an effort which was made possible through the encouragement, help and advice of many. I wish to take this opportunity to thank all those who have knowingly or unknowingly made a contribution to this effort.

I first wish to thank my advisor Dr. Mahdi Shahbakhti for providing me this opportunity to learn, and guide me through my research. I am fortunate to have witnessed his amazing organization skills and his dedication to his students. I also want to thank my defense committee members Dr. Naber and Dr. Mehendale for their valuable comments and reviews on my work.

I want to thank Mohammadreza Nazemi for his help in understanding HCCI combustion studies, it was a pleasure working with you. I thank Paul Dice, Vishal, Dennis, Deepak, Fouad, Zhao, Ninad and Shivaram for helping with the engine experimental setup. Special thanks to Ajinkya, Anup, Raviteja, Venugopal, Jayadev, Seyfi, Sunit, Ashutosh and Kaveh for their help with the supercharger and air heater setups. I wish to thank Mehran, Meysam and Mohammad Reza for helping me with Latex.

Finally I wish to thank all of my family, especially Abhay \& Shubhangi Saigaonkar, Soham Saigaonkar, Kiran Kulkarni, Sachin Kulkarni and my grandmother Kusum Kulkarni for their love and constant support throughout this journey. My roommates Shinde, Murali, Vyankatesh, Naag and friends at Michigan Tech who were an instrumental part of this journey, I thank you for the good times. 



\section{Abstract}

The Homogeneous Charge Compression Ignition (HCCI) engine is a promising combustion concept for reducing $\mathrm{NO}_{\mathrm{x}}$ and particulate matter (PM) emissions and providing a high thermal efficiency in internal combustion engines. This concept though has limitations in the areas of combustion control and achieving stable combustion at high loads. For HCCI to be a viable option for on-road vehicles, further understanding of its combustion phenomenon and its control are essential. Thus, this thesis has a focus on both the experimental setup of an HCCI engine at Michigan Technological University (MTU) and also developing a physical numerical simulation model called the Sequential Model for Residual Affected HCCI (SMRH) to investigate performance of HCCI engines. The primary focus is on understanding the effects of intake and exhaust valve timings on HCCI combustion.

For the experimental studies, this thesis provided the contributions for development of HCCI setup at MTU. In particular, this thesis made contributions in the areas of measurement of valve profiles, measurement of piston to valve contact clearance for procuring new pistons for further studies of high geometric compression ratio HCCI engines. It also consists of developing and testing a supercharging station and the setup of an electrical air heater to extend the HCCI operating region. The HCCI engine setup is based on a GM 2.0 L LHU Gen 1 engine which is a direct injected engine with variable 
valve timing (VVT) capabilities.

For the simulation studies, a computationally efficient modeling platform has been developed and validated against experimental data from a single cylinder HCCI engine. In-cylinder pressure trace, combustion phasing (CA10, CA50, BD) and performance metrics IMEP, thermal efficiency, and $\mathrm{CO}$ emission are found to be in good agreement with experimental data for different operating conditions. Effects of phasing intake and exhaust valves are analyzed using SMRH. In addition, a novel index called Fuel Efficiency and Emissions (FEE) index is defined and is used to determine the optimal valve timings for engine operation through the use of FEE contour maps. 


\section{Chapter 1}

\section{Introduction}

\subsection{What is HCCI and why is it needed?}

Combustion in Spark Ignition (SI) engines is initiated by the discharge of a high intensity spark to initiate combustion. Compression Ignition (CI) engines on the other hand rely on compressing air upto the self-ignition temperature of fuel to cause compression ignition by injecting fuel at high pressure to initiate a diffusive flame [6]. HCCI combustion is a Low Temperature Combustion (LTC) regime which can be said to have combined characteristics of SI and CI engines. This is because the homogeneous air-fuel mixture (i.e., similar to SI engines fuel-air charge preparation) is spontaneously ignited when the fuel auto-ignition temperature is reached; thus combustion is compression ignition, similar to CI engines. 
This type of combustion is difficult to control due to not having a definite means of actuation, such as a spark plug in SI engines. In an HCCI engine, multiple exothermal centers (ETC) act as ignition points [7]. The combustion is controlled by means of chemical kinetics, while mixing and turbulence effects are not of prime importance [8]. In order to control the ETCs it is important to achieve control over the mixture homogeneity with regards to temperature and composition. A characteristic of HCCI combustion is a rapid heat release which is the reason for its high thermal efficiency as it resembles ideal constant volume combustion [9].

Compared to SI engines, HCCI has the advantage of low cyclic variation and a high thermal efficiency at low equivalence ratios and low loads. In diesel engines a challenging trade-off exists between soot and $\mathrm{NO}_{\mathrm{x}}$ and it is difficult to reduce both soot and $\mathrm{NO}_{\mathrm{x}}$. $\mathrm{HCCI}$ addresses this challenge since $\mathrm{NO}_{\mathrm{x}}$ emissions and soot are low for HCCI engines as compared to diesel engines. High uHCs and $\mathrm{CO}$ emissions are drawbacks for HCCI engines compared to both SI and CI engines [7].

HCCI combustion is controlled by chemical kinetics and the start of combustion is dependent on the chemical compositions and the thermodynamic properties inside the cylinder [10]. For perfectly controlled combustion phasing and mixture preparation [11], there are five important factors:

i) initial mixture temperature

ii) initial mixture pressure 
iii) initial mixture composition

iv) rate and extent of compression work

v) local and global in-cylinder heat transfer $(\mathrm{HT})$ rate

The first four factors are easier to control since HT cannot be directly controlled during engine operation and is generally dependent on engine design and operating conditions [11]. A very basic way of directly controlling initial temperature is by using intake air heating ([12], [13]). Intake air boosting [14] can be used as a means to control initial pressure. In-cylinder composition can be modified by using different fuels [15] with different reactivities or by varying the amount of internal or external exhaust gas recirculation (EGR). Internal EGR is one of the most viable strategies for realizing HCCI in the current fleet of engines which typically have basic Variable Valve Timing (VVT) capabilities. Hot exhaust gases trapped inside the cylinder influence both the initial temperature and composition of the next cycle. Hence, a separate actuator is not needed for each individual case of factors affecting initial conditions [11]. For example a VVT actuator addresses several factors; Intake Valve Closing (IVC) timings can be varied to change the effective compression ratio, which can be used for combustion phasing and/or load control depending on the strategy used $[11,16]$. Such a case is based on the Miller cycle, which has a reduced duration compression event as compared to expansion event $[10,17]$. IVC timing can also be used for load control as per studies in HCCI engines [16, 18]. 


\subsection{Promises and challenges}

The main advantage of HCCI combustion is low fuel consumption due to overall lean operating conditions and thermal efficiency as high as 50\% [8]. HCCI also has the advantage of low (or negligible) $\mathrm{NO}_{\mathrm{x}}$, Particulate Matter (PM) emissions. In addition, throttling losses are eliminated in HCCI engines by running the engine at Wide Open Throttle (WOT) conditions. These make HCCI technology an attractive option to meet future fuel consumption and $\mathrm{NO}_{\mathrm{x}}, \mathrm{PM}$ emission regulations. The market penetration of HCCI technology is severely limited by the inability to have a robust mechanism for combustion control [8]. Apart from combustion control, the researchers in [19] have identified the following challenges to HCCI technology. These challenges include, high levels of noise along with $\mathrm{uHC}$ and $\mathrm{CO}$ emissions, limited operating range and difficulty to start in HCCI mode during cold start and homogeneous mixture preparation in order to reduce $\mathrm{uHC}$ and PM emissions.

HCCI combustion is largely influenced by chemical kinetics. Thus, the heat release rates and the pressure rise rates are much more than a SI or CI engine. This is because, for SI and CI engines, flame propagation, mixing and fuel vaporization rates reduce the heat release rate. HCCI technology is not suited for high load applications. Power output can be controlled by varying the mass flow rate of fuel. But, having rich combustion increases the chance for ringing. 
Overall, HCCI is a promising engine technology with several major challenges before realizing in practice. This thesis centers on providing uderstanding into HCCI combustion as a function of VVT which is currently considered the most practical method to control HCCI combustion.

\subsection{HCCI combustion chemistry}

HCCI combustion can be controlled by varying the fuel reactivity. Octane Number (ON) of the fuel is an important metric in determining the auto-ignition behaviour of the fuel. Fuels can be classified into two categories including

(i) fuels with single stage heat release

(ii) fuels with two or multiple stages of heat release

Fuels having low octane numbers such as n-heptane, diesel, PRF80 show two stages of heat release while fuels such as iso-octane, gasoline, ethanol display single stage heat release [8]. Di-methyl Ether (DME) exibits a three-stage heat release pattern [20]. The focus in this thesis is on two-stage heat release type of fuels including n-heptane.

The first stage of heat release is known as Low Temperature Heat Release (LTHR). The main stage of heat release occurs due to $\mathrm{H}_{2} \mathrm{O}_{2}$ decomposition which readily occurs at 
temperatures above $1000 \mathrm{~K}$. Below $1000 \mathrm{~K}$ the decomposition reaction is slow. LTHR causes some fuel to partially burn at temperatures below $850 \mathrm{~K}[21,22,23]$, resulting in an increase in the in-cylinder temperatures by 10 to $20 \mathrm{~K}[24,23,25]$. This is important to reduce the requirement of heating intake air in HCCI. The heat released during this first stage of heat release is due to the production of $\mathrm{OH}$ radicals which happens below $850 \mathrm{~K}[22,24,23]$. The reactions leading to $\mathrm{OH}$ radical formation are very sensitive to pressure and temperature and are inhibited at temperatures of $850 \mathrm{~K}$ or above [26]. This means that high intake temperatures cause lower LTHR $[27,28]$. The temperature rise from $850 \mathrm{~K}$ to $1000 \mathrm{~K}$ is primarily due to compressing the mixture due to compression by piston moving towards TDC [28]. The next major heat release stage occurs at $1000 \mathrm{~K}$ due to rapid breakdown of $\mathrm{H}_{2} \mathrm{O}_{2}$ radicals [26]. Further decomposition of $\mathrm{H}_{2} \mathrm{O}_{2}$ leads to auto-ignition of air-fuel mixture. At temperatures above $1200 \mathrm{~K}$, High Temperature Reactions (HTR) occur $[26,29]$.

Fuel molecules having more number of secondary carbon bonds are favourable to show two-stage heat release, since the secondary bond is weaker than the primary bond [8]. Consequently, long straight chained molecules (e.g., n-heptane) are more suited for LTHR as compared to branched molecules (e.g., iso-octane, or ethanol) [8]. 


\subsection{VVT effects on HCCI}

As previously discussed in section 1.1, internal EGR is identified as a viable option for achieving part load HCCI in the current fleet of engines with VVT capabilities. VVT can be used in three ways to affect HCCI combustion. These three ways include:

1) Recompression

2) Rebreathing

\section{3) Effective CR}

Of these three methods, the first two have a direct relation with trapping exhaust gases so as to affect the initial conditions for the next cycle. The geometric CR of engines depends on engine design, but adjusting the time the intake valve closes, causes the effective CR to be controlled. A comprehensive literature review is carried out to classify studies done in these three categories and is shown in Figure 1.1. Recompression consists of trapping exhaust gases by not letting them out from the cylinder in the exhaust stroke $[8,9,17,30,31]$ while rebreathing $[32,33]$ is achieved by the use of positive valve overlap (PVO) where both intake and exhaust valves are kept open over the gas exchange Top Dead Center (TDC). In a study by [33], the rebreathing strategy was successfully used to achieve HCCI combustion for different engine operating conditions giving a higher thermal efficiency as compared to SI operation. Caton et.al [11] studied the effects of changing the effective CR on an HCCI engine for independent load and combustion phasing. The amount of dilution was 

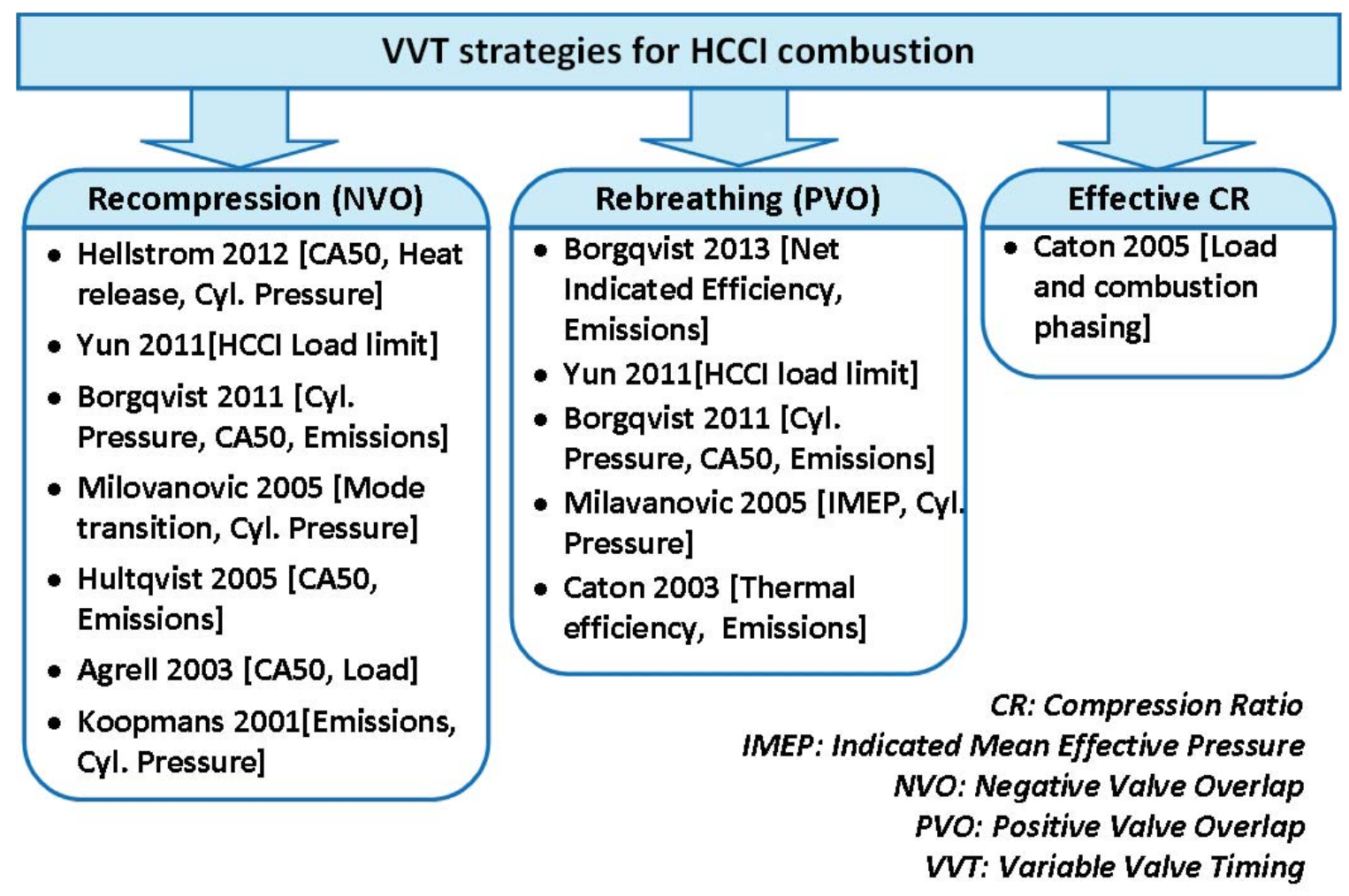

Figure 1.1: Background of main VVT strategies for HCCI combustion.

fixed, and it was found that the IVC timing played a significant role in controlling HCCI combustion. A similar study in [34] concluded that the method of IVC timing control can be successfully used to extend the range of HCCI operation, since the amount of Negative Valve Overlap (NVO) achievable in the Recompression method is limited by the engine valve train system. 


\subsection{Scope and organization of thesis}

Current United States' Corporate Average Fuel Economy (CAFE) has a target of $54.5 \mathrm{mpg}$ for cars and light duty trucks by the model year 2025 [35]. This target cannot be met by the current engines operating in SI or CI modes. HCCI engines hold the promise for lowering fuel consumption and emissions but their market penetration is blocked by the control challenges mentioned previously. $\mathrm{HCCI}$ engines are flexible and can be used in conventional and hybrid electric vehicle configurations to meet future CAFE standards.

Simulation models provide solution for proper control of $\mathrm{HCCI}$ as these models provide understanding of HCCI governing thermo-kinetic reactions. But, simulation models which can predict $\mathrm{HCCI}$ combustion need high computational resources and lack the flexibility to model VVT operating conditions. The aim of this thesis is to develop a simulation model for predicting residual affected $\mathrm{HCCI}$ combustion which will be computationally efficient and have the flexibility to model a variety of VVT operating conditions. At the same time this model should predict engine performance results accurately. To this end, a sequential model called Sequential Model for Residual Affected HCCI (SMRH) is developed in this thesis and results are validated against the experimental data from a single cylinder Ricardo HCCI engine [4]. In addition, this thesis provides contributions in developing an HCCI engine setup at Michigan Technological University. This engine setup will be used as a framework for future advanced HCCI engine studies. 
This thesis is organized in four chapters as shown in Figure 1.2. Next, Chapter includes the work done for developing an HCCI experimental setup for the test cell at Michigan Tech. Chapter 3 consists of the simulation model (SMRH) developed for studying HCCI combustion and engine cycle. Chapter 4 includes the conclusions from this thesis along with some suggestions for future work.

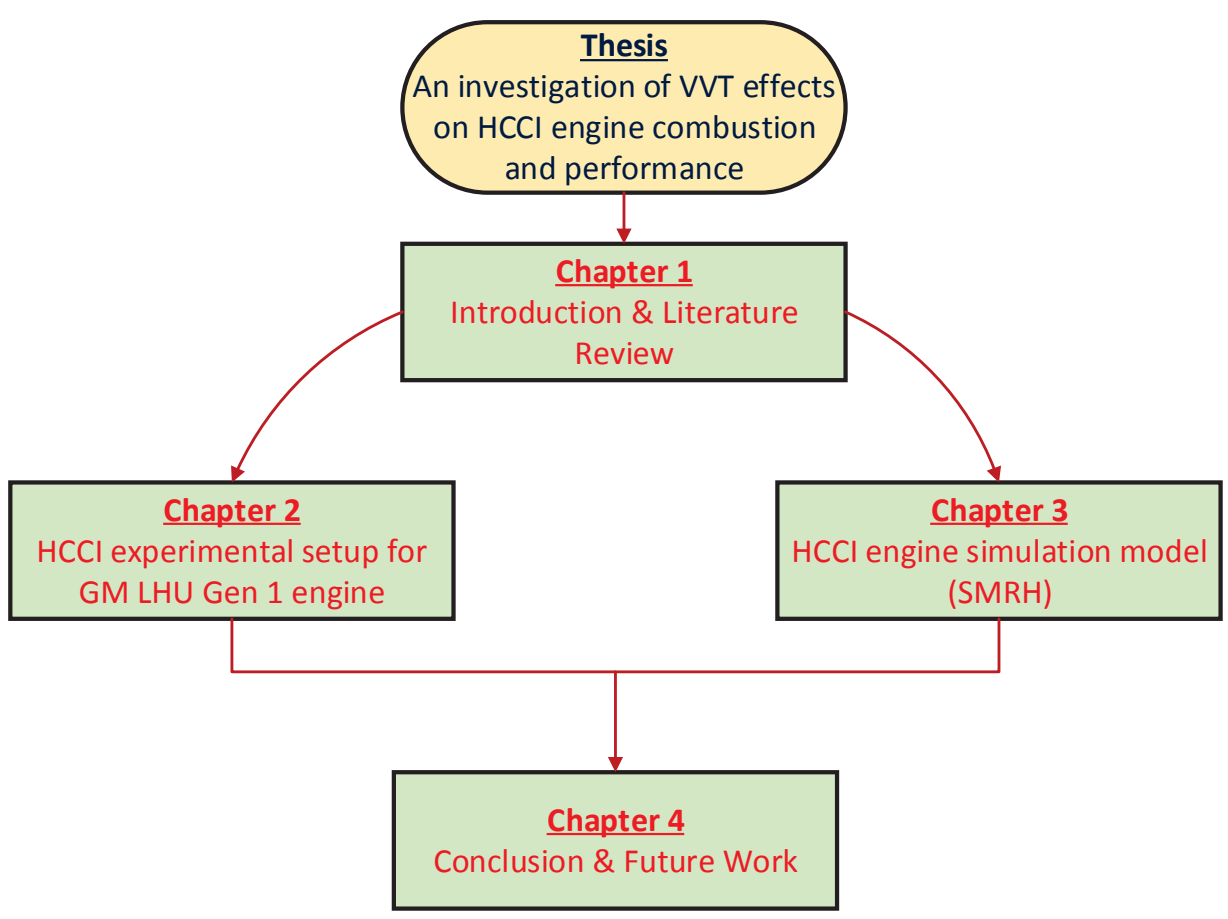

Figure 1.2: Thesis organization 


\section{Chapter 2}

\section{Experimental HCCI Engine Setup}

An experimental HCCI engine setup was designed and implemented through collaborative efforts. This chapter includes the major contributions from this thesis, while other contributions to build the engine setup can be found in $[36,37]$.

\subsection{Engine experimental setup}

Figure 2.1 shows the schematic of the entire experimental test setup for HCCI studies. A GM 2.0L Gasoline Direct Injection (GDI) Ecotec LHU Gen 1 engine is modified and instrumented in order to run in HCCI mode. The engine mounted on a cart and connected to the supercharging station as shown in Figure 2.2. The engine specifications are shown 


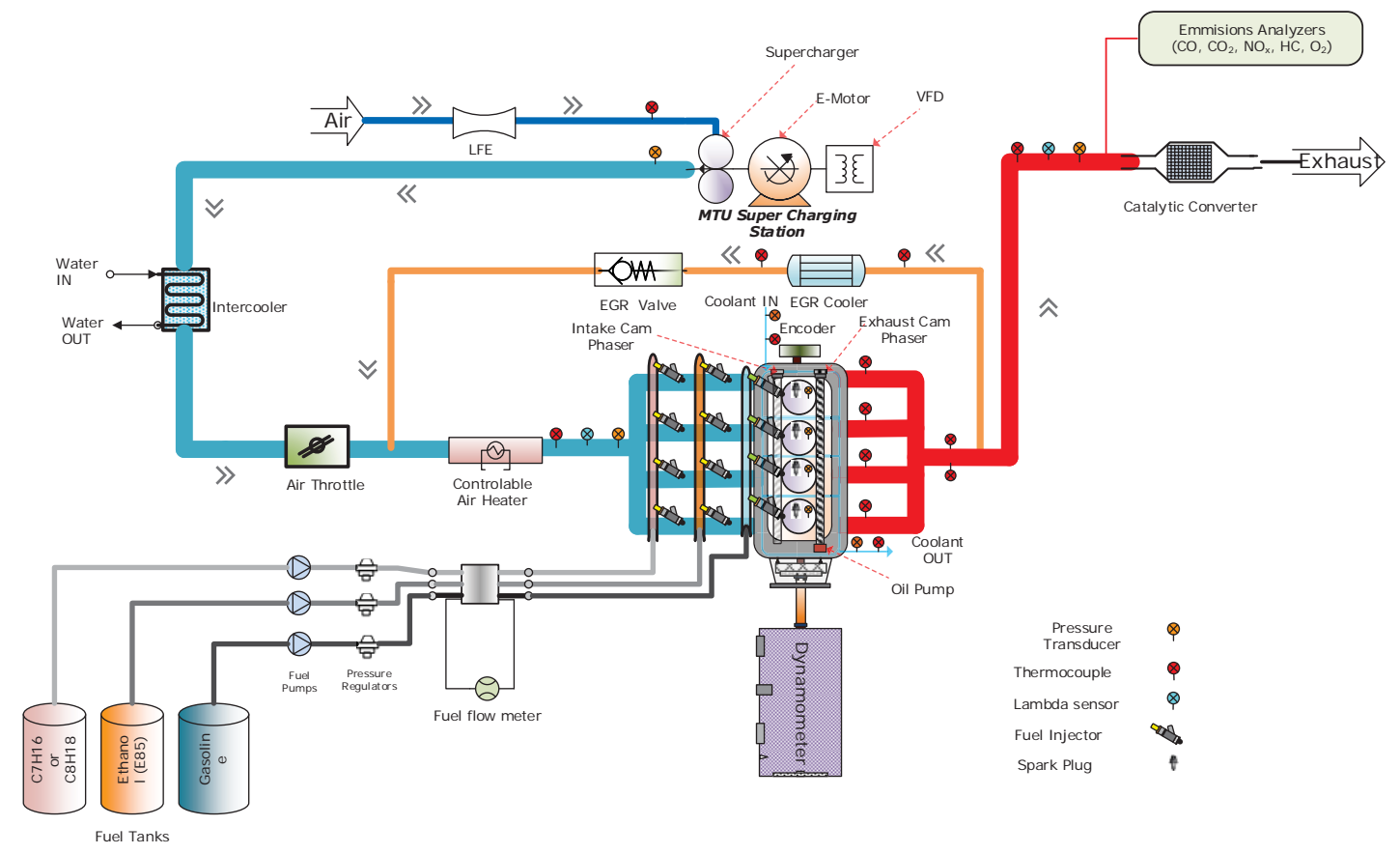

Figure 2.1: Schematic of the HCCI engine setup

Table 2.1

Engine specifications (GM Ecotec LHU A20NFT)

\begin{tabular}{cc}
\hline \hline Parameter & Value \\
\hline Bore & $86(\mathrm{~mm})$ \\
Stroke & $86(\mathrm{~mm})$ \\
Connecting rod length (center to center) & $145.5(\mathrm{~mm})$ \\
Compression Ratio & $9.2: 1$ \\
Displacement Volume & $2.0 \mathrm{~L}$ \\
Max Power@ RPM & 270kW@6000 rpm \\
Measured IVO/IVC @ 1mm lift & $24.5 / 228$ aTDC \\
Measured EVO/EVC @ 1mm lift & $36 /-158$ bBDC \\
Fuel injection system & Direct injection with \\
Valvetrain & 31 bar @ idle, 155 bar @ WOT [38] \\
Cam phasing mechanism & DOHC 4 valves/cylinder
\end{tabular}

in Table 2.1. It is a four-cylinder gasoline engine with dual overhead camshafts (DOHC) obtained from a 2011 Buick Regal. The engine under study is of the type A20NFT which is 
a high performance version of the LHU engine. This A20NFT engine is a European version of the original LHU. The difference with the North American version of the engine is use of a better alloy grade to work with higher octane rated fuels used in Europe. The following

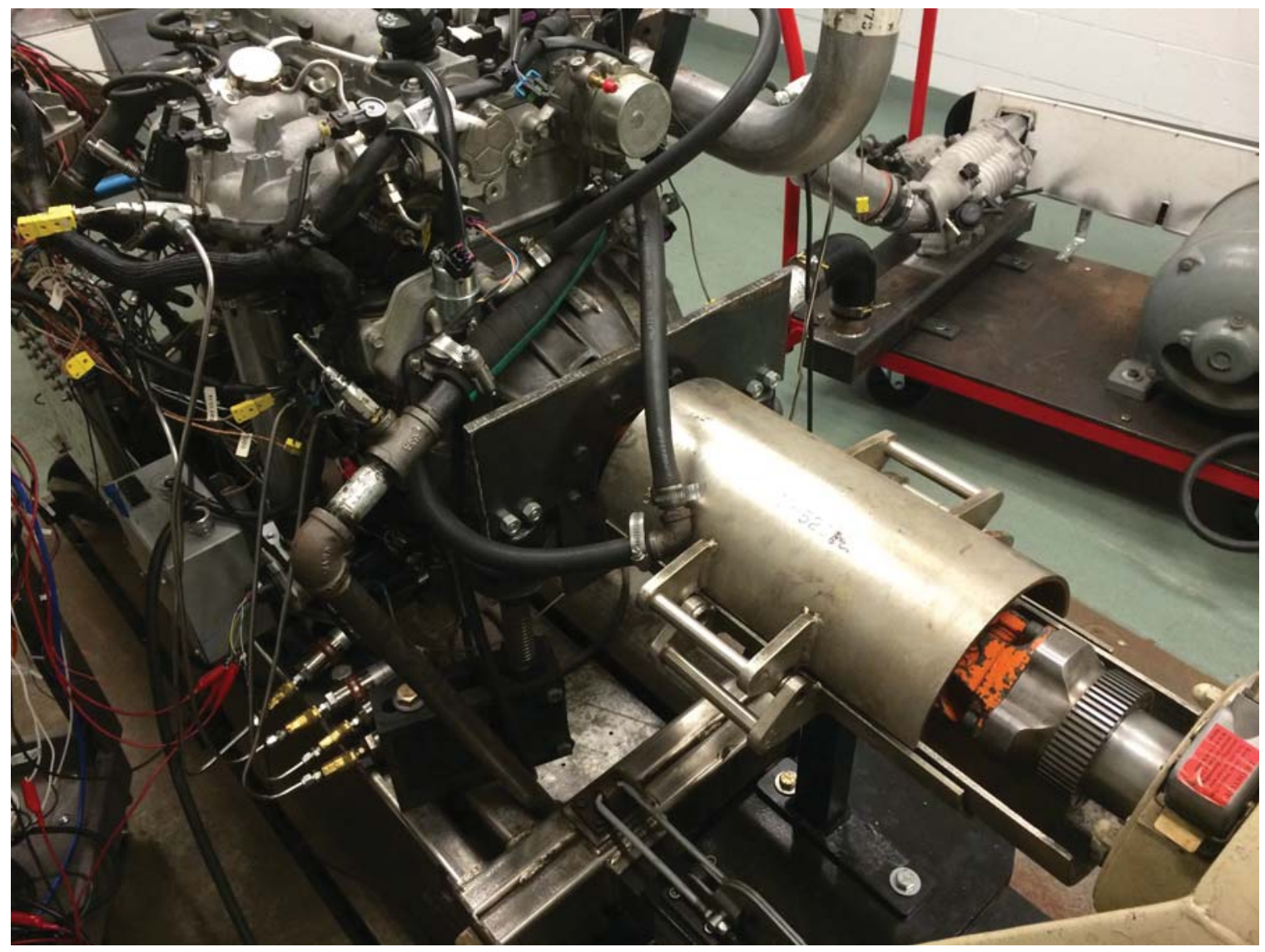

Figure 2.2: Experimental HCCI engine setup along with the supercharging station

sections explain the four major contributions from this thesis to build an experimental HCCI engine setup at Michigan Technological University. In particular this thesis has four contributions:

1. Experimental measurement of valve profiles for future modeling and control of HCCI 
combustion

2. Increase in engine compression ratio (CR) to enable HCCI operation in a broad operating region

3. Design and implementation of controllable air heater setup to adjust temperature of intake charge

4. Design and implementation of supercharging station setup to control intake air boost pressure and air flow rates

For making the engine suitable to operate in a test cell a few modifications are made. The wiring harness of the engine is modified so as to accept $12 \mathrm{~V}$ supply from the NI DAQ system linked to the test cell computer. An EGR line is tapped into the exhaust manifold to enable exhaust gas recirculation to prepare dilute mixtures for HCCI combustion. An electrically controlled intake air heater is also added downstream of the intercooler (Figure 2.1). The stock position of the throttle valve is changed to upstream of the air heater in order to protect the throttle valve from high temperatures. Exhaust gases from external EGR line are mixed with intake air between the throttle and the air heater as shown in Figure 2.1. The outlet of the EGR line is made downstream of the throttle so as to obtain maximum amount of exhaust gases from the vacuum generated during the induction stroke. A supercharging station is built to provide boosted air which is proven to increase load range in HCCI engines [14]. The test setup for the supercharging station will be discussed in Section 2.5. Dynamometer testing for research purposes involves measuring 
in-cylinder pressure data through pressure transducers. The stock cylinder head on the engine is replaced with a new machined cylinder head to allow installation of in-cylinder pressure transducers. The encoder installation previously done in [36] is modified by using shims to remove any eccentricities.

\subsection{Experimental measurement of valve profiles}

A test setup was built to measure valve profiles to achieve two purposes. One is to generate valve profiles and understand the phasing ability and the second is to check the probability of piston to valve contact (Section 2.3) for modifying engine pistons to increase compression ratio for HCCI operation. The test setup for valve profile measurement is shown in Figure 2.3. In order to obtain the valve opening and closing timings in crank angle degrees, valve profiles are experimentally measured and the resulting data is plotted to generate lift versus Crank Angle Degree (CAD) curves. The LHU engine consists of independent cam phasers for intake and exhaust camshafts. The cam phasers are hydraulically actuated using an oil pump located at the drive shaft end of the exhaust camshaft. The cam actuation solenoids adjust the flow of oil so that the required phasing can be achieved. Phasing authority of $50 \mathrm{CAD}$ is available on the LHU engine. The cam phasers are hydraulically operated with an internal vane mechanism for phasing. At the park position, the intake cam is fully retarded while the exhaust cam is fully advanced. Hence, the valve overlap is minimum at park position and increases during phasing. 


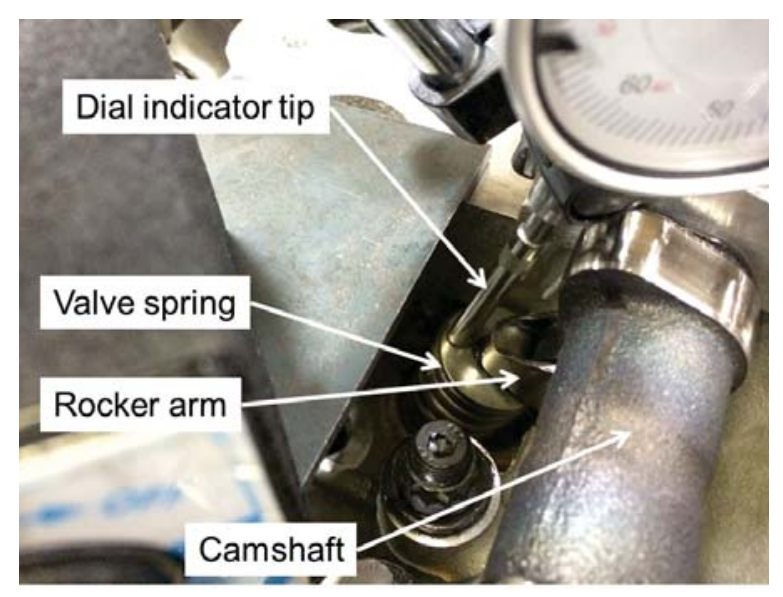

(a)

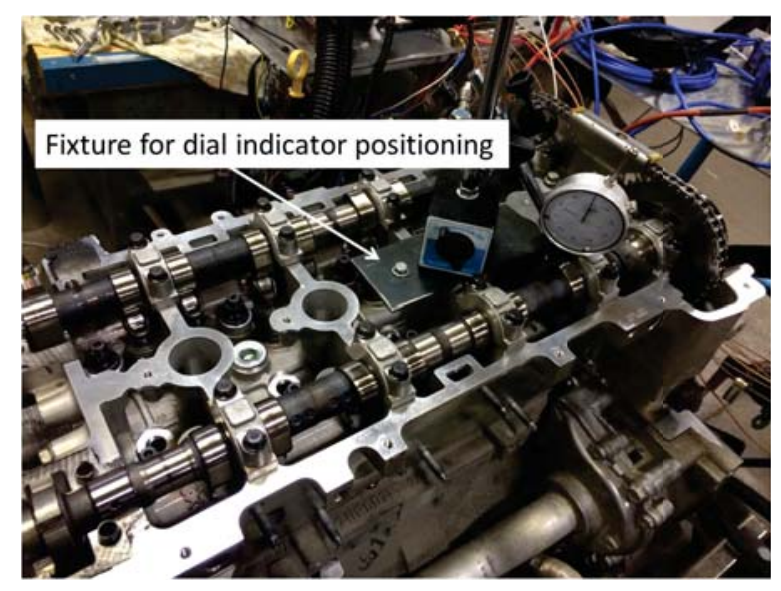

(b)

Figure 2.3: (a): Lift measurement at the valve; (b): Overview of the valve profile measurement setup

\subsubsection{Valve profile measurement procedure}

The LHU engine uses hydraulic lash adjusters in its stock configuration. Lash is optimally adjusted using oil pressure when the engine is running. Using hydraulic lash adjusters during measurements causes them to squish and hence gives incorrect readings. Solid lash adjusters on proper height adjustment enable to adjust the lash between the cam and roller 
follower. Thus, JESEL solid lash adjusters (part number: KLA-81500) are used in the process of valve profile measurements. Lash is made zero during the measurements. These measurements are carried out when the engine is not firing and hence did not have any oil pressure.

Vale lift can be measured in two ways. Measurements can either be taken based on the cam lobe or can be taken at the tip of the valve stem. Lifts measured on the cam lobe have to be multiplied by a factor known as the rocker arm ratio defined in Appendix A. In this study measurements are taken on the first cylinder from the rear end of the engine. The

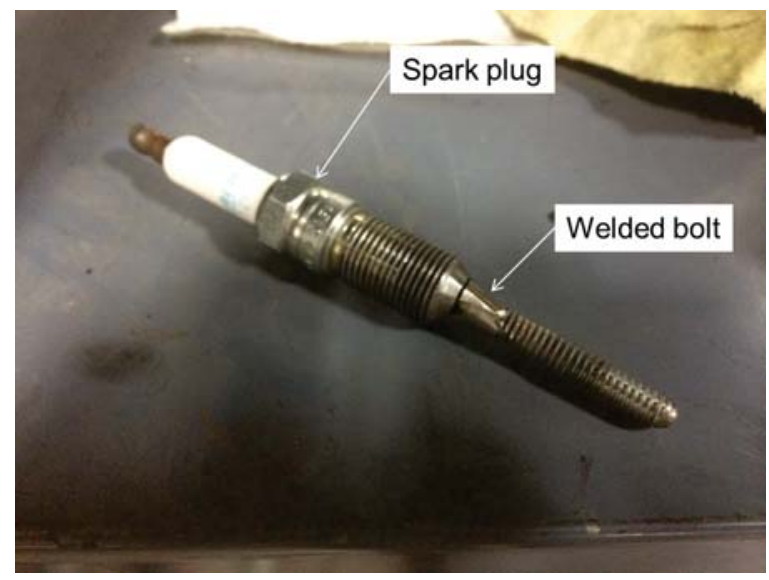

Figure 2.4: Piston stop for measuring TDC crank angle

first step is to determine the location of top dead center (TDC). A detailed description of TDC measurement can be found in [39]. A custom piston stop as mentioned in [39] is fabricated and shown in Figure 2.4. The test setup for measurement is shown in Figure 2.3. Least count on the dial gauge is 0.001 ". Precaution is taken to position the dial indicator tip along the valve axis as accurately as possible. The readings obtained are plotted in 
Figure 2.5(a).

Commercial camshaft manufacturers specify duration of valve operation assuming a certain valve lift as opening/closing point. It is commonly referred at 0.05 " (or $1 \mathrm{~mm}$ ) of valve lift as opening/closing point [39]. Theoretically, at valve lift of $1 \mathrm{~mm}$, the intake (or exhaust) valves would still be open and the opening and closing timings will not be the exact crank angles when the valves just open or close. In reality, at high speeds, negligible flow would occur at a valve lift of $1 \mathrm{~mm}$. Measured values for crank angle for peak lift and duration are compared with advertised values obtained from GM engineers in Table 2.2. The advertised values are seat to seat values at $0.04 \mathrm{~mm}$ lash and an unknown lift. Hence, comparing the opening, closing and duration values would not make any sense as discrepancy is also seen between exhaust valve duration in Table 2.2. Instead, the intake and exhaust centerline values along with the lobe separation angle can be effectively compared as they are independent of lift. Equations for calculation of the values in Table 2.2 are mentioned in Appendix A. Figure 2.5(a) shows the final plot for measured intake and exhaust valve profiles with $50 \mathrm{CAD}$ phasing. Thus, the valve profiles at completely phased condition will be as seen in Figure 2.5(a). Table 2.1 shows the values of measured valve timings, assuming valve opening/closing at $1 \mathrm{~mm}$ lift. The raw data obtained consisted of some irregularities which are smoothed to obtain the profile in Figure 2.5(a). A velocity plot of the raw data showed the irregular data points which are then adjusted to obtain a smooth curve. These irregularities are a result of human errors, backlash in the engine crankshaft and a comparatively low resolution on the degree wheel used to measure crank angle 
rotation.

Table 2.2

Valve timing data for the Ecotec LHU engine

\begin{tabular}{lrr}
\hline \hline Parameter & Measured values & Advertised values \\
\hline \hline Intake centerline & 126 aTDC & 126 aTDC \\
Intake duration & $203.5 @ 1 \mathrm{~mm}$ lift zero lash & $(-)$ \\
Exhaust centerline & -118.5 aTDC & -125 aTDC \\
Exhaust duration & $194 @ 1 \mathrm{~mm}$ lift zero lash & $(-)$ \\
Lobe separation angle (cam degrees) & 122.25 & 125.5 \\
Cam advance & -3.75 aTDC & -0.5 \\
\hline
\end{tabular}

\subsection{Compression ratio increase}

A high compression ratio (CR) is beneficial to achieve HCCI mode in a broad operating range. This thesis studied if increasing CR more than the original CR of $9.2: 1$ is possible and also by how much the $\mathrm{CR}$ can be increased. In addition, piston to valve clearance is measured to determine allowable CR increase without losing valve phasing authority. Volume measurements are carried out to determine the individual volumes occupied by the piston top geometry and the cylinder head dome. 


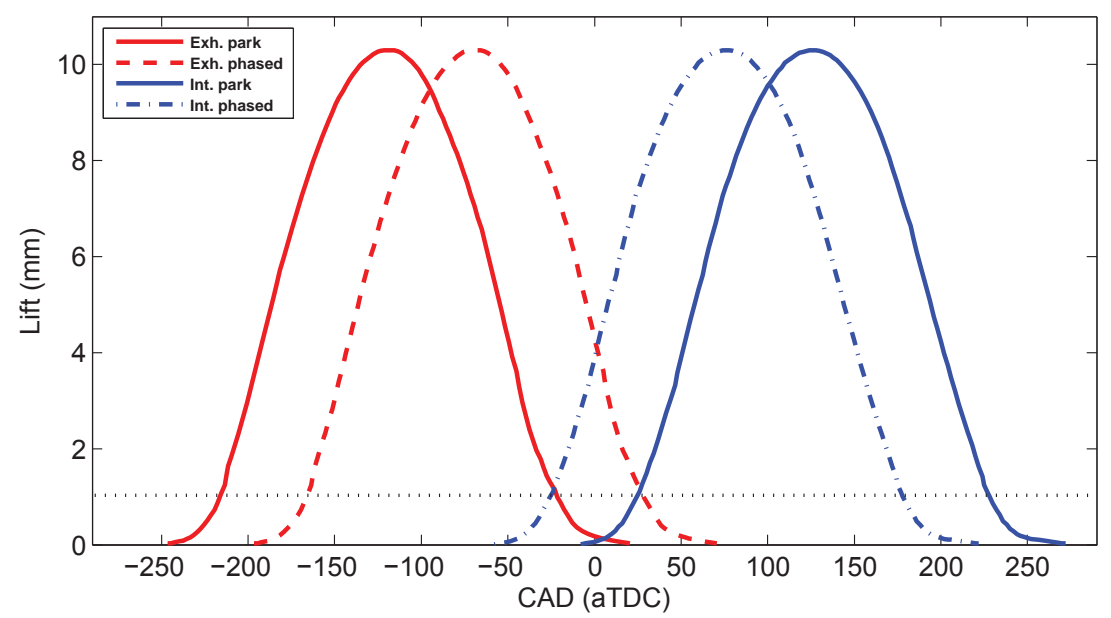

(a)
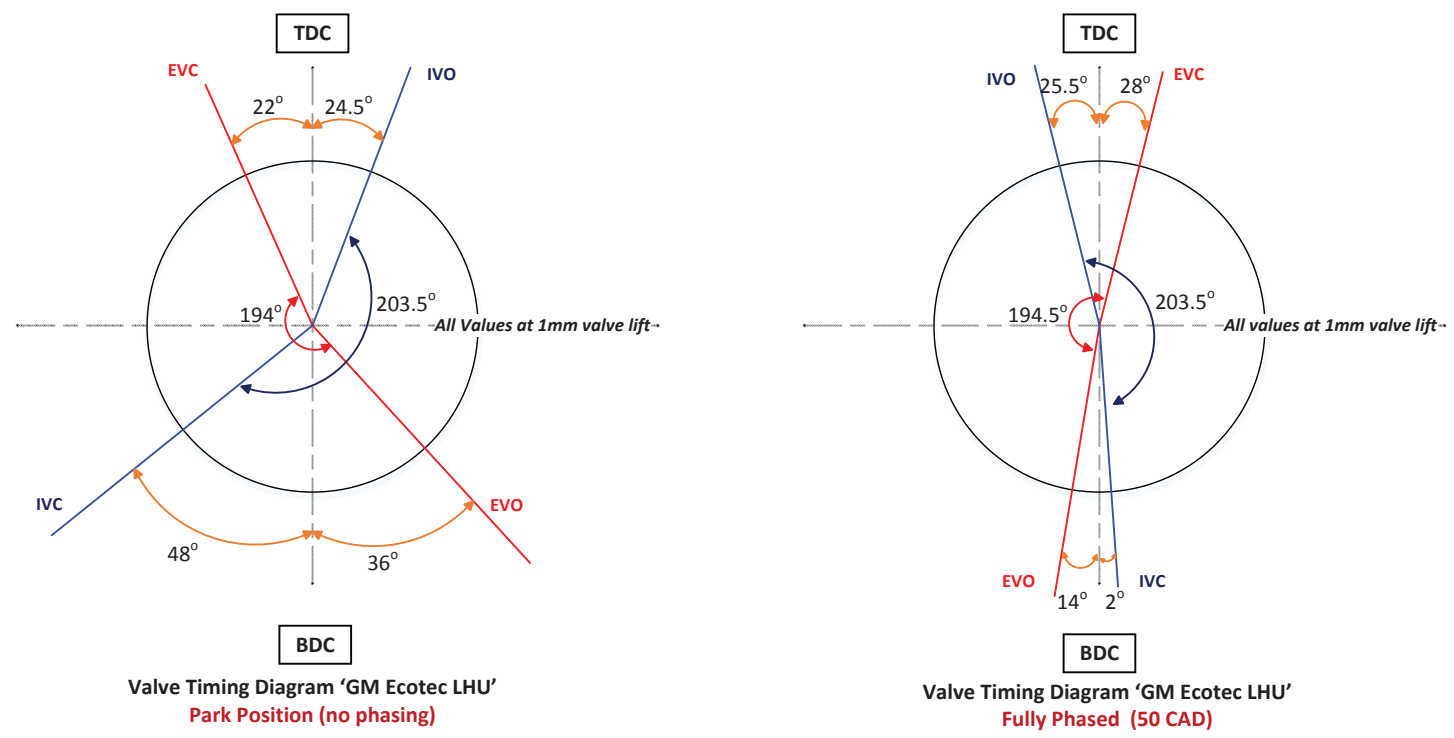

(b)

Figure 2.5: (a): Intake and exhaust valve profiles for park position and completely phased position; (b): Valve timing diagram for the GM Ecotec LHU engine. Dotted line near the base indicates the lift $(1 \mathrm{~mm})$ at which valve opening and closing crank angles are measured. 


\subsubsection{Piston to valve clearance}

The solid green line in Figure 2.6 shows the location of the piston with reference to the valve seat when the valve is completely closed. The intake valve is manually pushed open for suitable crank angle intervals of piston movement from BDC to TDC. In reality, the maximum valve lift is more than the advertised maximum lift. The valve never attains this maximum lift due to high spring forces inside the valve springs and due to valve retainers. The stock springs are replaced with dummy springs which could be compressed easily. Thus, the locus of points obtained when plotted along with the valve profiles gives the piston location along with the piston to valve clearance for a set of crank angle degrees. Selection of a flat top piston would either cause valve phasing authority to reduce if the

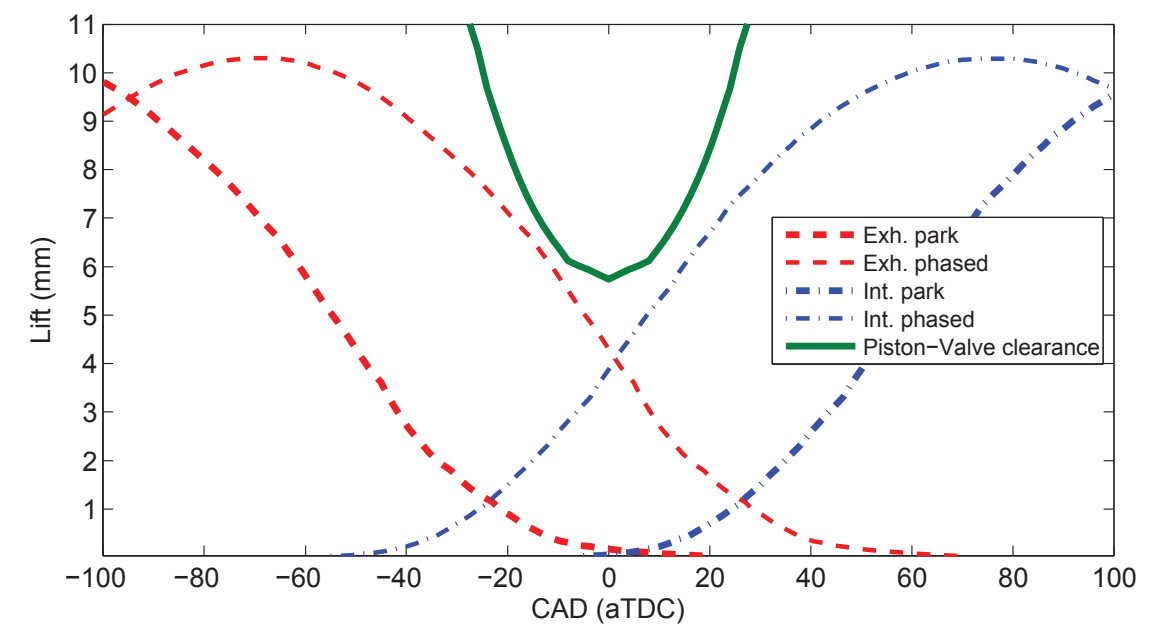

Figure 2.6: Measured piston to valve clearance, using the same reference point at which valve lifts are measured

piston top is considered above the valve pocket base, or it would increase the clearance 
volume if the piston top is considered at the base of valve pockets keeping full phasing authority. Hence, from Figure 2.6 it is concluded that a flat top piston is not a feasible option as it would limit the phasing ability for the increase in CR.

\subsubsection{Volume measurements}

Measurements are carried out to determine individual volumes of the combustion chamber dome and the volume occupied by the piston top geometry (Figure 2.7(a)). The piston surface is cleaned of any carbon deposit and dirt using a cleaning fluid such as a regular brake cleaner. The stock piston has a unique "dish" type profile for DI applications. The piston top geometry showing this "dish" and valve pockets are shown in Figure 2.7(a). The drive shaft is then rotated to bring the entire piston to an approximate distance below the firing deck and the height is measured using a vernier caliper. This distance is shown in Figure 2.8 as "s". A burette is completely filled with mineral fluid of low viscosity and its meniscus is adjusted suitably. The area between the piston and the cylinder liner is greased to avoid leakage inside the cylinder and a transparent plastic slide is used to cover the top. The liquid inside the burette is emptied gradually through a slight opening made by moving the slide. Flow is stopped once the liquid formed a uniform film on the slide's lower surface. Readings are noted at the start and end and the difference between these two readings indicates the volume under study. 


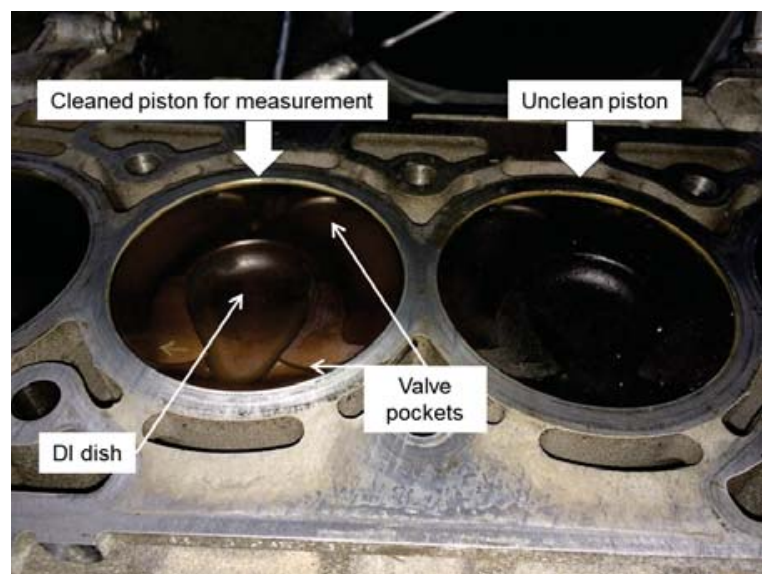

(a) Piston top geometry

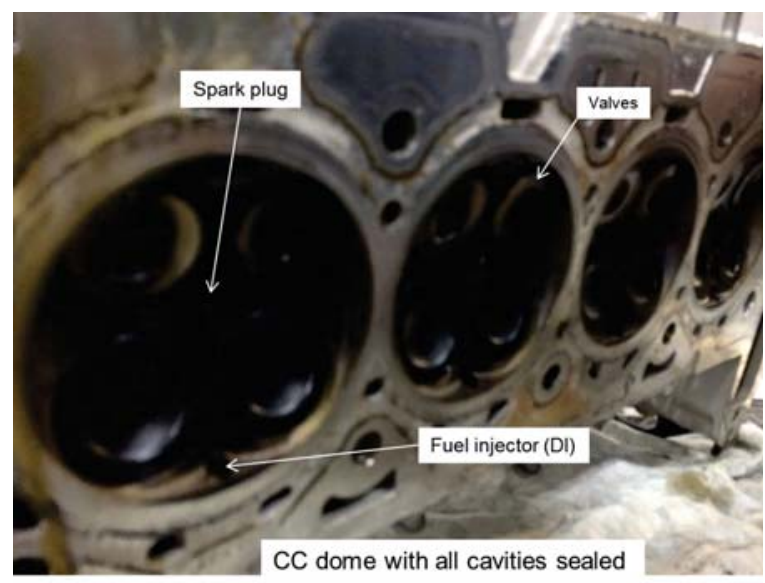

(b) Cylinder head dome volume

Figure 2.7: Experimental measurement of compression ratio

Thus, volume 1 from Figure 2.8 is determined. This gives the TDC volume or the effective volume considering the volume occupied by the piston top geometry. Swept volume is determined using Equation (2.1) where " $D$ " and " $L$ " represent the bore and the swept distance respectively.

$$
\text { Volume }=\frac{\pi}{4} D^{2} \times L
$$




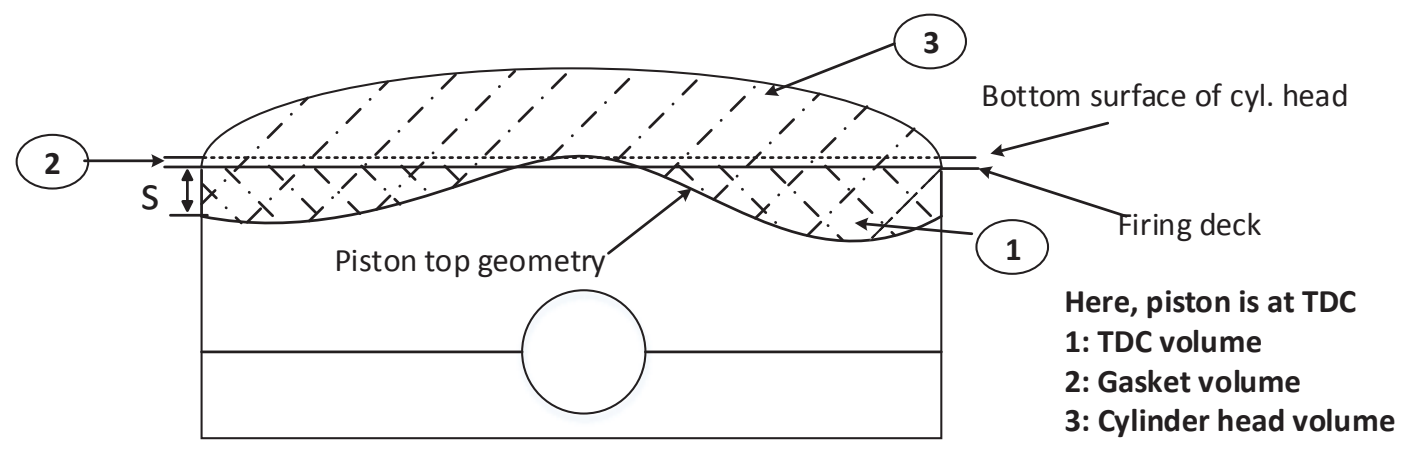

Figure 2.8: Figure showing different sections for which volume measurements are carried out

Volume 2 in Figure 2.8 is determined by using Equation (2.1) where, "L" is substituted with the measured thickness of the compressed cylinder head gasket. For determining volume 3 from Figure 2.8, all cavities are first closed by inserting the four valves, the fuel injector and the spark plug is inserted and tightened to avoid any leaks. Readings are taken once again for the volume of fluid occupied by the area under study. The clearance volume is calculated using Equation (2.2).

$$
\begin{aligned}
\text { Clearance Volume } & =[\text { Volume of cyl. head dome }] \\
& +[\text { Volume due to gasket thickness }] \\
& +[\text { Volume due to area surrounding piston at TDC }] \\
& -[\text { Volume due to piston top geometry }]
\end{aligned}
$$

The clearance volume is indicated by the entire hatched region in Figure 2.8. Measured volumes 1 and 2 along with the calculated gasket volume are shown in Table 2.3. CR is defined as the ratio of the maximum volume to the minimum volume in an engine cycle, 
Table 2.3

Measurements for engine combustion chamber volume

\begin{tabular}{cc}
\hline \hline Component & Measured volume (cc) \\
\hline \hline Cylinder head dome & 48.8 \\
Piston top geometry & 2 \\
Gasket (compressed) & 4.47 \\
Volume in section \#1 (Fig.2.8) & 9.4 \\
Clearance volume & 60.7 \\
\hline
\end{tabular}

and is given by Equation (2.3).

$$
C R=\frac{\left(V_{s}+V_{c}\right)}{\left(V_{c}\right)}
$$

Where, $V_{s}$ is the swept volume given by Equation (2.1) and $\mathrm{V}_{\mathrm{c}}$ is the clearance volume given by Equation (2.2).

\subsubsection{Piston selection}

One way to increase $\mathrm{CR}$ is by decreasing $\mathrm{V}_{\mathrm{c}}$ as Equation (2.3) suggests. From the results obtained in section 2.3.2 it becomes clear that material cannot not be added over the valve pockets and their depths can hence not be modified. Remaining areas surrounding the valve pockets could be used for material addition to reduce $\mathrm{V}_{\mathrm{c}}$. Thus, the "max dome" piston design from the Wiseco piston company is selected which offers a volume of $16.6 \mathrm{cc}$ due to piston top geometry. For this design, the valve pockets are kept at the same height using a fixed reference point for both the old and the new pistons. The valve pocket depths 
are 0.09 " for intake and 0.045 " for exhaust. These depths are measured with reference to the timing edge defined in Appendix A. This ensured that the valve phasing ability is not reduced or lost completely. The resulting calculated CR using the new piston is 12.31:1 for the GM Ecotec engine.

The actual new piston is shown in Figure 2.9 along with the old piston for comparison. Design specification sheet from Wiseco for the new piston is shown in Figure 2.10.

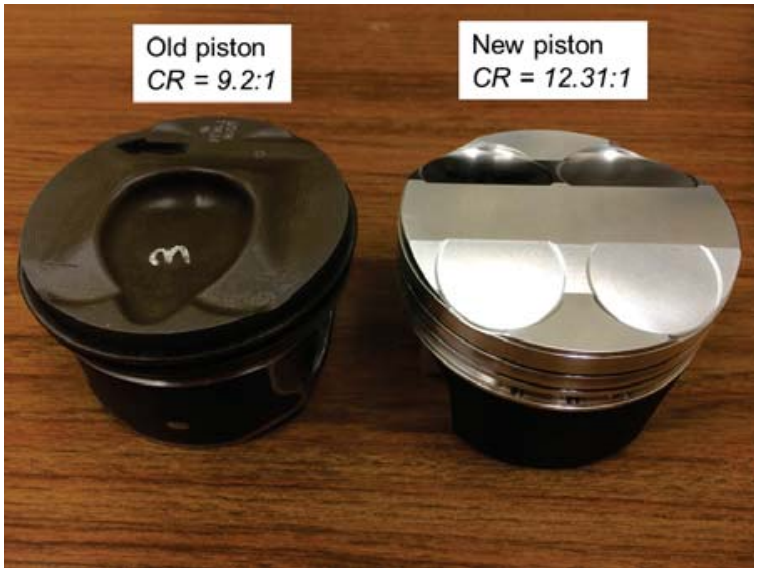

Figure 2.9: Stock and new piston top designs 


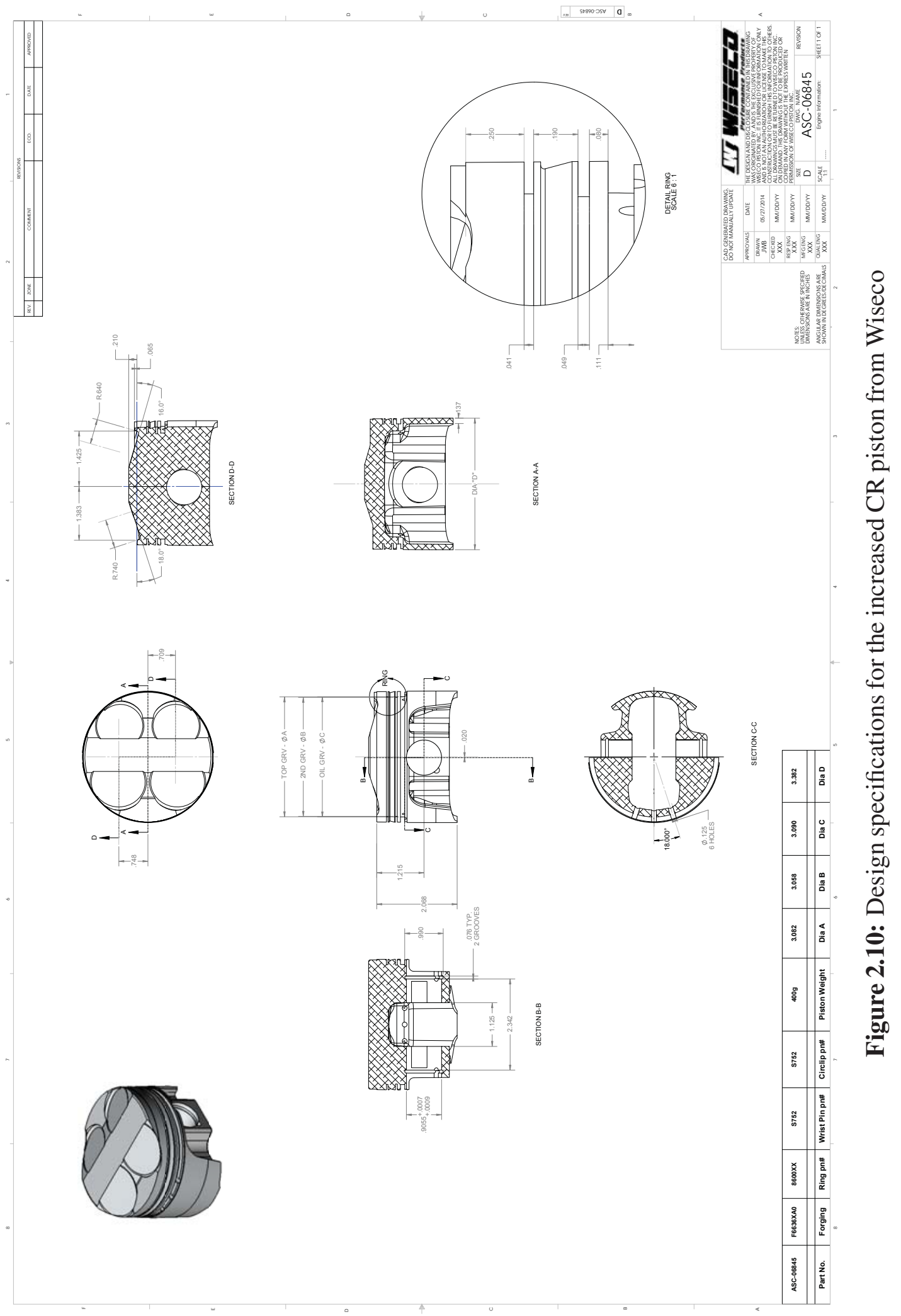




\subsection{Controllable air heater}

In order to heat the intake air, an electrical air heater from Omega Inc is selected. This selection is based on its air flow rate specification mentioned in Table 2.4. At $2000 \mathrm{rpm}$, the LHU engine needs $\frac{2000 \times 2}{1000 \times 60}=0.067 \mathrm{~m}^{3} / \mathrm{s}$. The air heater can support a maximum flow rate of $200 \mathrm{cfm}$ (or $0.094 \mathrm{~m}^{3} / \mathrm{s}$ ) and uses a AC supply with $240 \mathrm{~V}$ for its operation. The air heater specifications are shown in Table 2.4. The air heater temperature is controlled using

Table 2.4

Air heater specifications [2]

\begin{tabular}{cc}
\hline \hline Parameter & Value \\
\hline \hline Part number & AHF - 10120 \\
Input & $120 \mathrm{Vac} / 1000 \mathrm{~W}$ \\
Heated length & $203 \mathrm{~mm}$ \\
Maximum flow & $200 \mathrm{CFM}$ \\
Heating element & Nickel-Chrome, insulated with ceramic \\
Maximum exit air temperature & $315^{\circ} \mathrm{C}$ \\
Body material & Aluminum \\
\hline
\end{tabular}

a temperature controller (part number: CNi3244-C24) and a Solid State Relay (SSR) (part number: SSR330DC25) from Omega Inc. The temperature controller generates a DC pulse and has a built-in auto-tune enabled PID controller. The SSR is used as a switch. Thus, if the desired temperature is higher than the actual value, the controller will send a DC pulse to the SSR as gate voltage causing it to draw current which feeds the air heater. When the desired value is reached the SSR is turned off. A fan cooled enclosure is designed to house this control assembly. This is shown in Figure 2.11. A LabView user interface is 
designed to observe and control the desired temperature values from the test cell computer.

A screenshot of the designed user interface is shown in Figure 2.12.

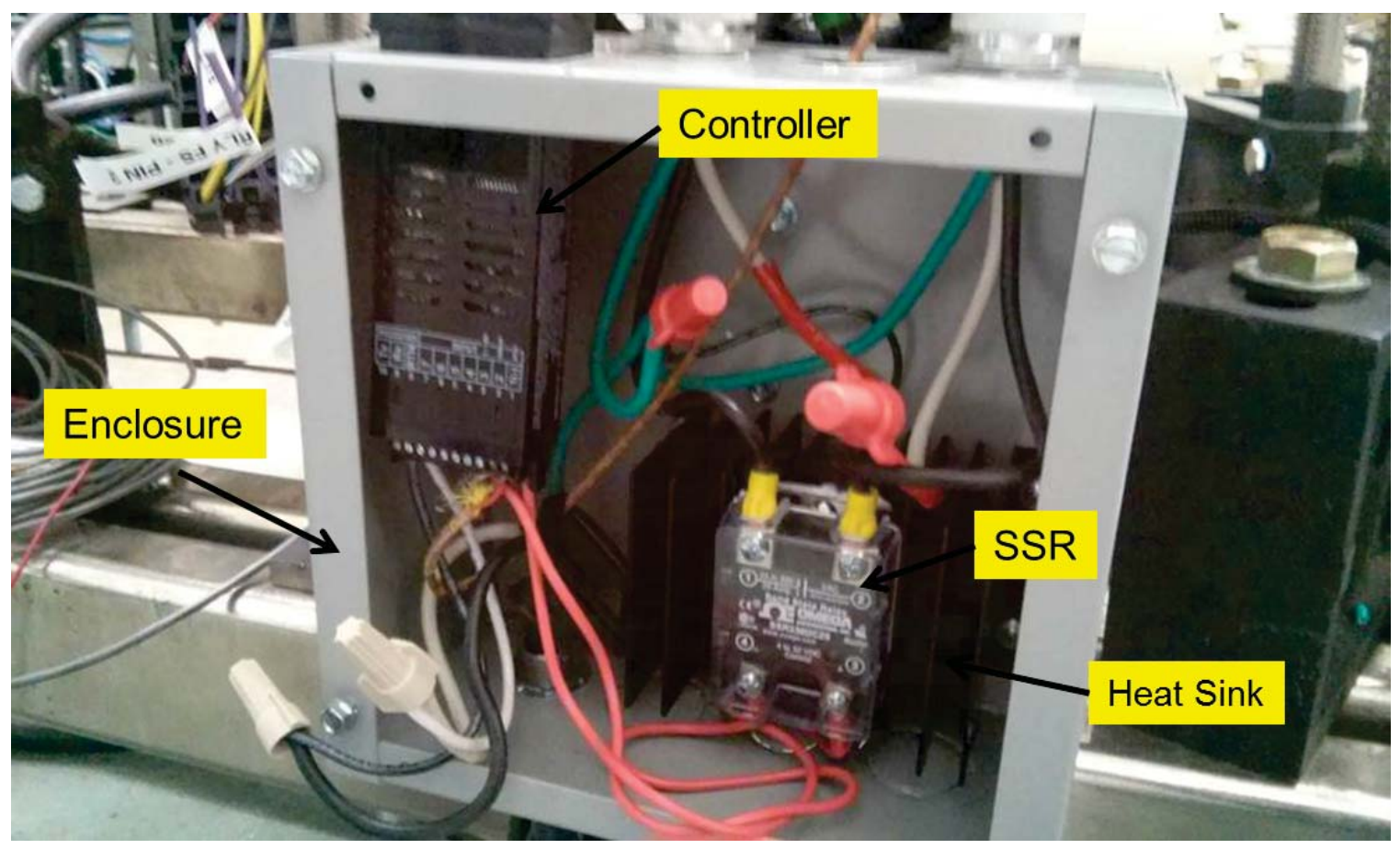

Figure 2.11: Enclosure for housing Omega controller and SSR with heat sink

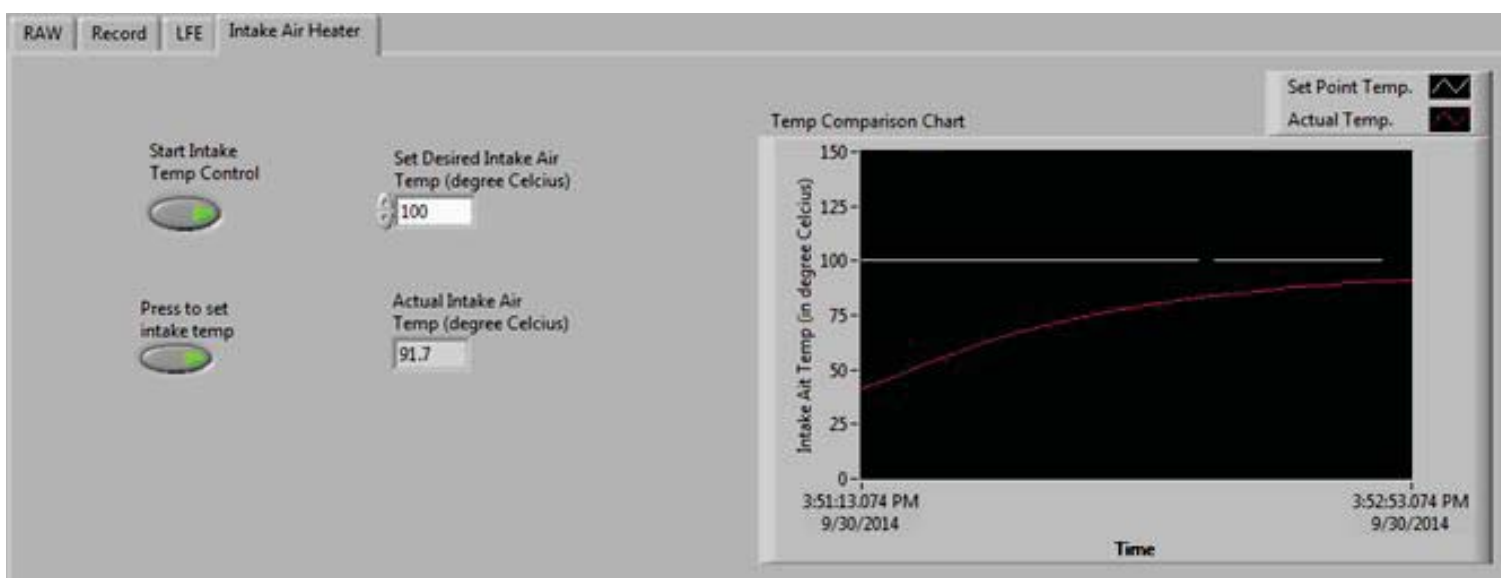

Figure 2.12: Designed LabView interface to control air heater 


\subsection{MTU Supercharging Station}

As previously discussed in the Chapter 1 intake air boosting is one of the enabling techniques for HCCI combustion and also for operating the engine at higher loads. By increasing the intake air pressure the specific energy of air entering the cylinder is increased along with the amount of air entering the cylinder. High gas pressure aids in auto-igniting the in-cylinder charge, resulting in HCCI combustion. A supercharging station is set up in order to provide boosted air. The supercharging station is shown in Figure 2.13. An Eaton M62 supercharger is used providing boosted air. The M62 supercharger displaces 62 cubic inch (ci) of air with each revolution. The LHU 2.0L engine displaces 1L (or approximately $62 \mathrm{ci}$ ) air for each crankshaft revolution. This supercharger is obtained from a 2.0L Chevrolet Cobalt whose engine is of comparable displacement with the LHU engine. The M62 is a positive displacement type blower having a pair of interlocking rotors that spin opposite to each other. It has a three lobe twin rotor design where the lobes have a $60^{\circ}$ helical twist. Both rotors are identical and have a 1:1 ratio. A bypass valve is provided as a safety feature in case of excessive boost pressure. In this study, the M62 supercharger is driven by a $20 \mathrm{hp}$ electric motor from the Louis Allis company. The specifications of the electric motor are shown in Table 2.5. It is a three phase induction motor with class B insulation on its windings. Winding insulations are classified by the National Electrical Manufacturers Association (NEMA). Some of the common classes are shown in Table 2.6. The temperature ratings are the average temperature of the windings and are based on a 


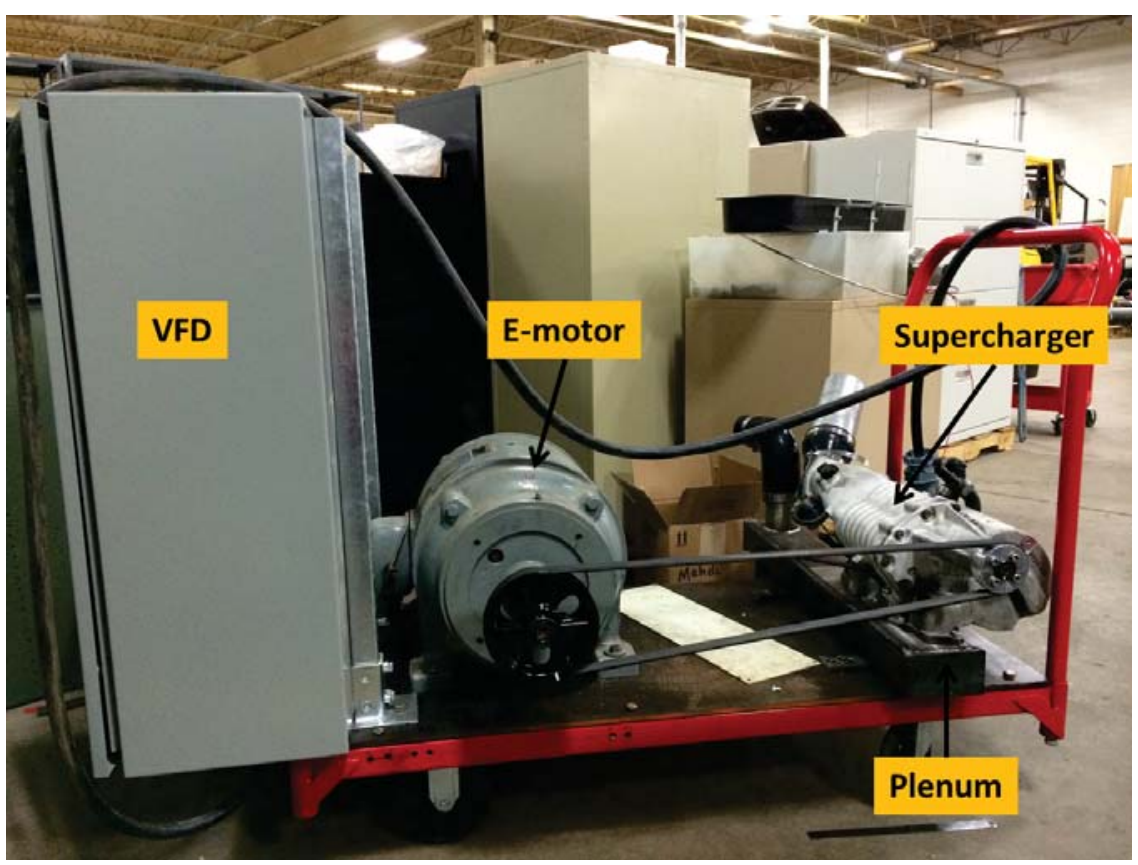

Figure 2.13: Figure showing the supercharger test setup

rated life of 200,000 hours or 20.8 years. Thus, a winding of class B type should last for 22.8 years if operated at $130^{\circ} \mathrm{C}[3]$.

Table 2.5

E-motor specifications mentioned on the physical motor

\begin{tabular}{cc}
\hline \hline Parameter & Value \\
\hline \hline Company & Louis Allis Co. \\
Type & Induction (3 phase) \\
Rated power & $20(\mathrm{hp})$ \\
Rated speed & $3515(\mathrm{rpm})$ \\
Voltage rating & $220 / 440(\mathrm{~V})$ \\
Current rating & $60 / 25(\mathrm{~A})$ \\
Insulation & Type B \\
\hline
\end{tabular}

A Durapulse Variable Frequency Drive (VFD) is selected and purchased to control the E-motor. The VFD specifications are shown in Table 2.7. The VFD is rated for controlling a $40 \mathrm{hp}$ motor as this supercharging station is also planned for future engine projects which 
Table 2.6

E-motor insulation classes by NEMA [3]

\begin{tabular}{cc}
\hline \hline Insulation class & Winding temperature \\
\hline \hline $\mathrm{A}$ & $105^{\circ} \mathrm{C}$ \\
$\mathrm{B}$ & $130^{\circ} \mathrm{C}$ \\
$\mathrm{F}$ & $155^{\circ} \mathrm{C}$ \\
$\mathrm{H}$ & $180^{\circ} \mathrm{C}$ \\
\hline
\end{tabular}

might need more boosted air flow rates depending on engine size.

Table 2.7

VFD specifications

\begin{tabular}{cc}
\hline \hline Parameter & Value \\
\hline \hline Part number & Durapulse GS34040 \\
Maximum motor output & $40 \mathrm{hp}$ \\
Rated output current & $60 \mathrm{~A}$ \\
Weight & $35 \mathrm{~kg}$ \\
Communication protocol & RS485 Modbus RTU \\
\hline
\end{tabular}

An intake air plenum is designed and is shown in Figure 2.14. The supercharger is bolted down on the plenum and a standard automotive 6 groove serpentine belt is used to couple it with the e-motor. A standard composite pulley of diameter 6.5 " is attached to the motor shaft and the corresponding supercharger speeds are measured. In this way, the transmission ratio is calculated to be 1:1.8 (driver:driven). Air from the supercharger is routed through an intercooler mounted below the engine. The waste gate valve on the stock turbocharger can be used to pass exhaust gases without spooling the turbocharger. The e-motor is limited by its maximum speed of $3515 \mathrm{rpm}$. Thus by using a 1:1.8 ratio by the coupling system, the maximum supercharger speed that can be achieved is about 6327 $\mathrm{rpm}$. Theoretically, by running the supercharger at twice the engine speed, a pressure ratio 


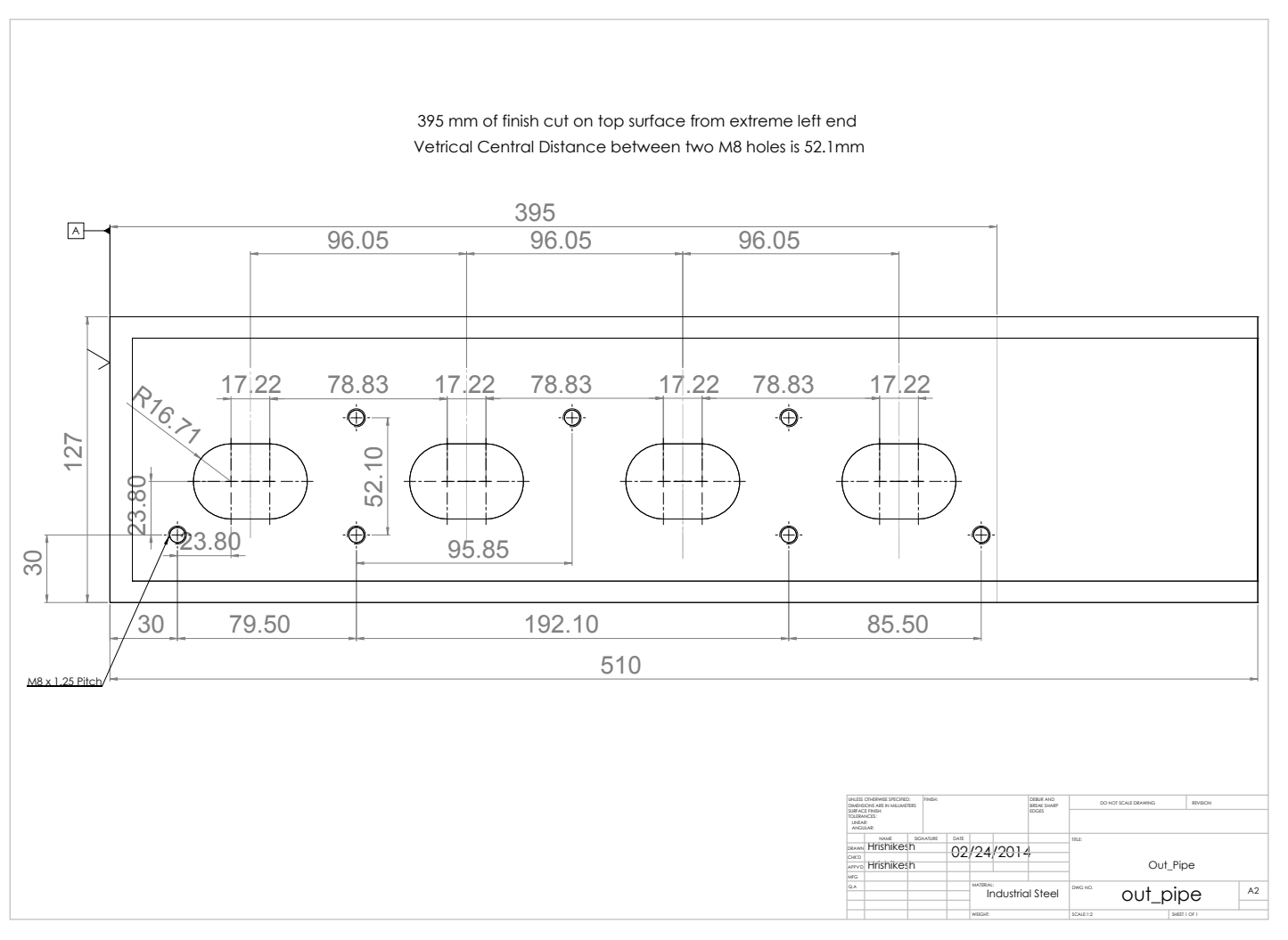

Figure 2.14: Design details of the intake plenum for carrying supercharged air

of 2:1 can be obtained. The official supercharger performance map from EATON is shown in Figure 2.15. The performance map shows us the limits within which the supercharger must operate. Pressure ratios of more than 2.2:1 (abs.) and speeds of more than 14,000 rpm can damage the supercharger. 


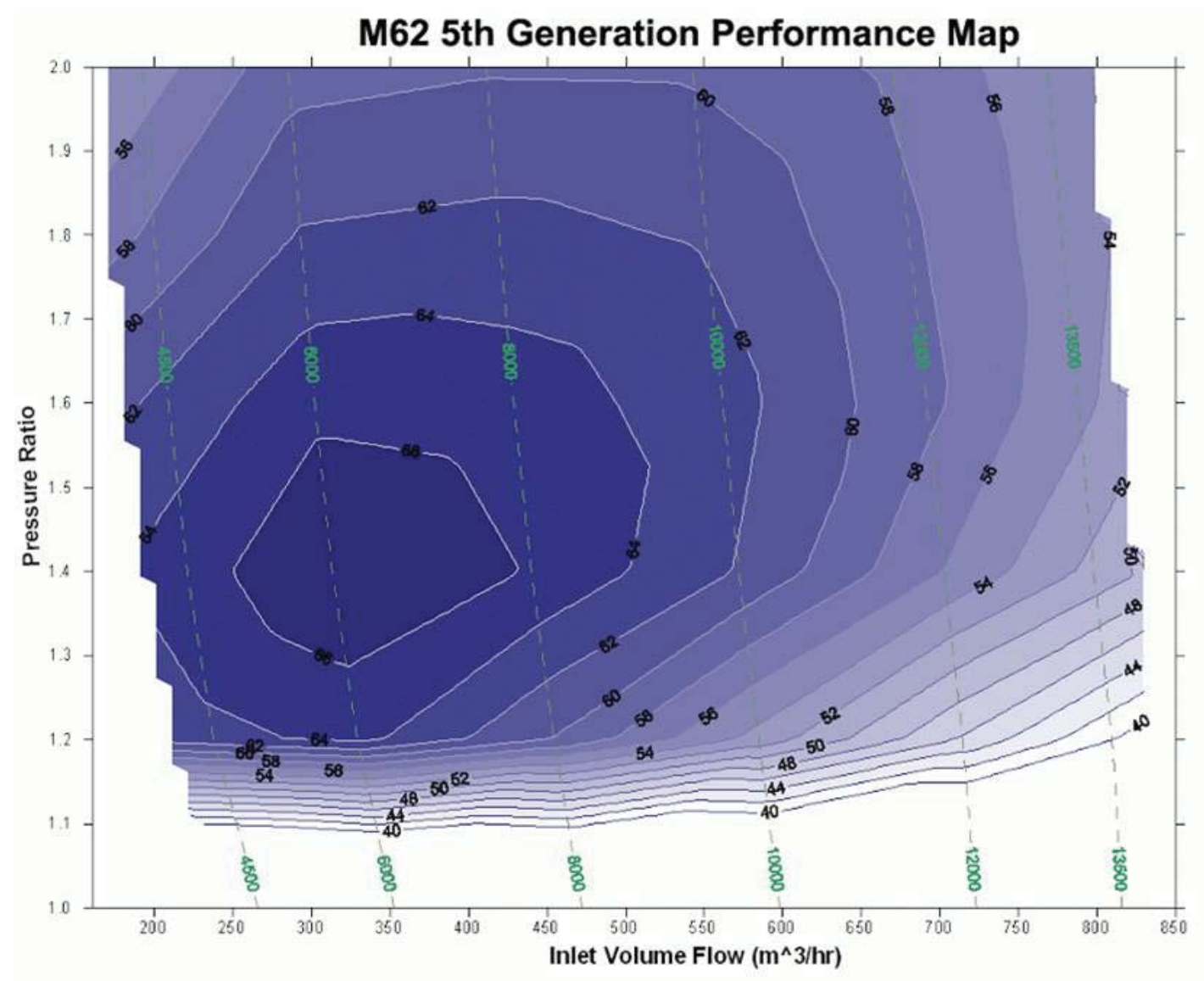

Figure 2.15: Performance map of the Eaton M62 supercharger[1]

\subsubsection{Supercharger testing results}

A stand alone test rig was designed and set-up for initial measurement of boost pressures without connecting the supercharger outlet to the engine. The test rig is shown in Figure 2.16.

The relationship between input voltage from the analog signal to the VFD and the corresponding E-motor speed is plotted shown in Figure 2.17. A throttle valve with its 


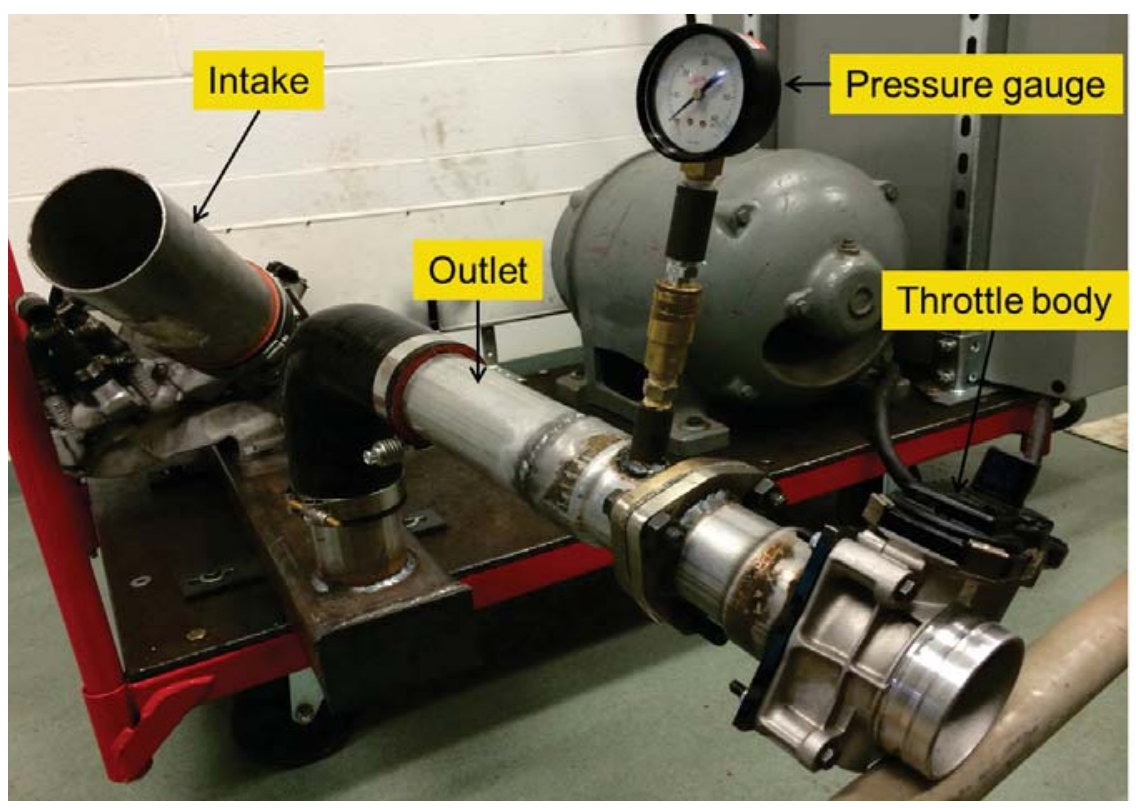

Figure 2.16: Test setup for boost pressure measurement

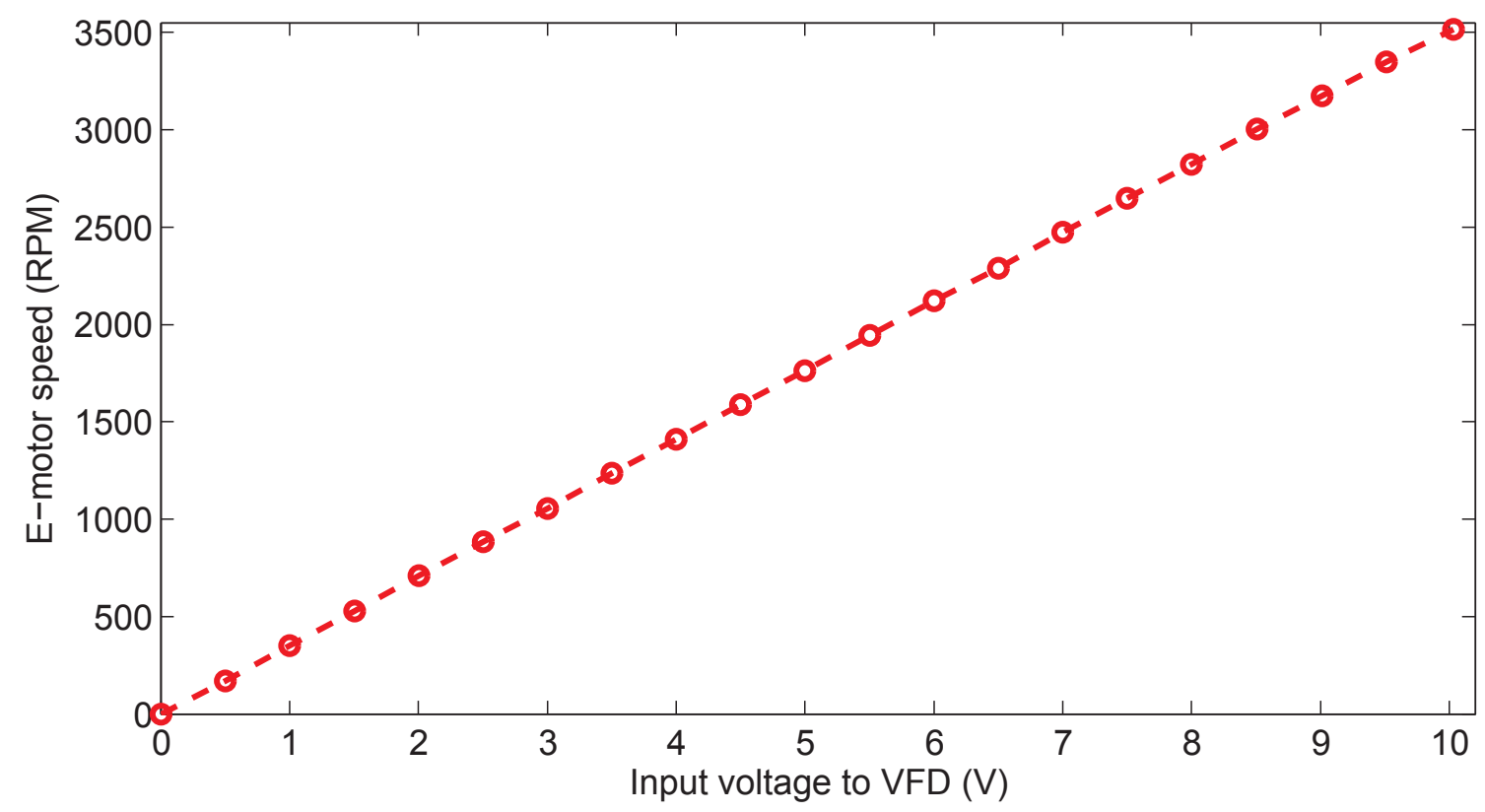

Figure 2.17: Mapping of E-motor speed as a function of input voltage $(0-10 \mathrm{~V})$ to the VFD

default opening is used to build pressure. A boost pressure close to 0.6 bar (gauge) is obtained as a result of this experiment. A 5V supply is provided to the VFD and the 
corresponding supercharger speed is $3526 \mathrm{rpm}$. The pressure trace is shown in Figure 2.18.

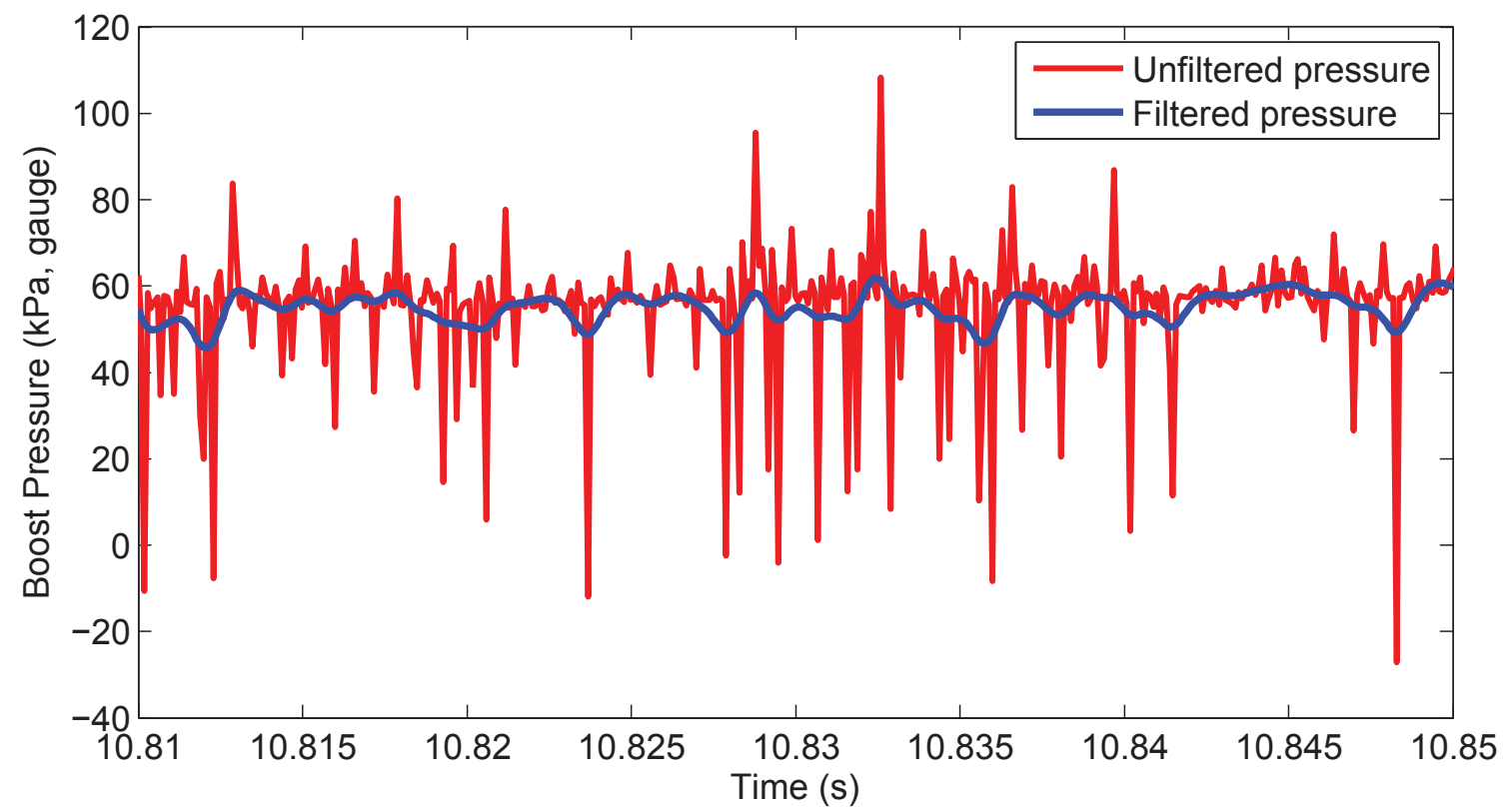

Figure 2.18: Test result for boost pressure from the supercharger for $5 \mathrm{~V}$ input to VFD

Next, the supercharger outlet is connected to the intake air circuit on the LHU engine and motoring tests are carried out at a constant engine speed of $1500 \mathrm{rpm}$. The intake manifold pressure is monitored on varying supercharger speed. Testing is carried out for a time of $120 \mathrm{~s}$ and the results are averaged. A simple butterworth filter is applied on the pressure trace and the results are shown in Figure 2.19. The average values of the individual pressure traces are $126.5 \mathrm{kPa}(\mathrm{abs}$.$) and 110.2 \mathrm{kPa}$ (abs.) respectively. This indicates that for the supercharger speed of $3600 \mathrm{rpm}$, the boost pressure obtained is 0.26 bar $_{\mathrm{g}}$ and for $2700 \mathrm{rpm}$ it is 0.1 bar $_{\mathrm{g}}$ (where the subscript $\mathrm{g}$ stands for gauge pressure). 
(a)

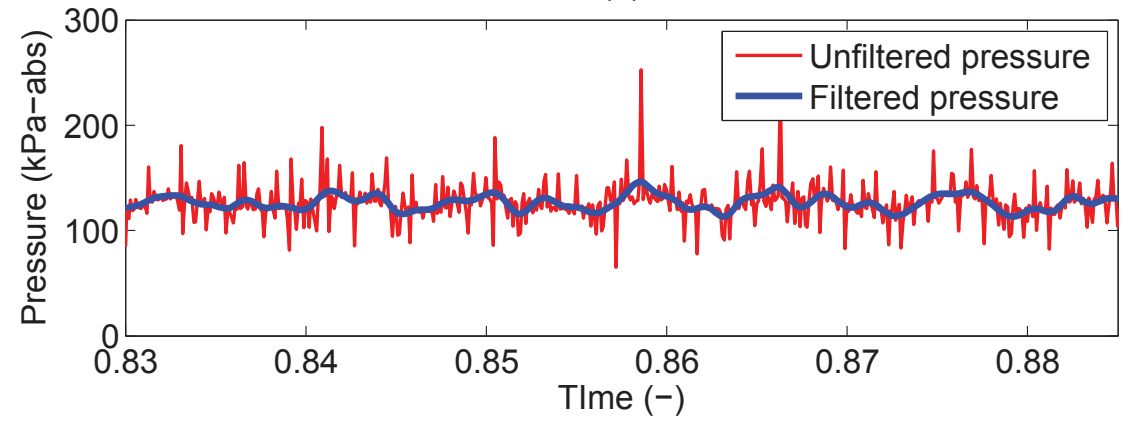

(b)

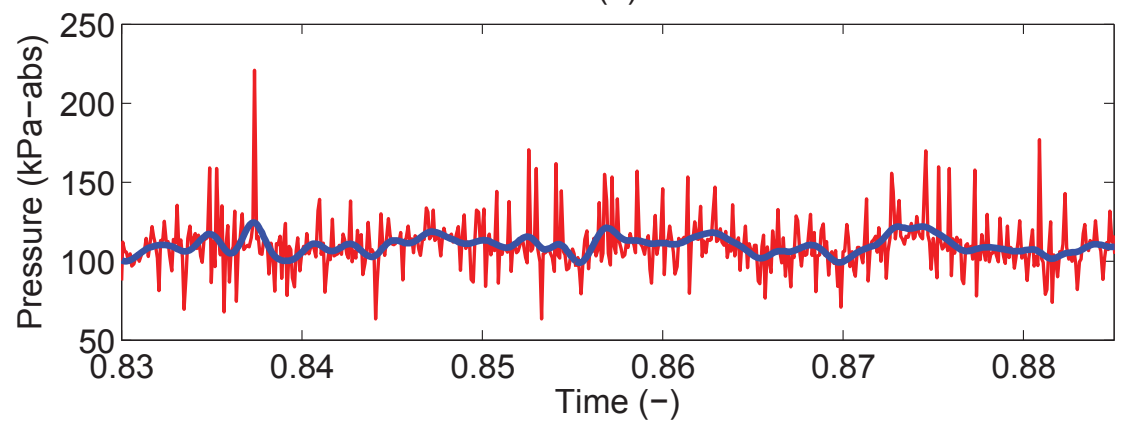

Figure 2.19: Filtered pressure trace with engine motoring at $1500 \mathrm{rpm}$ and supercharger speeds of (a) $3600 \mathrm{rpm}$ and (b) $2700 \mathrm{rpm}$ 



\section{Chapter 3}

\section{Sequential Combustion Modeling of}

\section{HCCI Engines with Variable Valve}

\section{Timing}

Experimental testing is useful for measuring combustion and performance metrics for engine operation. But, direct measurement of some combustion and engine performance metrics is not always possible and is often quite expensive. A good example of this is measuring the mass of residuals inducted by means of internal EGR [40]. It can be calculated based on the pressure trace and by using mathematical relations like the ideal gas law used in [41]. Other parameters such as emissions can be measured directly coming out of the engine. In order to understand emissions formation and engine performance, 
combustion phenomenon taking place inside the $\mathrm{HCCI}$ engine needs to be analyzed in depth. It is essential to know and understand thermo-kinetics of HCCI combustion and means (e.g., VVT) to control HCCI; thus, one can address the challenges faced by the market penetration of HCCI technology discussed in Chapter 1. HCCI simulation models help to better understand and predict HCCI combustion and performance. A classification of the HCCI simulation models found in literature is shown in Figure 3.1. HCCI thermo

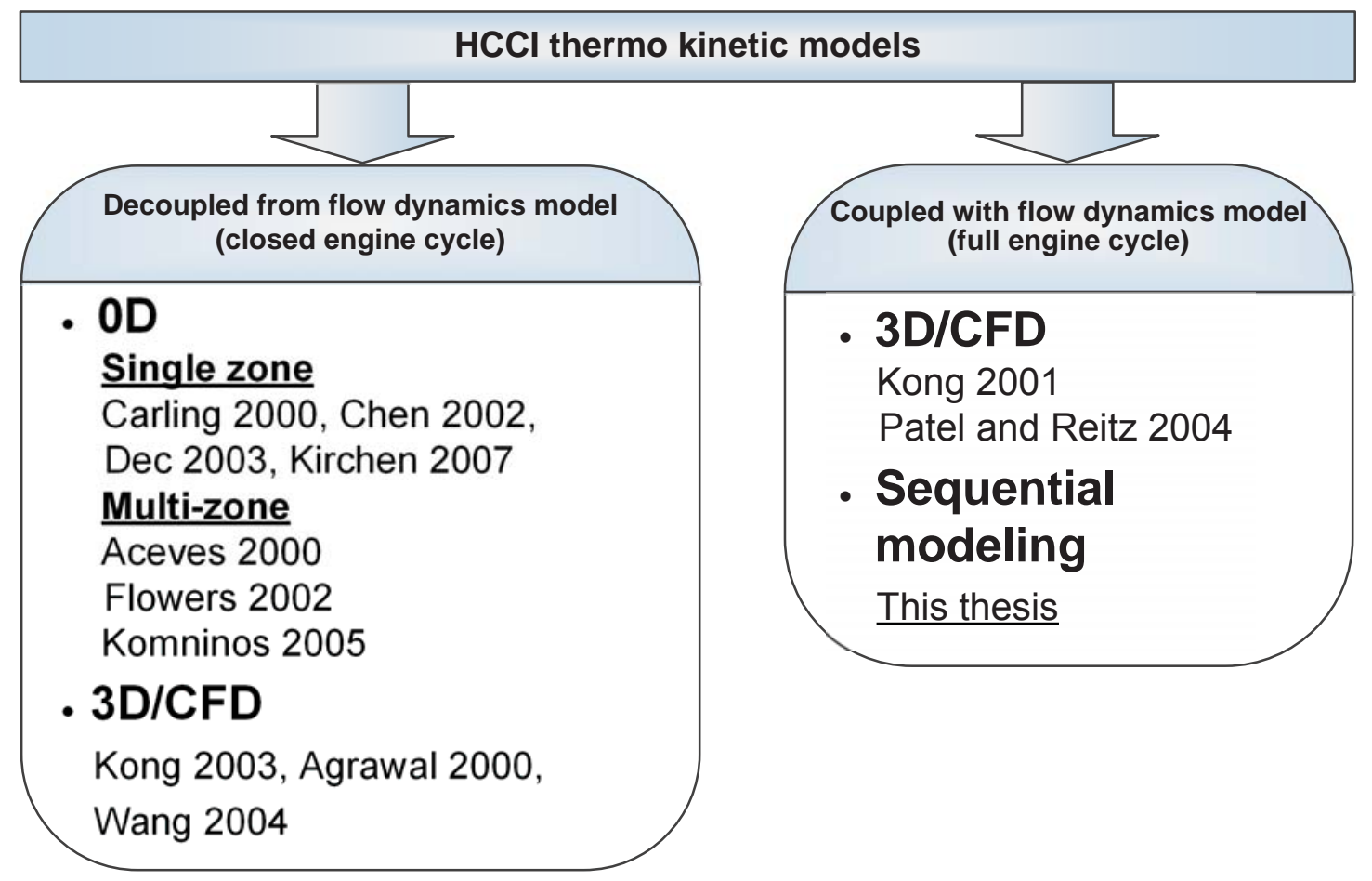

Figure 3.1: Simulation models for HCCI combustion modeling available in literature

kinetic models's (TKM's) are classified into two main categories as shown in Figure 3.1.

The first group includes the models that simulate the full engine cycle, while the second 
group focuses on closed engine cycle between Intake Valve Closing (IVC) and Exhaust Valve Opening (EVO). A TKM is part of both these main categories for simulating the engine cycle between IVC and EVO. The main difference between these two categories is whether to couple a TKM with flow dynamics models to predict IVC conditions and residual gas amount. Coupling a TKM with flow dynamic model often leads to more accurate combustion prediction, but requires more computational resources.

First category of HCCI models in Figure 3.1 are distributed into two groups including zero dimensional (0-D), and 3D/CFD models. Zero dimensional models can be further divided into two categories. First group includes single zone models (SZM's) [42, 43, 44] with a simplified or detailed chemical kinetic mechanism. These are among the simplest models for simulating HCCI combustion [19]. SZM's typically assume the entire combustion chamber as one uniform zone where combustion takes place in the entire zone simultaneously. Study conducted by [42] uses a detailed iso-octane reaction mechanism from the Lawrence Livermore National Laboratory and treats in-cylinder charge as a uniform lumped mass having uniform composition and thermodynamic properties. SZM's assume that the in-cylinder conditions are like a homogeneously mixed reactor with uniform temperature, pressure and composition. SZM's have the advantage of predicting start of combustion (SOC) accurately and in most cases in-cylinder gas pressure is overpredicted. This is because, the entire combustion chamber is assumed to combust together. As a result, emissions prediction is not accurate by SZM's. The disadvantages include an overprediction of $\mathrm{NO}_{\mathrm{x}}$, underprediction of burn duration (BD) and failing to 
predict carbon monoxide (CO) and uHC emissions [5]. In an HCCI engine turbulence and mixing effects are not of importance for combustion phasing [8]. However, these effects influence the temperature and mass distribution along with the boundary layer thickness in an HCCI combustion chamber [5].

Multi zone modeling (MZM) is able to predict combustion phasing along with $\mathrm{CO}$ and $\mathrm{uHC}$ emissions [5]. In MZM the combustion chamber is divided into a number of zones. Zones are imaginary regions in the cylinder based upon the temperature and mass distribution specified in the model. The MZM approach is less simplified than the SZM approach and yields results that can accurately simulate real engine conditions. Consequently a MZM is computationally expensive.

Studies carried out in [45],[46] use a 3D CFD code coupled with a CHEMKIN ${ }^{\circledR}$ code for the open HCCI cycle. KIVA-3V was used for the CFD part. The results in [46] indicate an accurate prediction of ignition timing, cylinder pressure and heat release rates along with $\mathrm{CO}$ and uHC emissions. CFD models can predict both closed engine cycle [47][48][49] and open engine cycle [45][46][50]. However, they require high computational resources and are consequently not desirable for controller designs.

Sequential modeling is a hybrid approach [5] where combustion models such as a TKM can be used along with other models to predict the performance metrics for the entire engine cycle. In HCCI modeling studies done by $[5,51,52]$ the CFD code is only used to find in-cylinder conditions at SOC after which a 0-D TKM model is used. This thesis proposes 
a new sequential modeling approach to combine 1-D flow models with a multi zone TKM for simulating residual affected HCCI engines.

To the best of the author's knowledge, this is the first study undertaken to develop a sequential computationally efficient model for residual affected HCCI including VVT effects. The HCCI model developed in this study is denoted as SMRH (Sequential Model for Residual affected HCCI). SMRH is computationally efficient and is capable of accurately predicting HCCI combustion and performance under the effects of internal EGR through Variable Valve Timing (VVT).

\subsection{SMRH Description}

This section describes the sequential modeling platform developed in this study for simulating VVT impacts on HCCI combustion. Results are first validated with the experimental data from a Ricardo HCCI engine [4] and an analysis of simulation results is presented in Section 3.2.

A multi zone combustion model is developed in CHEMKIN ${ }^{\circledR}-$ PRO in this study. The multi-zone model is a model which couples the thermodynamics of the combustion process with the chemical kinetic reactions associated with them. HCCI combustion is largely dependant on the mixture conditions at IVC [8], particularly for residual affected HCCI. 
The important IVC conditions are pressure, temperature and mixture composition.

A two-stage modeling approach is developed to incorporate accurate IVC conditions for modeling residual affected HCCI combustion. Schematic of the modeling approach, shown in Figure 3.2, indicates the two-stage approach for prediction of HCCI combustion and performance metrics. Modeling done in this way is validated for three different engine

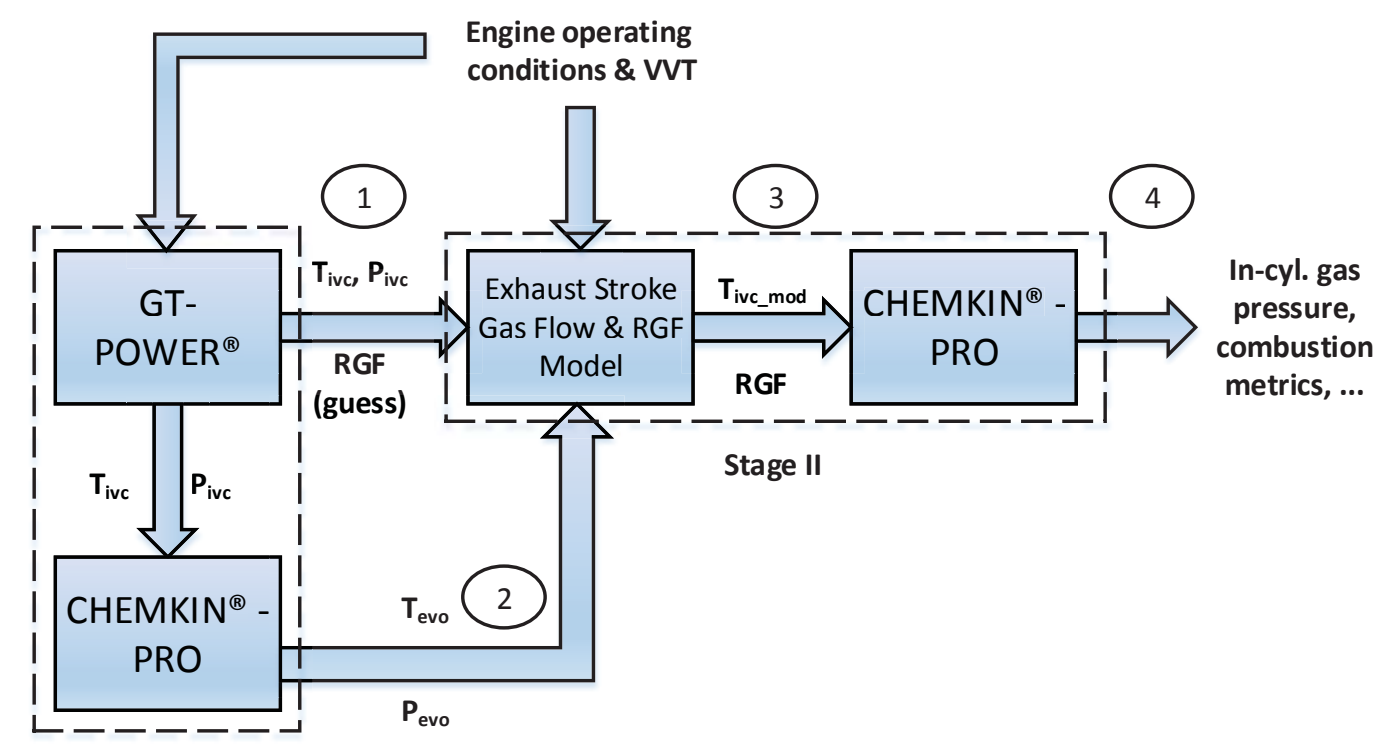

Stage I

Figure 3.2: Simulation path for the SMRH modeling platform. The path includes four steps shown by circled numbers.

operating conditions shown in Table 3.1. The conditions at IVC are first guessed using the results from a one dimensional (1-D) HCCI engine model in GT - POWER ${ }^{\circledR}$ and the IVC conditions are then fed into CHEMKIN ${ }^{\circledR}$ - PRO for multi zone combustion modeling. Two stages of multi zone modeling are used where the first stage gives the initial values for 
the end of combustion (i.e., EVO conditions) which are then used in an Exhaust Stroke Gas Flow \& RGF model [41] to determine Residual gas Fraction (RGF) quantity and temperature of residual gases. The last step consists of multi zone modeling to determine the final simulation results. Outputs of SMRH include in-cylinder gas pressure, combustion metrics (CA10, CA50 and BD), performance metrics (IMEP and $\eta_{t h, i}$ ), and engine-out emissions. The SMRH includes four steps as will be discussed next.

\section{Table 3.1}

Engine operating conditions of the experimental data [4] used to validate SMRH

\begin{tabular}{ccccc}
\hline \hline Case \# & $\mathrm{P}_{\operatorname{man}}(\mathrm{kPa})$ & $\mathrm{T}_{\operatorname{man}}\left({ }^{\circ} \mathrm{C}\right)$ & $\phi$ & Engine Speed $(\mathrm{rpm})$ \\
\hline \hline $\mathrm{a}$ & 117.2 & 87.6 & 0.45 & 1016 \\
$\mathrm{~b}$ & 108.8 & 87.6 & 0.45 & 1016 \\
$\mathrm{c}$ & 89.1 & 90.8 & 0.56 & 920 \\
\hline
\end{tabular}

\subsubsection{Step 1: 1-D HCCI engine model for conditions at IVC}

A one dimensional HCCI engine model is developed in GT - POWER ${ }^{\circledR}$ to determine the mixture conditions at IVC. The 1-D model used in this study is shown in Figure 3.3. This

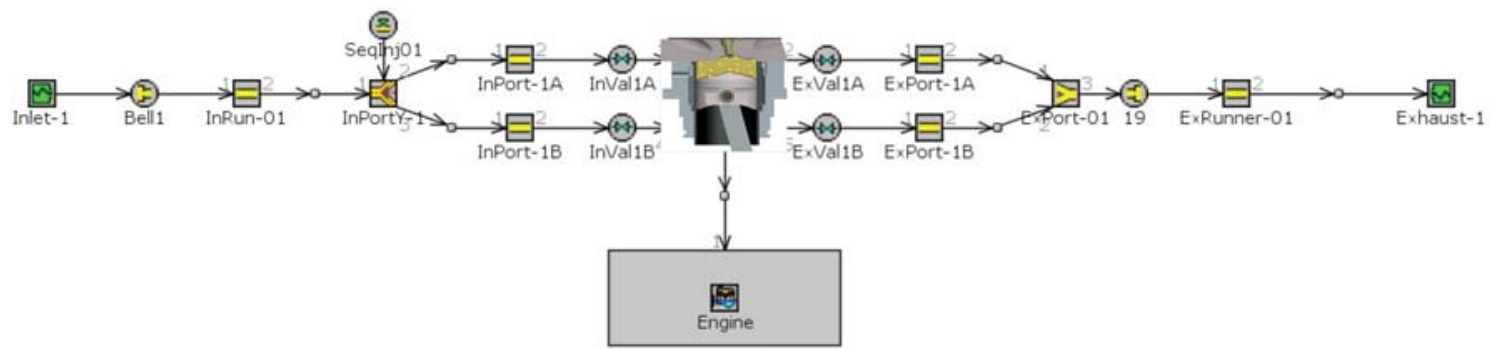

Figure 3.3: Single cylinder HCCI engine model in GT - POWER ${ }^{\circledR}$ 
step offers the flexibility to simulate a wide range of engine operating conditions by making use of its flow model. Thus, the results obtained from this step serve as an initial guess for the next simulation steps. Moreover the computational requirement is extremely low for this type of model and results are obtained in a short time. It takes $17 \mathrm{sec}$ to simulate one engine cycle on a computer with an Intel I7 processor with 8 GB RAM.

The simulation results from the GT - POWER ${ }^{\circledR}$ model provide guess for initial IVC values. In-addition, this 1-D GT - POWER ${ }^{\circledR}$ model allows the user to change the default valve timings to study VVT impact on RGF, temperature at IVC $\left(\mathrm{T}_{\mathrm{ivc}}\right)$, pressure at IVC $\left(\mathrm{P}_{\mathrm{ivc}}\right)$ and eventually see the impact on the combustion process.

\subsubsection{Step 2: Multi zone modelling (IVC-EVO)}

This section details the multi zone HCCI model developed in CHEMKIN-PRO. A reduced n-heptane chemical mechanism [53] is used for this study. This mechanism consists of 770 chemical reactions and 159 species. The reduced mechanism is able to provide suitable results in a short time as compared to detailed chemical mechanisms.

To carry out the modeling process, the combustion chamber is divided into ten zones, since this number of zones is found to provide good accuracy in predicting HCCI combustion [5]. The zone mass distribution is shown in Table 3.2, which is selected based on [5] and adjusted suitably. Zone numbering is considered in an ascending order from 
Table 3.2

Zone mass distribution for SMRH. This mass distribution is based on the results in [5] and is modified suitably.

\begin{tabular}{ccccccccccc}
\hline Zone (\#) & 1 & 2 & 3 & 4 & 5 & 6 & 7 & 8 & 9 & 10 \\
\hline \hline Mass (\%) & 0.001 & 0.001 & 0.05 & 0.3 & 0.55 & 3.098 & 8 & 19 & 29 & 40 \\
\hline
\end{tabular}

the combustion chamber wall to the core in-cylinder region (i.e., from zone \#10 with the highest temperature to zone \#1 with the lowest temperature). Figure 3.4 shows the zone temperature distribution. Zones \#1 to \#3 represent the crevices, zone \#4 is an interface between crevices and the boundary layer. Zones \#5 to \#7 represent the boundary layer. The core region is represented by zones \#8 to \#10. Zones associated with crevices and boundary layers are known to be the primary causes of uHC and $\mathrm{CO}$ emissions $[5,54]$. The aim in this study is to minimize computation time and increase the operation range of

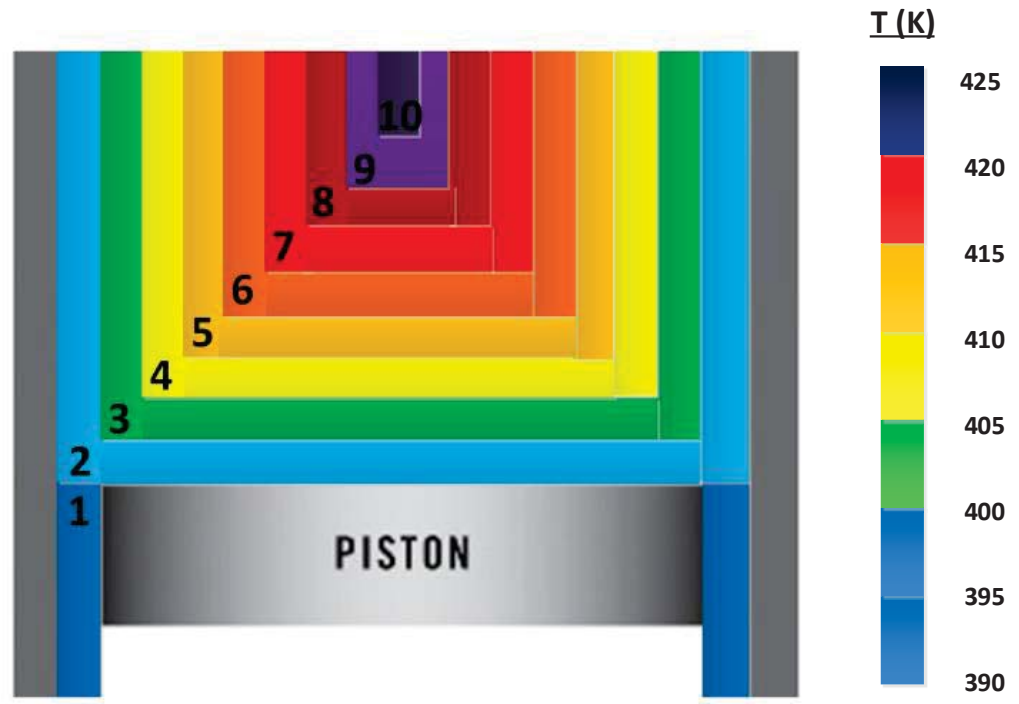

Figure 3.4: Zone temperature distribution inside a cylinder

SMRH to simulate residual gas effects. To minimize computational load, instead of using a 
CFD code, gas temperatures in the individual zones are calculated based on a linear relation between the wall temperature (zone \#1) and the core (zone \#10) temperature using the $\mathrm{T}_{\mathrm{ivc}}$ obtained from Step \#1.

\subsubsection{Multi zone modeling and heat transfer correlations}

The purpose of Step \#2 is to obtain initial combustion results which are used in the next step of the sequential modeling process. Multi zone modeling carried out using

CHEMKIN ${ }^{\circledR}$ - PRO uses the equations mentioned in this section. Equations (3.1) to (3.4) from [55] describe the multi zone modeling approach followed in this thesis to determine in-cylinder gas properties from IVC to EVO.

$$
\rho^{i} \frac{d Y_{k}^{i}}{d t}=\dot{\omega}_{k}^{i} W_{k}^{i} \quad, \text { for } i=1, \ldots, N_{\text {zone }}
$$

Where, $\rho$ is the zone density, superscript " $i$ " and subscript " $k$ " represent the zone and species number respectively, while $Y_{k}, W_{k}$ and $\dot{\omega}_{k}$ represent the mass fraction, molecular weight and molar production rate of the $k^{\text {th }}$ species, respectively. Calculation of zone temperature is done using Equation (3.2).

$$
\rho^{i} C_{v}^{i} \frac{d T^{i}}{d t}=-\sum_{k=1}^{k_{\text {gas }}} \dot{\omega_{k}^{i}} W_{k} u_{k}^{i}-\frac{P^{i}}{V^{i}} \frac{d V^{i}}{d t}-\frac{h_{w}^{i}\left(T^{i}-T_{w}\right) A_{w}^{i}}{V^{i}}, \quad \theta(t)>\theta_{t}
$$


Where, $P, V$ and $T$ represent the zone pressure, volume and temperature respectively. $C_{v}$ is the constant volume specific heat capacity for the gases in a particular zone. $u_{k}$ represents the internal energy of the $k^{\text {th }}$ species. $A_{w}$ is the zone wall surface area. Zone wall convective heat transfer coefficient is denoted by $h_{w}$. Here, $h_{w}$ is computed by using the Woschni heat transfer correlation [55]. Cylinder pressure is assumed to be uniform throughout the zones and is given by:

$$
P^{N_{z o n e}}=\frac{G^{N_{z o n e}}}{V_{c y l i n d e r}}
$$

where, $V_{\text {cylinder }}$ is the instantaneous cylinder volume. The variable $G$ is the accumulated product of individual zone pressure and volume and is given by:

$$
G^{i}=\sum_{j=1}^{i} P^{j} V^{j}
$$

Equations (3.1), (3.2), (3.3) and (3.4) are solved simultaneously in CHEMKIN ${ }^{\circledR}-$ PRO for all zones to obtain zone properties. Heat transfer is accounted by using the Woschni heat transfer correlation for IC engines [6]. Convective heat loss from the in-cylinder gas mixture to the cylinder walls is determined by:

$$
Q_{\text {wall }}=h A\left(T-T_{\text {wall }}\right)
$$


where $T_{\text {wall }}$ is the wall temperature and $h$ is obtained based on Equation (3.6).

$$
N u=a \operatorname{Re}^{b} \operatorname{Pr}^{c}
$$

Where $\mathrm{Nu}, \quad \operatorname{Re}$ and $\operatorname{Pr}$ are the Nusselt, Reynolds and Prandtl numbers. a, b, c are constants. For the Woschni correlation the Reynolds Number is defined by Equation (3.7).

$$
R e=\frac{D w \rho}{\mu}
$$

Where, $D$ represents the cylinder bore diameter and $\mu$ is the dynamic viscosity of the fluid. The average gas velocity $(w)$ is determined by:

$$
w=\left[C_{11}+C_{12} \frac{v_{\text {swirl }}}{\overline{S_{p}}}\right] \overline{S_{p}}+C_{2} \frac{V_{d} T_{i}}{P_{i} V_{i}}\left(P-P_{\text {motored }}\right)
$$

In Equation (3.8), the terms $C_{11}, C_{12}$ and $C_{2}$ are constants whose values are determined using the engine experimental data. $v_{\text {swirl }}$ represents the swirl velocity and $\overline{S_{p}}$ represents the mean piston speed. Here, $v_{\text {swirl }}$ is assumed to be zero and the value of $P_{\text {motored }}$ is the pressure at IVC obtained from Step \#1. The constants shown in Table 3.3 are for the experimental conditions in case $a$ and case $b$ from Table 3.1. For case $c$ all values in Table 3.3 are the same except for $C_{11}$ which is changed to 2.7 to account for the change in engine speed. 
Table 3.3

Constants used in the Woschni correlation for multi zone modeling in CHEMKIN-PRO

\begin{tabular}{lr}
\hline \hline Constant & Value \\
\hline \hline HT coefficient a & 0.151 \\
HT coefficient b & 0.8 \\
HT coefficient c & 0 \\
Coefficient C11 & 2.2 \\
Coefficient C12 & 0 \\
Coefficient C2 & 0.00324 \\
Prandtl number & 0.7 \\
\hline
\end{tabular}

\subsubsection{Step 3: Exhaust stroke gas flow and RGF model (EVO-EVC)}

This section describes the third stage in the SMRH modeling process. This stage is responsible for giving the exact inputs i.e., (RGF, modified $\mathrm{T}_{\mathrm{ivc}}$ ) for the final stage of multi zone modeling in CHEMKIN-PRO. The model used here is part of a complete physical model for the HCCI engine cycle and more details for the complete model are found in [41].

\subsubsection{Determination of $T_{e v c}$}

$T_{e v c}$, gas temperature at exhaust valve closing (EVO), is calculated by applying the first law of thermodynamics to an open control volume as:

$$
T_{2}=\frac{T_{1}\left(\sum_{i} m_{i, 1} c_{v_{i, 1}}-\sum_{i} c_{p_{i, 1}}\left(m_{i, c e}+m_{i, e c}\right)\right)+Q_{w}+P_{1} d V}{\sum_{i} m_{i, 2} c_{v_{i, 2}}}
$$


where, subscripts " 1 " and " 2 " correspond to consecutive crank angle degree instances called as "state 1" and "state 2" while the subscripts "ce" and "ec" refer to flow from the cylinder

to the exhaust manifold and vice-versa, respectively. Thus, if "state 1" would correspond to EVO crank angle, then "state 2" would correspond to the next crank angle after EVO (i.e., $\left.\mathrm{EVO}+1^{\circ}\right)$ and so on.

The terms $Q_{w}$ represents the heat loss from the cylinder and the term $P_{1} d V$ represents the boundary work. Heat loss is determined by using the Woschni correlation [56] for HCCI and boundary work is calculated by using the difference between the volumes of "state 1" and "state 2 " multiplied by the cylinder pressure for "state 1".

\subsubsection{Flow through Exhaust Valves}

For modeling flow through the exhaust valves, a 1-D, steady state, compressible and isentropic orifice flow model from [6] is used. Depending on the pressure ratio $\left(\mathrm{P}_{\mathrm{T}} / \mathrm{P}_{\mathrm{O}}\right)$ between the exhaust and cylinder, either of Equation (3.10) or Equation (3.11) is used to calculate in-cylinder gas flow rate $(\dot{\mathrm{m}})$ when the exhaust valves are open.

If, $\left.P_{T} / P_{o}>[2 /(\mathrm{k}+1)]^{\mathrm{k} /(\mathrm{k}-1)}\right]$

$$
\dot{m}=\frac{C_{D} A_{R} P_{O}}{\sqrt{\mathrm{R} T_{o}}}\left(\frac{P_{T}}{P_{O}}\right)^{\frac{1}{\mathrm{k}}}\left\{\frac{2 \mathrm{k}}{\mathrm{k}-1}\left[1-\left(\frac{P_{T}}{P_{o}}\right)^{\frac{\mathrm{k}-1}{\mathrm{k}}}\right]\right\}^{\frac{1}{2}}
$$

else,

$$
\dot{m}=\frac{C_{D} A_{R} P_{o}}{\sqrt{\mathrm{R} T_{o}}} \mathrm{k}^{\frac{1}{2}}\left(\frac{2}{\mathrm{k}+1}\right)^{\frac{\mathrm{k}+1}{2(\mathrm{k}-1)}}
$$


In Equation (3.10) and Equation (3.11), fluid properties upstream of valves are given by the subscript " $O$ " while those at the downstream of the valves are given by " $T$ ". $C_{D}$ and $A_{R}$ refer to the discharge coefficient and the curtain area. $C_{D}$ and $A_{R}$ are given by Equation (3.12) and Equation (3.13), respectively.

$$
A_{R}=\pi d_{v} L_{v}
$$

where, $d_{v}$ and $L_{v}$ are the diameter and axial lifts of the exhaust valve. $C_{D}$ is calculated by [41]:

$$
C_{D}=\mathrm{A}+\mathrm{B} \ln \left(\frac{L_{v}}{d_{v}}\right)+\mathrm{C}\left(\ln \left(\frac{L_{v}}{d_{v}}\right)\right)^{2}+\mathrm{D} \ln \left(\frac{P_{o}}{P_{T}}\right)
$$

where, $\mathrm{A}=-0.152, \mathrm{~B}=-0.577, \mathrm{C}=-0.082$, and $\mathrm{D}=0.294$. Equations (3.10) to (3.13) are used to simulate the mass flow rate of exhaust gases exiting the cylinder at a particular valve lift and crank angle. Modifying the valve profiles for depicting intake and exhaust valve phasing affects the $A_{R}$ and hence, the mass flow rate of gases exiting the cylinder. Thus, $m_{i, c e}$ and $m_{i, e c}$ are calculated as a function of valve timing. The mass remaining inside the cylinder after EVC constitutes the residual gases, hence RGF is also determined. Temperature of residual gases is assumed to be the gas temperature at EVC. The gas temperature at IVC is then modified due to the presence of hot residual gases. Thus, a 
modified $\mathrm{T}_{\mathrm{ivc}}$ is defined as [41]:

$$
T_{i v c-\bmod }(i)=\left(1-X_{r}\right)\left(\frac{c_{v, c h}}{c_{v, t}}\right) T_{i v c}(i)+X_{r}\left(\frac{c_{v, r}}{c_{v, t}}\right) T_{r}(i-1)
$$

where, $X_{r}$ is the RGF quantity and the subscripts " $r$ ", " $c h$ " and " $t$ " represent the residual gases, in-cylinder charge and the total mass of in-cylinder gas at IVC. Here the charge comprises of air, fuel and residual gases.

The EVO gas pressure and temperature conditions from Step \#2 (Section 3.1.2) are given as inputs to the Exhaust Flow and Residual gas (EFR) model in Section 3.1.3. Therefore $T_{e v c}, P_{e v c}$ and RGF can be calculated as a function of valve timing.

For simulating the effects of change in valve timings, the exhaust/intake valve lift versus crank angle can be changed and fed to the EFR model. Thus, when IVC and EVO timings are changed, corresponding values of $\mathrm{T}_{\mathrm{ivc}-\bmod }$, $\mathrm{RGF}$ and temperature of residual gases $\left(\mathrm{T}_{\mathrm{rg}}\right)$ are calculated.

\subsubsection{Step 4: Multi zone modelling in CHEMKIN-PRO (Stage II)}

The $\mathrm{T}_{\mathrm{ivc}-\bmod }$, RGF obtained from the EFR model are then used as inputs to the CHEMKIN-PRO multi zone combustion model to determine the in-cylinder gas pressure trace and combustion metrics for the HCCI engine. The simulation procedure followed 
during this step is similar to Step \#2 of SMRH except that effects of residual gases are accounted for during this step. The residual gases are considered to be comprised of $\mathrm{CO}_{2}, \mathrm{H}_{2} \mathrm{O}$ and $\mathrm{N}_{2}$. The mole fractions are determined based on general combustion equation for n-heptane combustion:

$$
\begin{aligned}
& \beta_{C_{7} H_{16}} C_{7} H_{16}+\beta_{O_{2}}\left(O_{2}+3.76 N_{2}\right)+ \\
& R G\left(\beta_{O_{2}, R G} O_{2}+\beta_{N_{2}, R G} N_{2}+\beta_{C O_{2}, R G} C O_{2}+\beta_{H_{2} O, R G} H_{2} O\right) \longrightarrow \ldots \\
& \ldots \longrightarrow \beta_{O_{2}, R G} \mathrm{O}_{2}+\beta_{N_{2}, R G} \mathrm{~N}_{2}+\beta_{C_{2}, R G} C_{2}+\beta_{\mathrm{H}_{2} O, R G} \mathrm{H}_{2} \mathrm{O}+ \\
& R G\left(\beta_{O_{2}, R G} O_{2}+\beta_{N_{2}, R G} N_{2}+\beta_{C O_{2}, R G} C O_{2}+\beta_{H_{2} O, R G} H_{2} O\right)
\end{aligned}
$$

where $R G$ subscripts denote for residual gases. On substituting values for mole fractions for case $a$ in Table 3.1, Equation (3.15) is written as:

$$
\begin{aligned}
& 1 \mathrm{C}_{7} \mathrm{H}_{16}+24.44\left(\mathrm{O}_{2}+3.76 \mathrm{~N}_{2}\right)+ \\
& R G\left(13.44 \mathrm{O}_{2}+91.89 \mathrm{~N}_{2}+7 \mathrm{CO}_{2}+8 \mathrm{H}_{2} \mathrm{O}\right) \longrightarrow \ldots \\
& \ldots \longrightarrow 13.44 \mathrm{O}_{2}+91.89 \mathrm{~N}_{2}+7 \mathrm{CO}_{2}+8 \mathrm{H}_{2} \mathrm{O}+ \\
& R G\left(13.44 \mathrm{O}_{2}+91.89 \mathrm{~N}_{2}+7 \mathrm{CO}_{2}+8 \mathrm{H}_{2} \mathrm{O}\right)
\end{aligned}
$$

The results obtained from this final step are compared with experimental data from a Ricardo single cylinder HCCI engine [4]. The experimental validation results of SMRH will be discussed in Section 3.2. 


\subsection{Results and Discussion}

\subsubsection{Model Validation}

Given the number of assumptions done in developing the SMRH, it is critical to experimentally validate the SMRH before moving on to the discussion of HCCI combustion results. Experimental data is taken from [4] for a single cylinder Ricardo Mark III HCCI engine with specifications shown in Table 3.4. Details of the engine experimental setup are found in [41]. Uncertainty analysis of the experimental data obtained from the Ricardo engine can be found in [57].

This section presents the results for in-cylinder gas pressure, crank angle for 10 percent mass of fuel burned (CA10), crank angle for 50 percent mass of fuel burned (CA50), burn duration (BD), indicated mean effective pressure (IMEP), indicated thermal efficiency $\left(\eta_{t h, i}\right)$ and $\mathrm{CO}$ emissions and their comparison with experimental data for the HCCI operating conditions previously listed in Table 3.1. Validations for in-cylinder gas pressure are shown in Figures 3.5, 3.6 and 3.7, while quantitative metrics are compared with the experimental values in Table 3.5.

From Figures 3.5, 3.6 and 3.7, it is observed that the simulation pressure traces are in good agreement with those from the experiments. In addition, from Table 3.5 the 
Table 3.4

Ricardo single cylinder engine specifications

\begin{tabular}{cc}
\hline \hline Parameter & Value \\
\hline \hline Bore & $80 \mathrm{~mm}$ \\
Stroke & $88.9 \mathrm{~mm}$ \\
Compression ratio & $10: 1$ \\
Displacement volume & $0.447 \mathrm{~L}$ \\
IVO/IVC & $-175 /+55^{\circ} \mathrm{aBDC}$ \\
EVO/EVC & $-70 /-175^{\circ} \mathrm{aBDC}$ \\
Number of valves & 4 \\
\hline
\end{tabular}

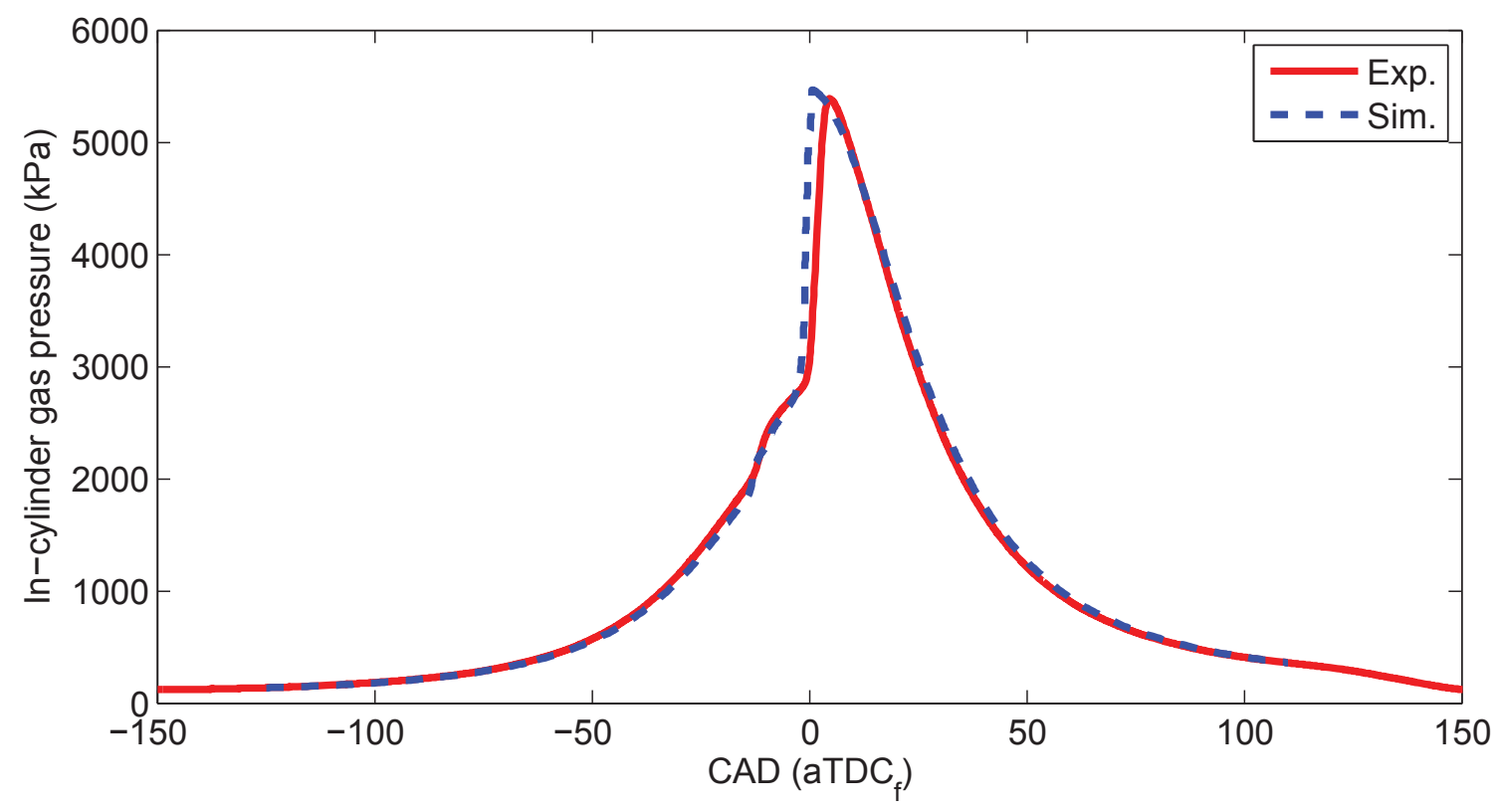

Figure 3.5: Pressure trace validation for the engine operating condition corresponding to case a in Table 3.1

predicted values of the combustion and performance metrics match closely with the experimental values. The average error values for predicting CA50, BD, IMEP, $\eta_{\mathrm{th}, \mathrm{i}}$ and CO concentration are $1.11 \mathrm{CAD}, 1.2 \mathrm{CAD}, 0.47 \mathrm{bar}, 6.7 \%$ and $0.04 \%$ respectively. The largest relative error belongs to $\mathrm{CO}$ prediction since multi zone modeling is limited in accuracy for prediction of $\mathrm{CO}$ as previously reported in $[5,52]$. Studies in $[5,52]$ show that 


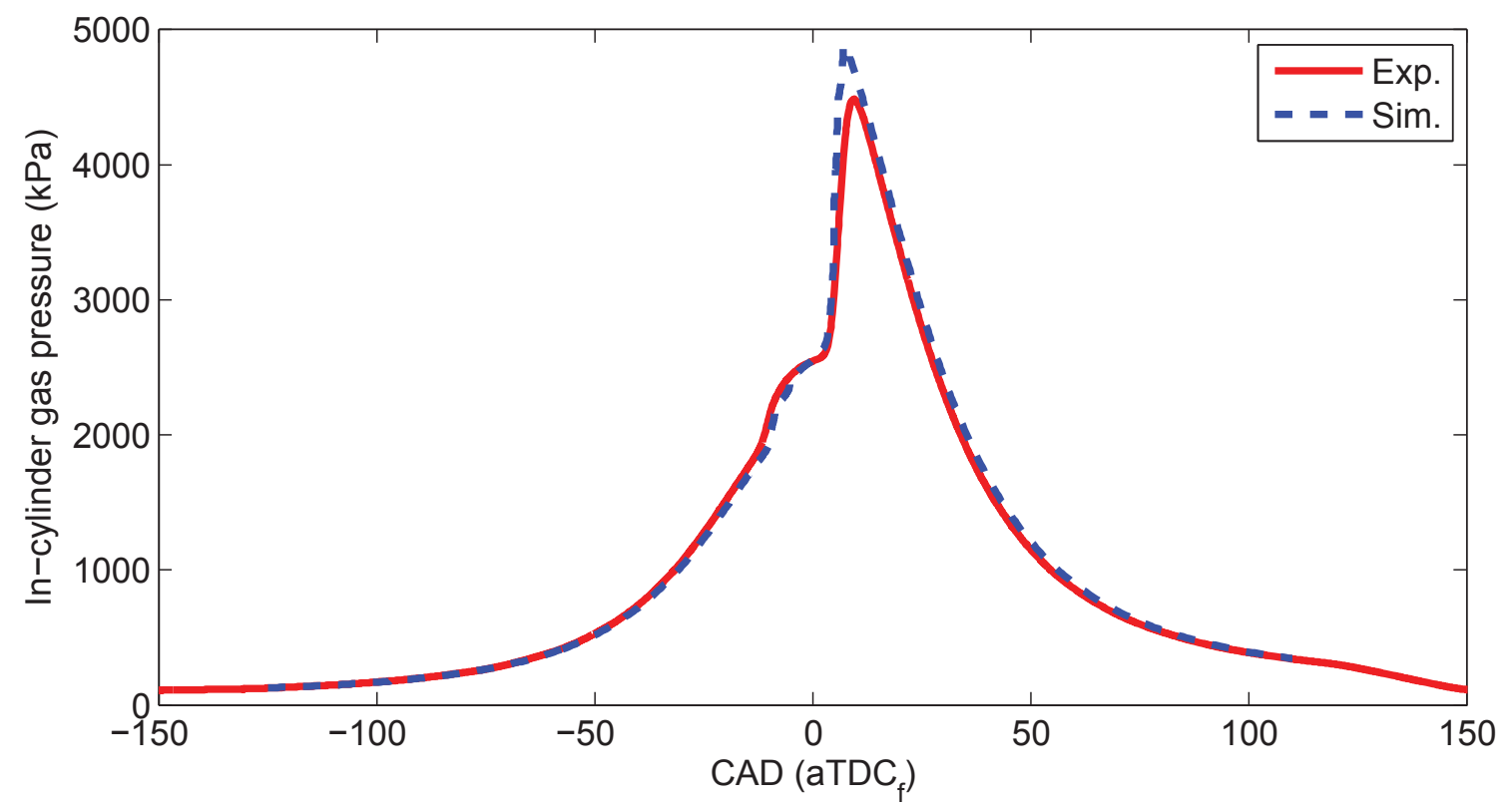

Figure 3.6: Pressure trace validation for the engine operating condition corresponding to case $b$ in Table 3.1

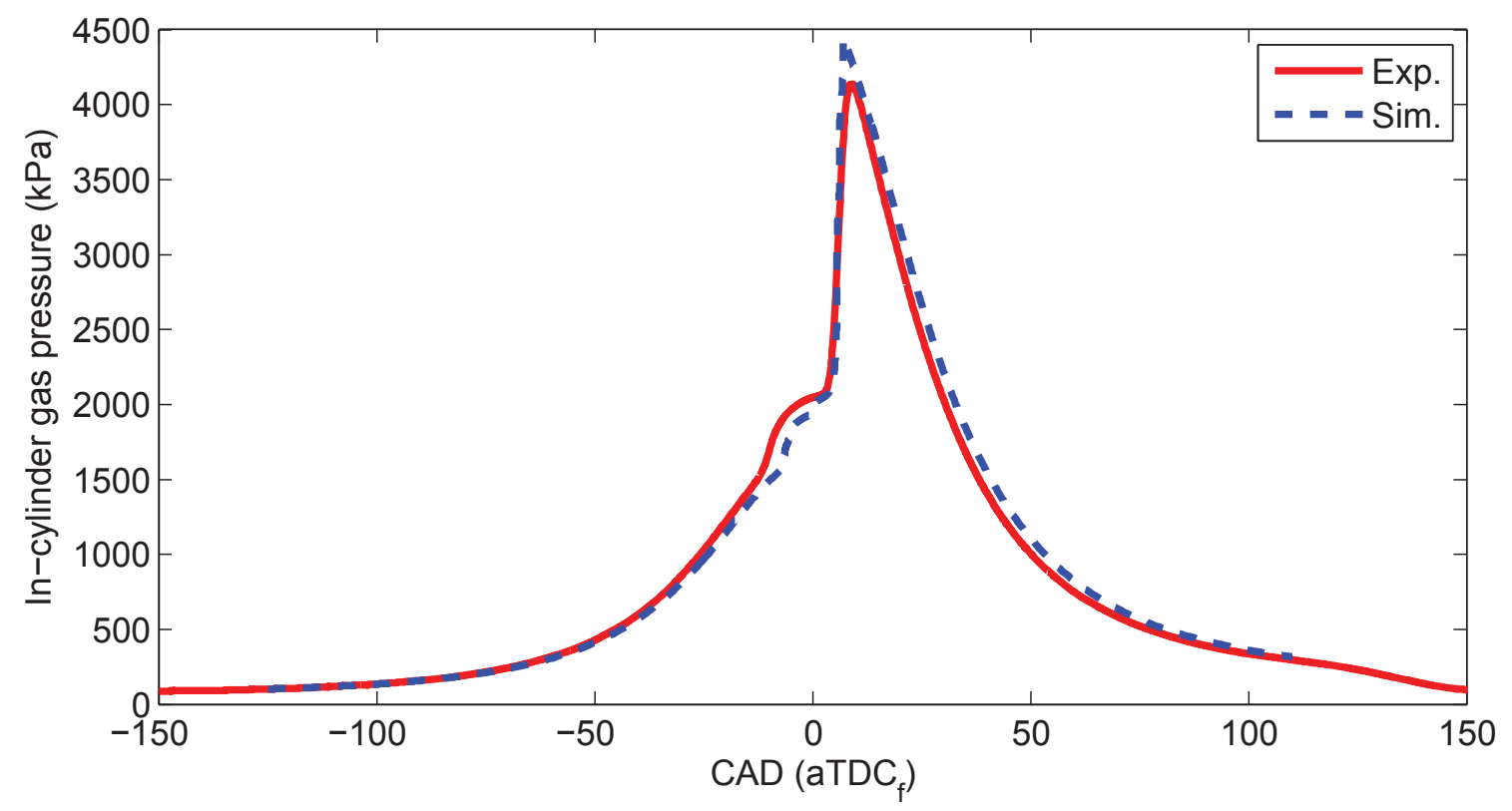

Figure 3.7: Pressure trace validation for the engine operating condition corresponding to $\underline{\text { case } c}$ in Table 3.1 
Table 3.5

Comparison between experimental (Exp.) and simulated (Sim.) combustion phasing, IMEP, indicated thermal efficiency $\left(\eta_{\mathrm{th}, \mathrm{i}}\right)$ and $\mathrm{CO}$ emission

\begin{tabular}{|c|c|c|c|c|c|c|c|c|c|c|}
\hline \multirow{2}{*}{ Case \# } & \multicolumn{2}{|c|}{$\begin{array}{c}\text { CA50 } \\
\left({ }^{\circ} \text { aTDC }_{\text {f }}\right)\end{array}$} & \multicolumn{2}{c|}{$\begin{array}{c}\text { BD } \\
\text { (CAD) }\end{array}$} & \multicolumn{2}{c|}{$\begin{array}{c}\text { IMEP } \\
\text { (bar) }\end{array}$} & \multicolumn{2}{c|}{$\begin{array}{c}\eta_{t h} \\
(\%)\end{array}$} & \multicolumn{2}{c|}{$\begin{array}{c}\text { CO } \\
(\%)\end{array}$} \\
\cline { 2 - 12 } & Exp. & Sim. & Exp. & Sim. & Exp. & Sim. & Exp. & Sim. & Exp. & Sim. \\
\hline a & 1.4 & -1 & 3.7 & 2.8 & 5.1 & 5.3 & 40 & 40 & 0.08 & 0.13 \\
\hline $\mathrm{b}$ & 5.9 & 5.0 & 5.2 & 3.7 & 4.7 & 5.1 & 40 & 40 & 0.1 & 0.07 \\
\hline $\mathrm{c}$ & 5.7 & 5.8 & 3.7 & 2.5 & 4.3 & 5.1 & 40 & 50 & 0.07 & 0.1 \\
\hline
\end{tabular}

a conventional multi zone $\mathrm{HCCI}$ model bears a significant error in predicting $\mathrm{CO}$ emissions. But, predictions of $\mathrm{CO}$ emissions in Table 3.5 are close to experimental data with an average error of $0.04 \%$ mole fraction.

\subsubsection{Results for impact of valve timings on HCCI combustion}

In order to assess the impact of changing valve timings on the performance and combustion metrics for HCCI combustion, both intake and exhaust valves are phased individually in steps of $5 \mathrm{CAD}$ as shown in Figures 3.8 and 3.9. For the intake valves, the IVC timing is focused upon while for the exhaust valve the EVO timing is focused upon. The base IVC of $-125^{\circ} a T D C_{f}$ is advanced upto $-140^{\circ} a T D C_{f}$ in steps of $5 \mathrm{CAD}$ and retarded upto $-110^{\circ} a T D C_{f}$ in steps of $5 \mathrm{CAD}$. Similar variations are made for the exhaust valves which have its base EVO timing of $110^{\circ} a T D C_{f}$. EVO timing is advanced upto $95^{\circ} a T D C_{f}$ and retarded upto $125^{\circ} a T D C_{f}$. The parameters studied for changes in valve timing are in-cylinder gas pressure, in-cylinder gas temperature, combustion phasing, Net 
Heat Release Rate (NHRR) and engine-out emissions.

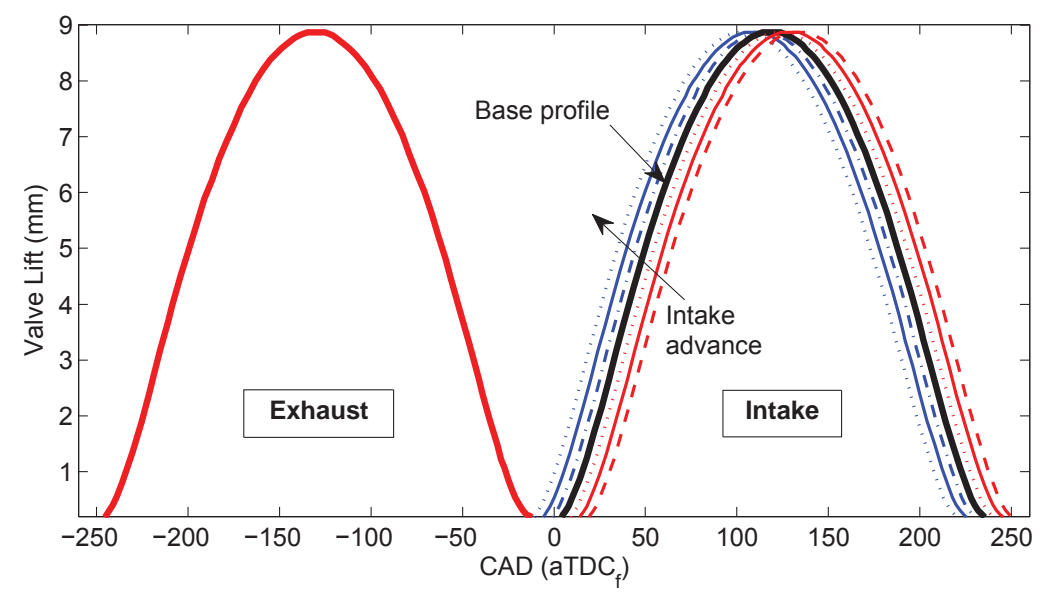

Figure 3.8: Intake valve profile variations in this study

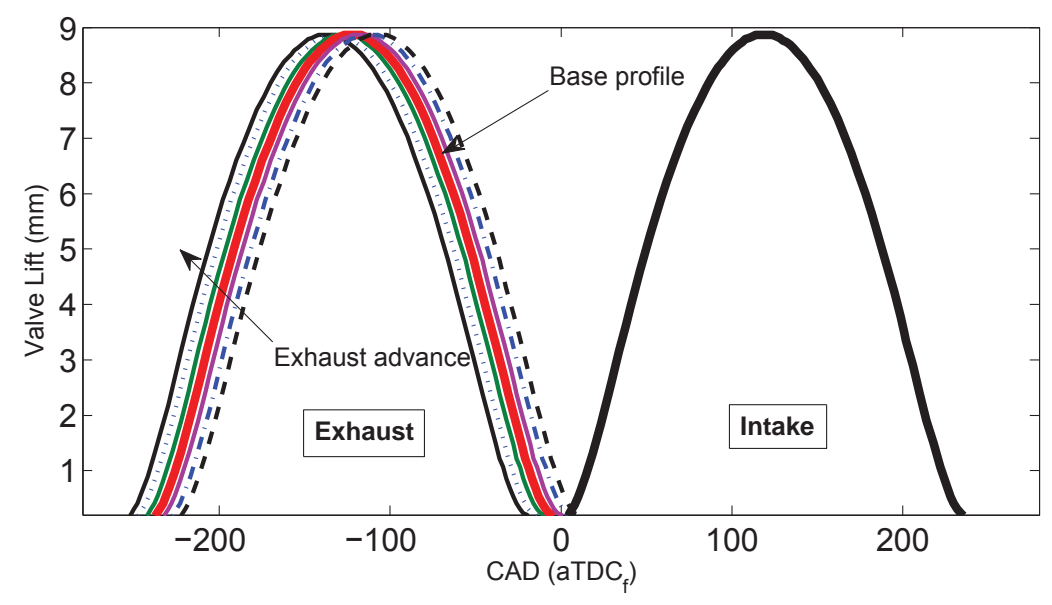

Figure 3.9: Exhaust valve profile variations in this study

\subsubsection{Effect of IVC variations}

The first set of results deals with the impact of changing IVC timings on HCCI combustion. Experimentally validated case a from Table 3.1 is selected as a representative HCCI 
operating point. IVC timing sweep from $-140^{\circ} a T D C$ to $-110^{\circ} a T D C_{f}$ is studied with the baseline value at $-125^{\circ} a T D C_{f}$. The variations in the in-cylinder gas pressure trace are seen in Figure 3.10. It can be seen that as the IVC timing is advanced from the base position upto $-140^{\circ} a T D C_{f}$ the peak pressure $\left(\mathrm{P}_{\max }\right)$ rises in magnitude along with advancement of the crank angle for $\mathrm{P}_{\max }$. The $\mathrm{P}_{\max }$ for the most advanced valve position is 57.5 bar occurring at $-1.3^{\circ} a T D C_{f}$ while $\mathrm{P}_{\max }$ of the most retarded position is 46.5 bar at $6.3^{\circ} a T D C_{f}$. It can be inferred that, the rise in $\mathrm{P}_{\max }$ is due to advancing of IVC timing where the compression stroke begins earlier. The calculated temperature versus crank angle degree (CAD) is plotted in Figure 3.11 by considering the average of all ten zones. Peak gas temperatures $\left(\mathrm{T}_{\max }\right)$ are found to increase as the IVC is advanced. Cases with IVC $=-140^{\circ}$ and $-135^{\circ}$ are found to exhibit two peaks for the gas temperature profile. The reason for this will be discussed later when analyzing emissions results. For the case of advancing IVC timing, the CA10 and CA50 are also found to advance as shown in Figure 3.12. The CA50 advances from $3.8^{\circ} a T D C_{f}$ for the IVC timing of $-110^{\circ} a T D C_{f}$ to $-1.8^{\circ} a T D C_{f}$ for the IVC timing of $-140^{\circ} a T D C_{f}$.

For the case of intake valve phasing the RGF is not expected to vary significantly since the RGF is not directly affected by IVC timing. Although, changing IVC timing might have an impact on the in-cylinder gas velocities and the gas pressures at end of combustion. These factors can contribute to small changes in the RGF. Simulated RGF values in Figure 3.13 also confirm small variation. From the most advanced, to the most retarded position, the RGF changes less than $1 \%$. 


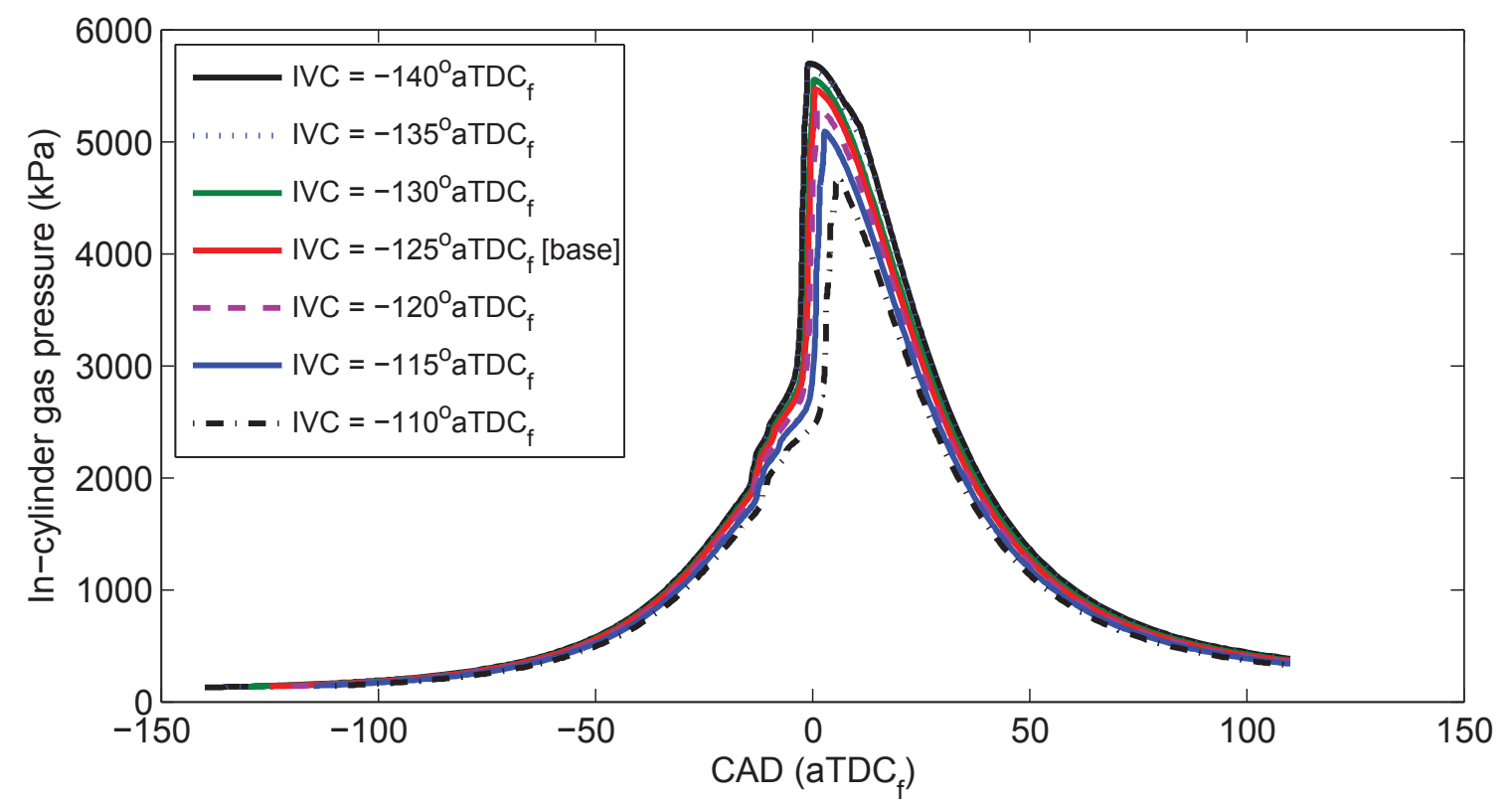

Figure 3.10: Variation in in-cylinder gas pressure as a function of intake valve phasing

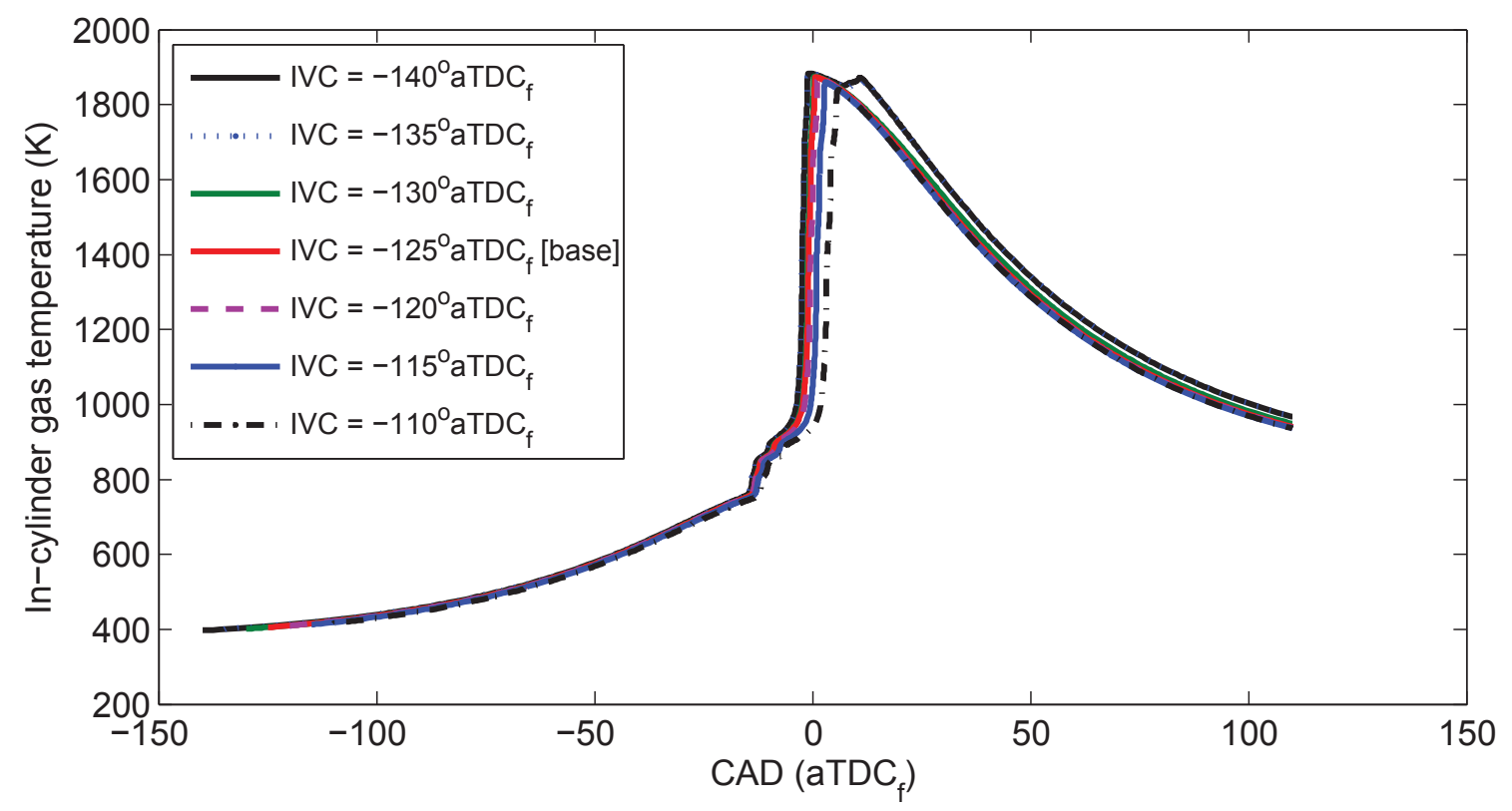

Figure 3.11: Variation in in-cylinder gas temperature as a function of intake valve phasing 
(a)

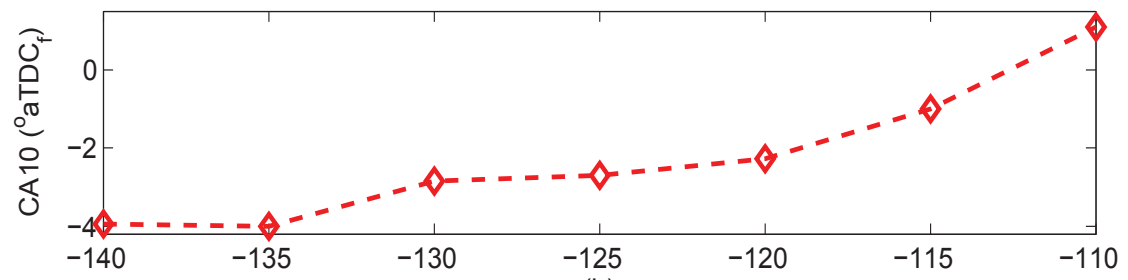

(b)

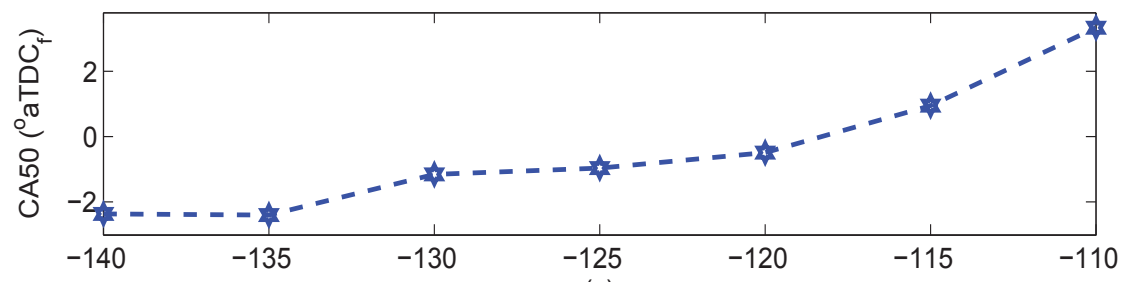

(c)

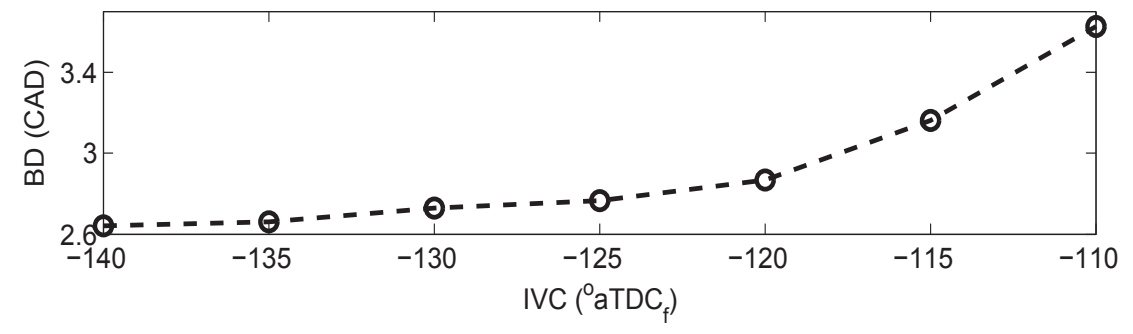

Figure 3.12: Variations of combustion metrics (CA10, CA50 and BD) for changes in intake valve phasing

The trend of $\mathrm{T}_{\mathrm{ivc}-\text { mod }}$ variations along with the RGF quantities and residual gas temperatures $\left(\mathrm{T}_{\mathrm{rg}}\right)$ can be seen in Figure 3.13. The $\mathrm{T}_{\mathrm{rg}}$ drops as the IVC is advanced. This can be explained by looking into $\mathrm{T}_{\text {evo }}$ in Figure 3.11 that affects $\mathrm{T}_{\mathrm{evc}}$. Delayed combustion at retarded IVC timing leads to higher gas temperature in the exhaust stroke and consequently higher residual gas temperature. As seen in Figure 3.14, for each fixed crank angle before SOC, in-cylinder gas temperature is higher for earlier IVC timings. Thus, the onset of combustion occurs earlier with early IVC as shown in Figure 3.12.

IMEP, $\eta_{\text {th,i }}$ along with the NHRR versus IVC timing are shown in Figures 3.15 and 3.16. The NHRR shown in Figure 3.16 is determined using the heat release model from [6]. 
(a)

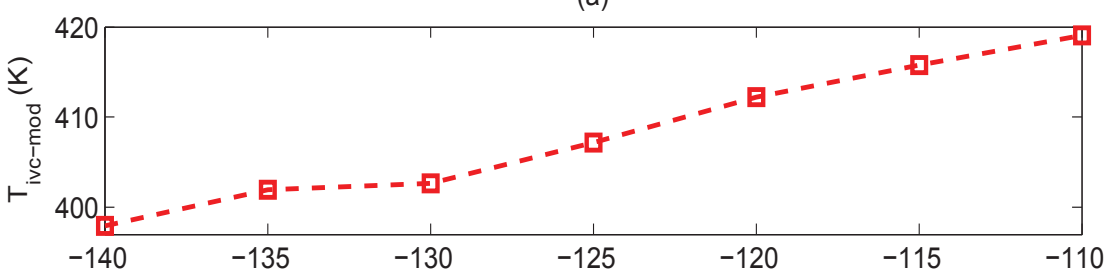

(b)

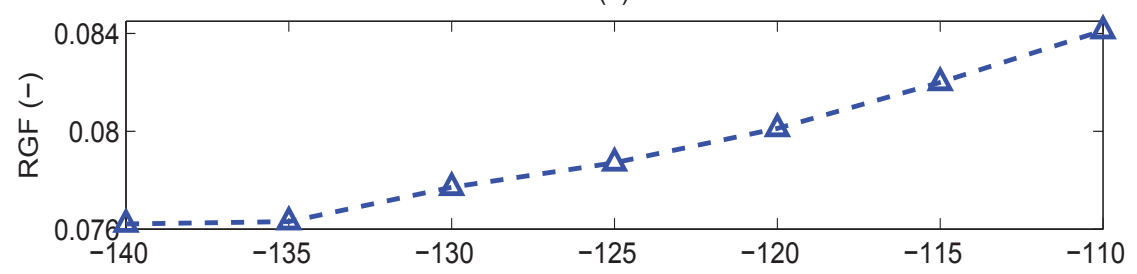

(c)

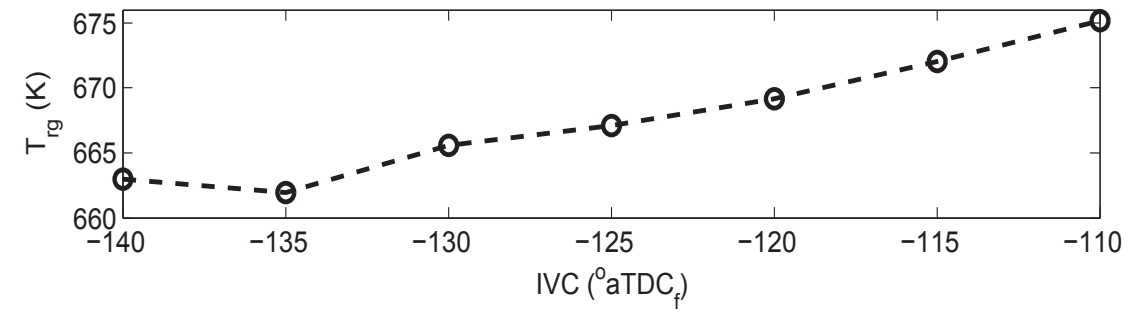

Figure 3.13: Impact of intake valve phasing on (a): in-cylinder gas temperature at IVC due to presence of RGF, (b): RGF quantity, (c): temperature of trapped residual gases.

It can be seen that, as the intake valves are closed earlier, the IMEP and $\eta_{t h, i}$ increase, indicating that a stronger combustion event takes place as IVC occurs early. Pumping losses are also reduced [6]. As expected, the NHRR increases with advancing IVC and its curve shifts leftwards on the X-axis for early IVC timing (Figure 3.16). Results in Figure 3.16 confirm that both stages of n-heptane heat release occur early confirming both Low Temperature Reactions (LTR) and High Temperature Reactions (HTR) occur earlier when IVC is advanced.

One disadvantage of advancing IVC is that, the effect of using inertia of intake air due to 


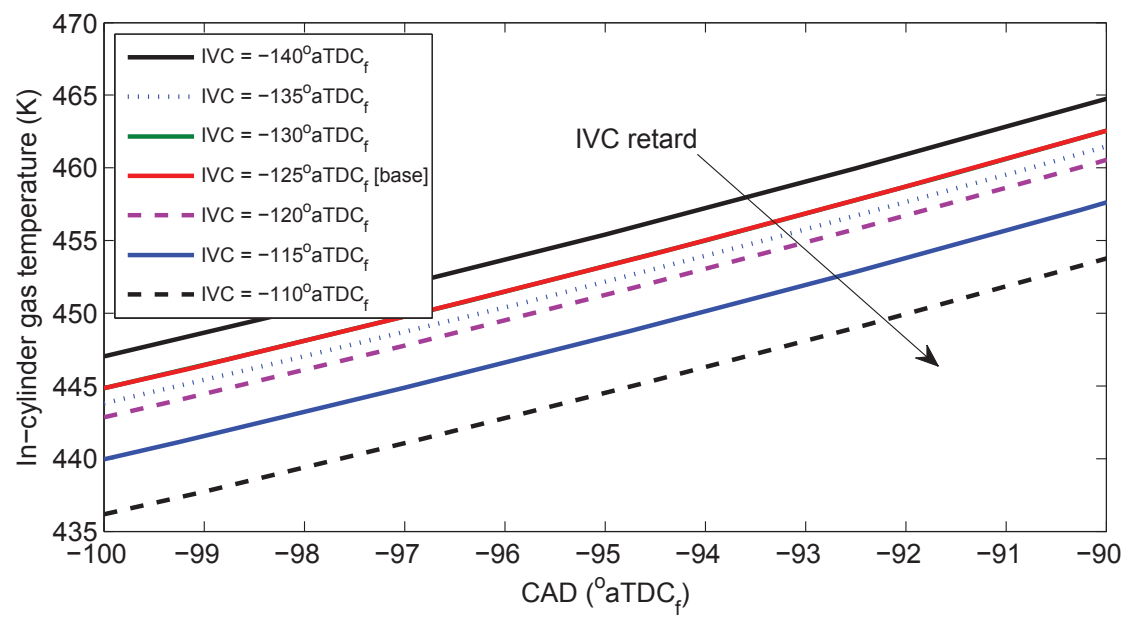

Figure 3.14: Close-up view of in-cylinder gas temperatures history before start of combustion

(a)

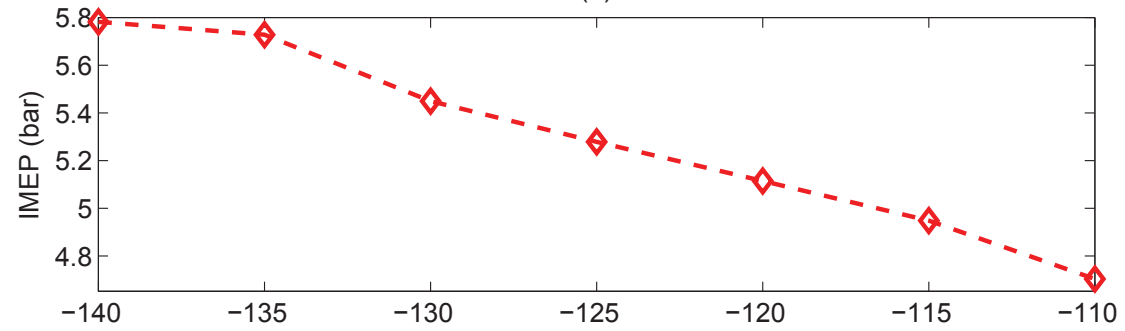

(b)

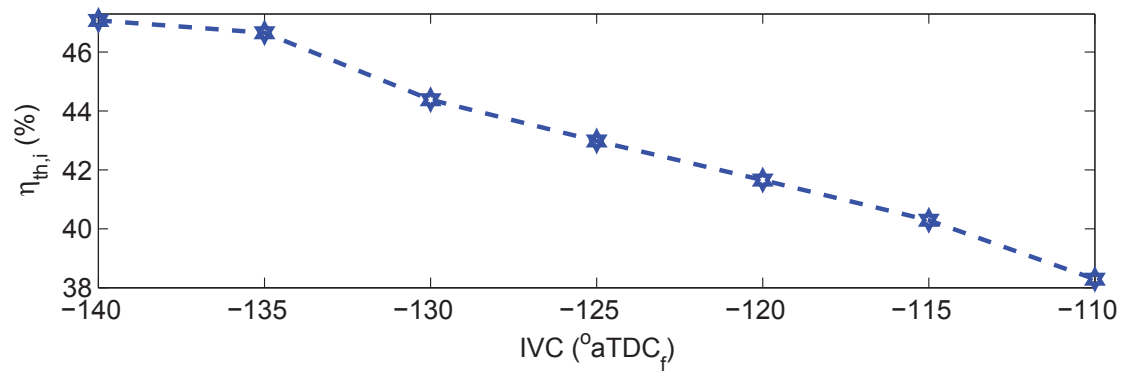

Figure 3.15: Variation of IMEP and indicated thermal efficiency $\left(\eta_{\mathrm{th}, \mathrm{i}}\right)$ as a function of intake valve timing

its velocity, to increase the quantity of air taken in during the intake stroke is reduced, but in reality this effect, also known as "Ram Effect" [6], is negligible since engine speed is low (i.e., $1016 \mathrm{rpm})$. For low engine speeds, delaying IVC can cause some of the air-fuel 


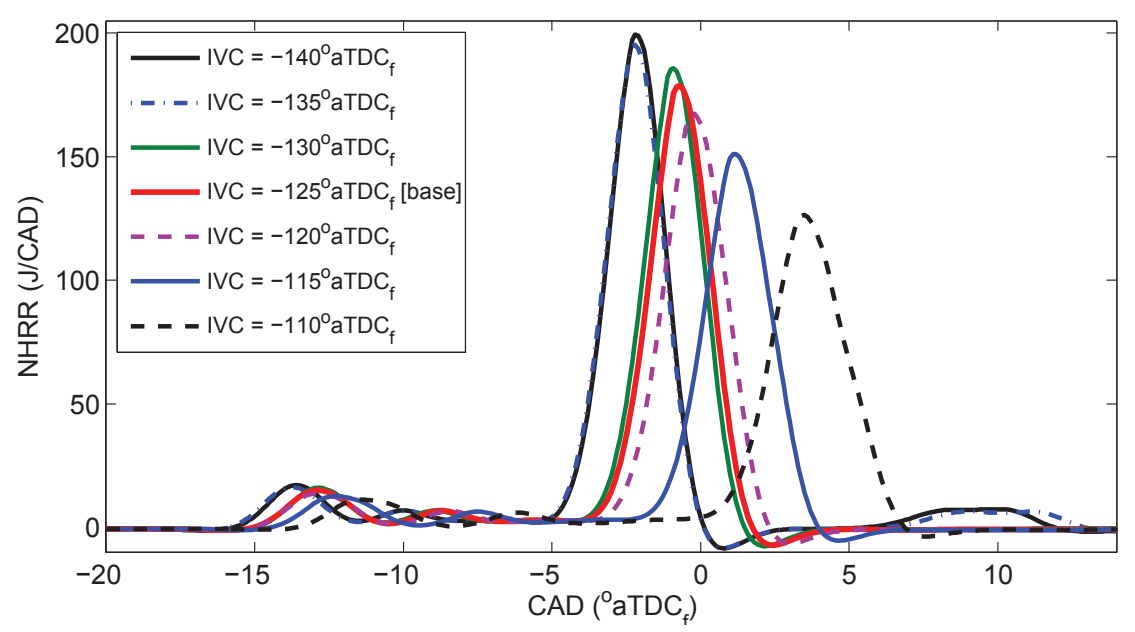

Figure 3.16: Net heat release rate (NHRR) as a function of changing intake valve timing

mixture to go into the intake manifold due to less inertia effect of the incoming charge. Volumetric efficiency is hence reduced by too delayed IVC timings. In addition, since the mixture is very lean $(\phi=0.45)$, there is a chance of misfire for the operating conditions with highly delayed IVC.

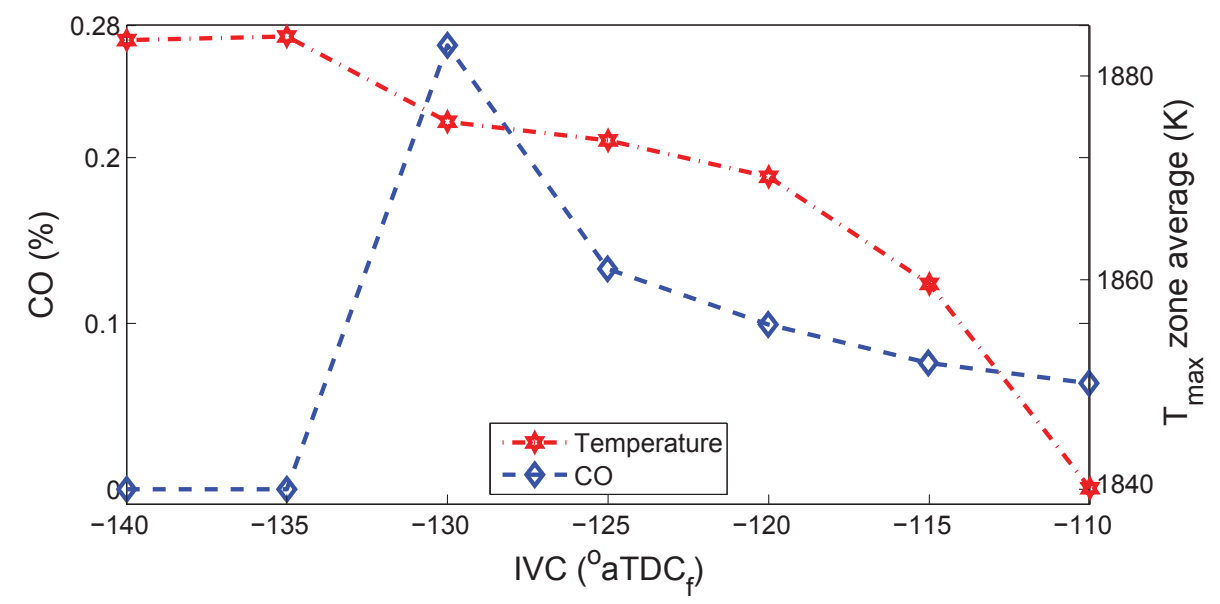

Figure 3.17: Impact of intake valve timing on Carbon monoxide (CO) concentration and maximum gas temperature $\left(\mathrm{T}_{\max }\right)$ averaged including all ten zones 


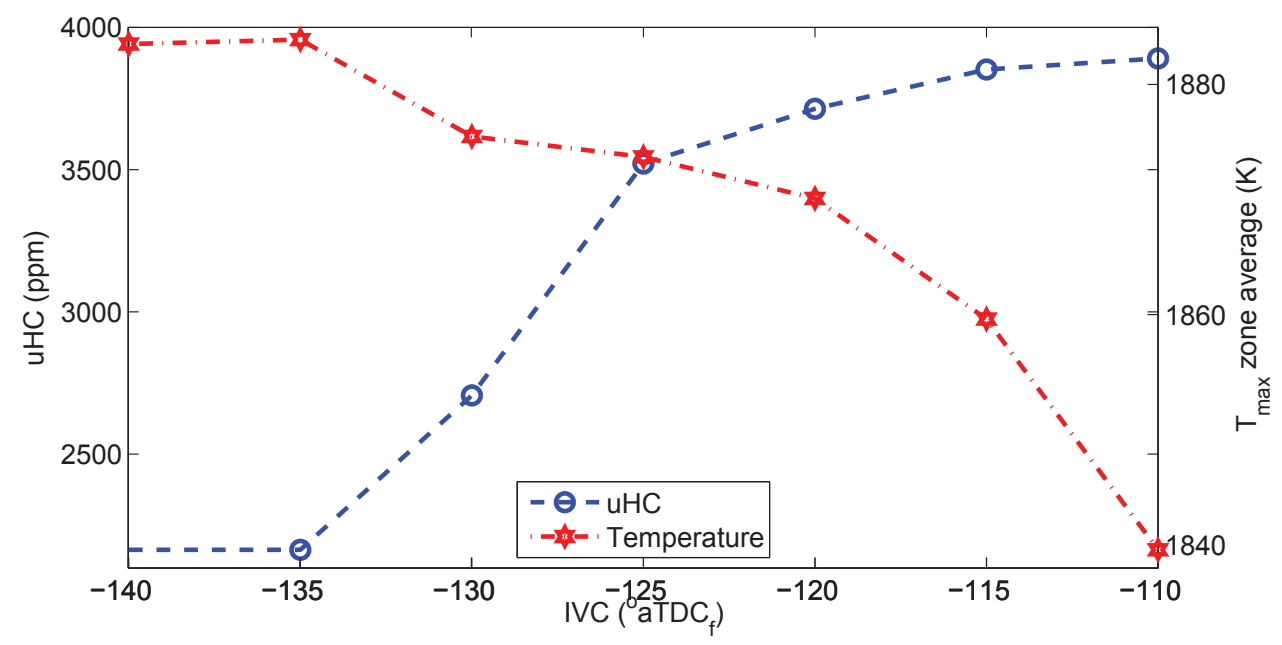

Figure 3.18: Unburned hydrocarbons (uHC) concentration and maximum zone averaged gas temperature $\left(\mathrm{T}_{\max }\right)$ as a function of intake valve timing

Figures 3.17 and 3.18 show the trend of $\mathrm{CO}$ and $\mathrm{uHC}$ emissions as a function of IVC timings. Figures 3.17 and 3.18 also show the impact of the maximum in-cylinder gas temperature on $\mathrm{CO}$ and $\mathrm{uHC}$ emissions. $\mathrm{uHC}$ and $\mathrm{CO}$ emissions are the two major emissions known to be high in HCCI engines. uHC emissions occur primarily when some of the fuel remaining unburnt due to low gas temperatures and highly lean conditions [6]. Formation of $\mathrm{CO}$ emissions on the other hand is more dependant on chemical kinetics [52]. $\mathrm{CO}$ emissions are formed when gas temperature is not high enough and the conditions are air deficient for the oxidation of $\mathrm{CO}$ into $\mathrm{CO}_{2}$. The general equation for $\mathrm{CO}$ to $\mathrm{CO}_{2}$ oxidation is as follows $[58,59]$ :

$$
\mathrm{CO}+\mathrm{OH} \rightarrow \mathrm{CO}_{2}+\mathrm{H}
$$

From Figure 3.17, $\mathrm{CO}$ emissions are negligible for cases with $\mathrm{IVC}=-140$ and $-135^{\circ} a T D C_{f}$. For cases after $-135^{\circ} a T D C_{f}$ the $\mathrm{CO}$ emissions suddenly rise and appear to reduce as IVC is 
further retarded. On further observation of the NHRR curves, cases with low CO emissions show a small peak after the main heat release around $10^{\circ} \mathrm{aTDC}_{\mathrm{f}}$. The excess heat released is due to late fuel combustion in zone \#7. Impact of this late combustion is observed in gas temperature for zone \#7 in Figure 3.19. Correspondingly, when emissions data is plotted against crank angle $\mathrm{CO}$ to $\mathrm{CO}_{2}$ oxidation is also observed as shown in Figure 3.20. Considering the zone mass distribution in Table 3.2 , about $11 \%$ of the total fuel mass is present in zones \#6 and \#7. A study by [52] states that $\mathrm{CO}$ to $\mathrm{CO}_{2}$ oxidation occurs for peak gas temperatures above $1500 \mathrm{~K}$. Also, for the cases having peak temperatures closer to $1000 \mathrm{~K}$, uHC into $\mathrm{CO}$ oxidation is difficult [8]. Peak gas temperature in zone \#6 is not observed to go above $1500 \mathrm{~K}$ in the operating conditions studied. Hence, peak gas temperature in zone \#7 has a significant effect on emissions formation. For the two cases with low $\mathrm{CO}$ emissions peak temperature in zone \#7 is above $1500 \mathrm{~K}$ and is favourable for $\mathrm{CO}$ to $\mathrm{CO}_{2}$ oxidation. Thus, for these two cases zones (7-10) composing about $96 \%$ of the total mass of fuel have peak temperatures above $1500 \mathrm{~K}$. Hence, $\mathrm{CO}$ emissions are low. For the remaining cases of IVC phasing, peak temperature for zone \#7 is below $1000 \mathrm{~K}$ causing high $\mathrm{CO}$ emissions. As peak temperature reduces below $1000 \mathrm{~K}$ for a zone, rate of uHC to $\mathrm{CO}$ oxidation slows down causing $\mathrm{CO}$ emissions to reduce but increasing $\mathrm{uHC}$ emissions. Zone's \#1-4 have peak temperatures well below $1000 \mathrm{~K}$, hence remain too cold for the fuel to burn resulting in $\mathrm{uHC}$ emissions. The temperature threshold for $\mathrm{NO}_{\mathrm{x}}$ emission formation is around $1800 \mathrm{~K}[8]$. The peak temperatures in the core zones in Figure 3.19 are above $1800 \mathrm{~K}$ and $\mathrm{NO}_{\mathrm{x}}$ is expected to be formed in these zones. 


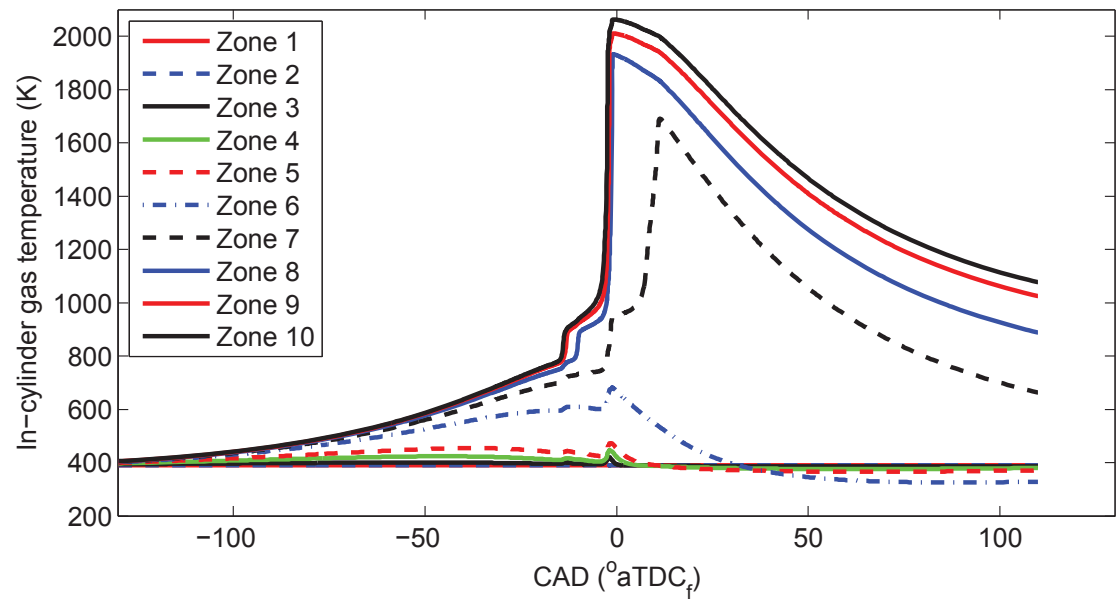

Figure 3.19: Zone temperature versus $\mathrm{CAD}$ for $\mathrm{IVC}=-140^{\circ} \mathrm{aTDC}$ showing peak temperature above $1500 \mathrm{~K}$ for zone \#7

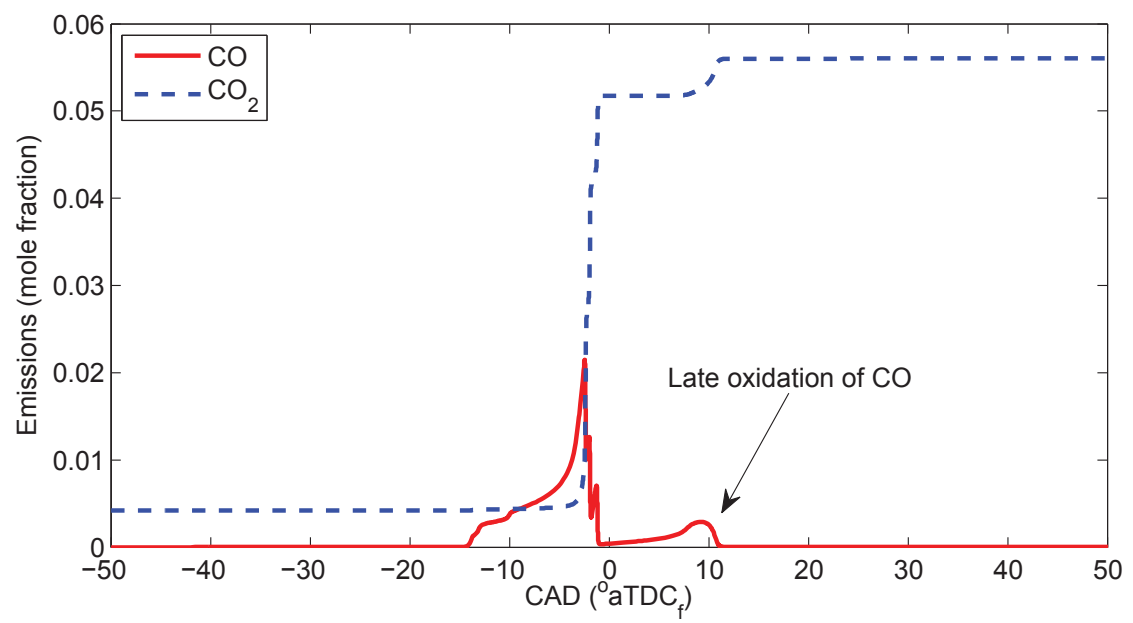

Figure 3.20: $\mathrm{CO}$ and $\mathrm{CO}_{2}$ variation versus crank angle for $\mathrm{IVC}=$ $-140^{\circ}$ aTDC $\mathrm{f}$ showing late oxidation of $\mathrm{CO}$ to $\mathrm{CO}_{2}$, leading to low $\mathrm{CO}$ concentration for this operating point

A conclusion thus can be drawn that, engine-out $\mathrm{CO}$ emissions are mainly dependant on the oxidation of $\mathrm{CO}$ to $\mathrm{CO}_{2}$ which is a function of the peak temperature in "each" zone. Thus averaged $\mathrm{T}_{\max }$ for whole cylinder is not a sufficient criteria to determine $\mathrm{CO}$ trend as Figure 3.17 shows that $\mathrm{CO}$ increases and then decreases, while $\mathrm{T}_{\max }$ continuously drops as IVC is advanced. Peak temperature in zone \#7 is found to have an important role in 
formation of $\mathrm{CO}$ emissions.

$\mathrm{uHC}$ emissions are primarily caused due to incomplete combustion and quenching effects due to low wall temperatures. The trend for uHC emissions observed is found to be reducing as the peak temperature reduces (Figure 3.18). Further observation is that uHC emissions increase with an increase in BD (Figure 3.12). This can be because mixtures with slow burning rate (i.e., longer BD) have more time for heat loss during the expansion stroke and are hence favourable towards the formation of uHC emissions. The uHC emission observed in this study is a mixture of C-7 molecules from unburnt fuel in zones \#1 to 6 and C-1 and other low carbon molecules from partial burning of fuel in zones \#7 to 10.

\subsubsection{Effect of EVO variations on HCCI combustion}

Similar to the IVC variations carried out in Section 3.2.2.1, the exhaust valve timings are also varied to assess their impact on HCCI combustion. The graphical representation of lift versus CAD for the exhaust valve was previously shown in Figure 3.9. For the baseline condition, the exhaust valve opens at $110^{\circ} a T D C_{f}$ and is advanced upto $95^{\circ} a T D C_{f}$ and is retarded until $125^{\circ} a T D C_{f}$ in steps of $5 \mathrm{CAD}$. Combustion and performance metrics from the resulting EVO sweeps are analysed and presented in this section.

Figures 3.21 and 3.22 show the variations of in-cylinder gas pressure and temperature 


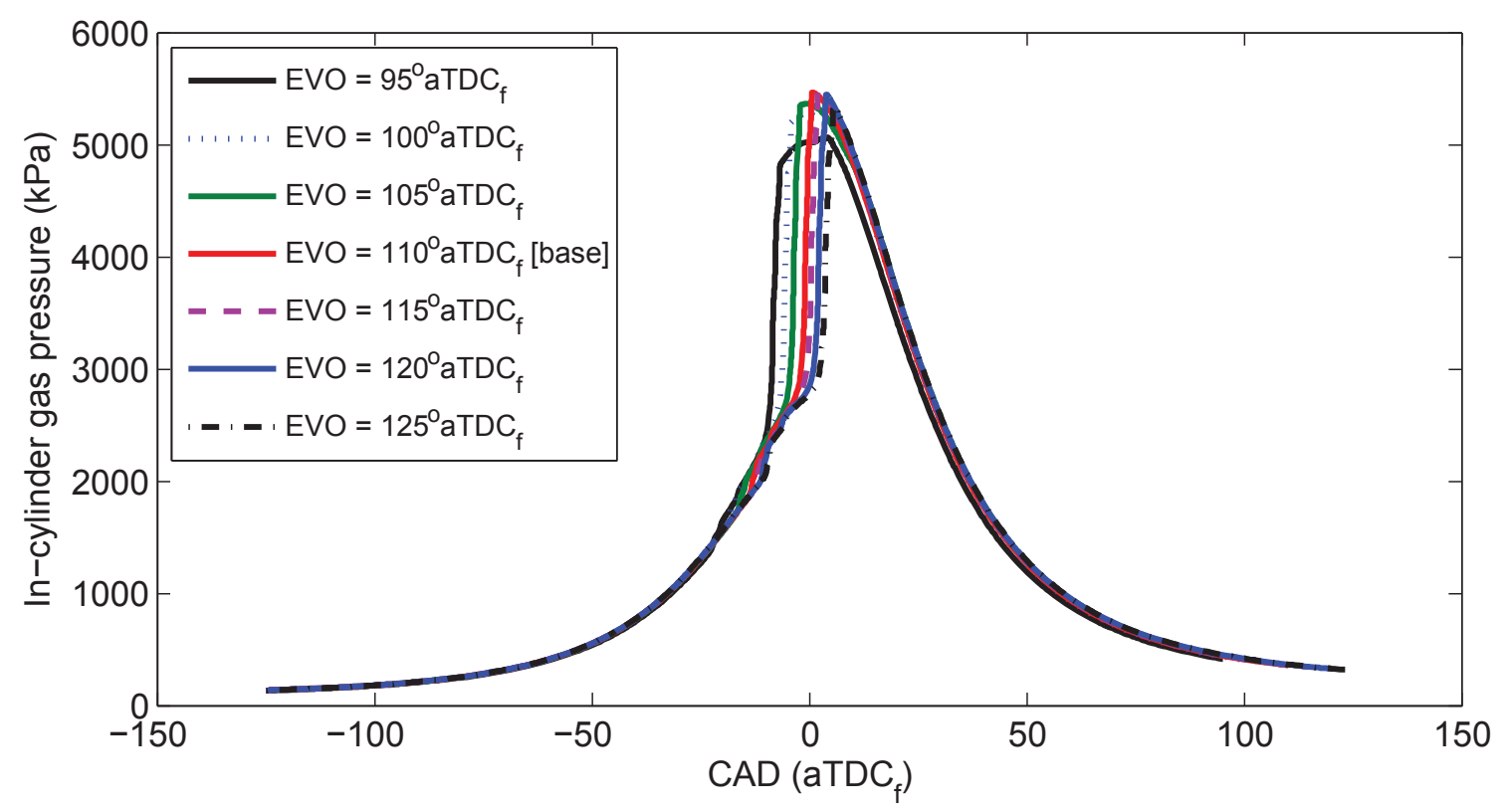

Figure 3.21: Variation of in-cylinder gas pressure vs. CAD as a function of exhaust valve timing

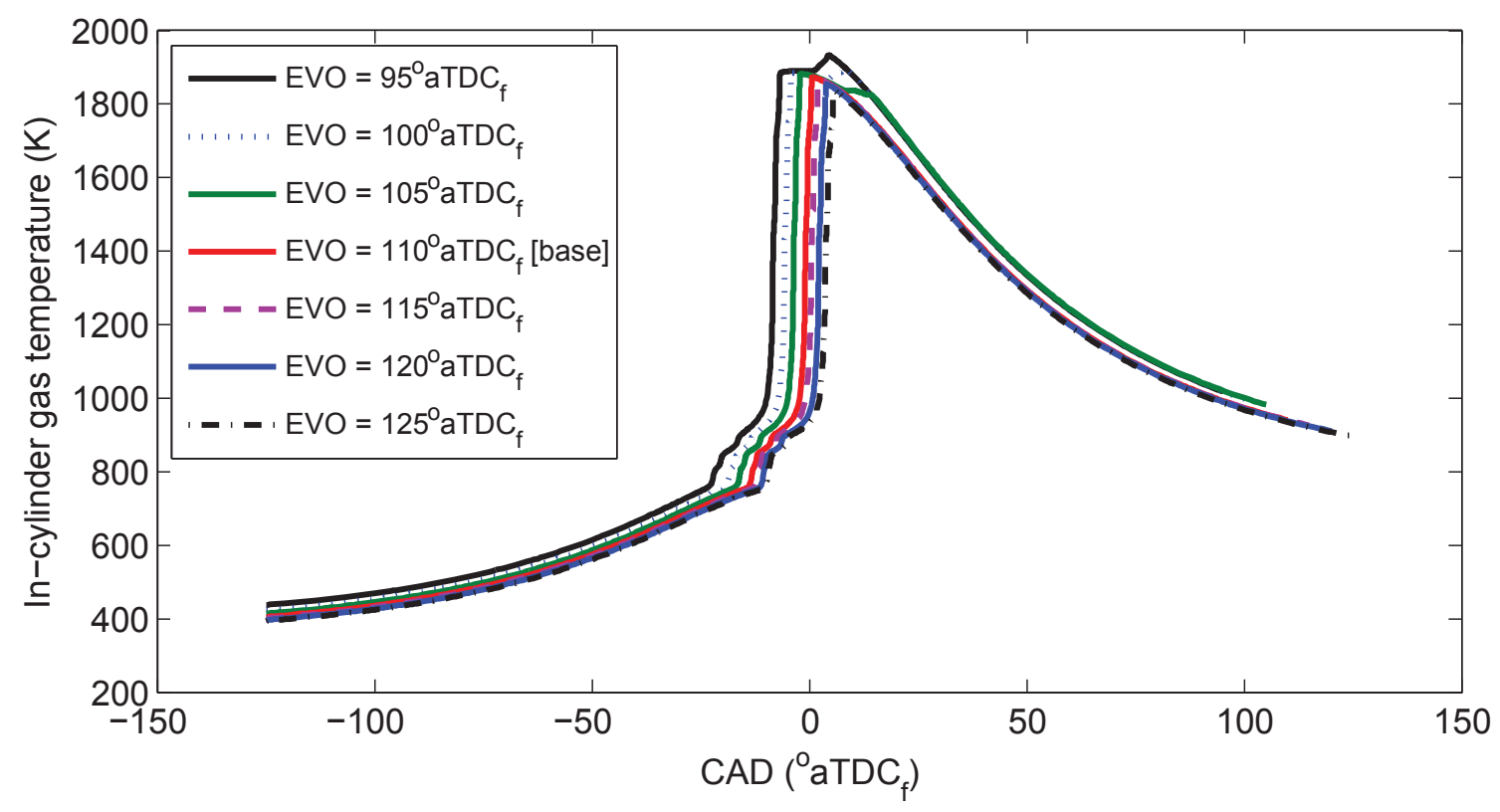

Figure 3.22: Variation of in-cylinder gas temperature vs. CAD as a function of exhaust valve timing 
when EVO timing is varied. It can be seen that as the EVO timing is advanced from $125^{\circ}$ to $95^{\circ} a T D C_{f}, \mathrm{P}_{\max }$ rises upto the baseline case and then reduces till the most advanced case. In-addition, the peak in-cylinder gas temperature $\left(\mathrm{T}_{\max }\right)$ increases with advancing EVO. Another observation in Figure 3.22 is that there are two peaks in the gas temperature for the three most advanced $\mathrm{EVO}$ (i.e., $\mathrm{EVO}=95^{\circ}, 100^{\circ}, 105^{\circ} \mathrm{aTDC}_{\mathrm{f}}$ ). This means that after the main combustion event some of the zones in the boundary layer are combusting, resulting in the second peak in-cylinder gas temperature. As previously discussed in Section 3.2.2.1, fuel burning in zone \#7 is found to cause this phenomenon.

(a)

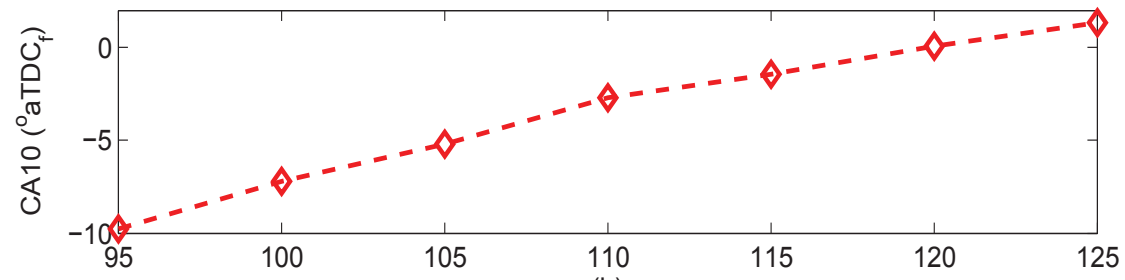

(b)

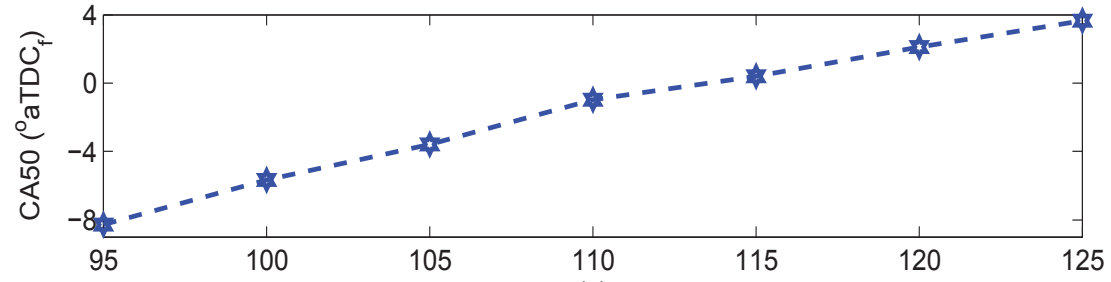

(c)

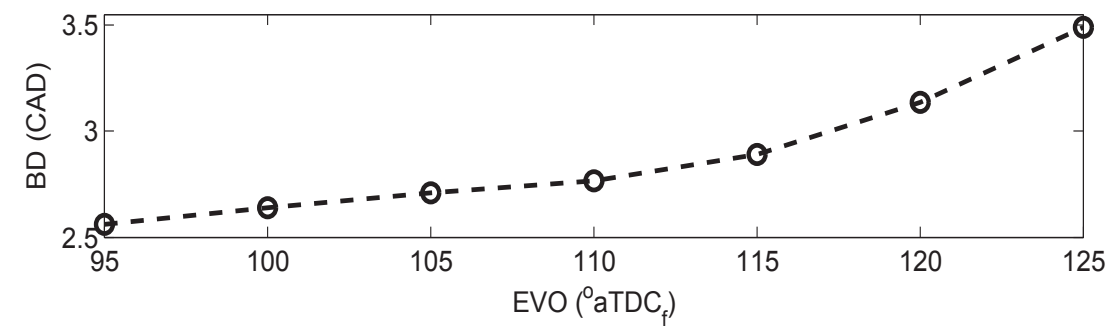

Figure 3.23: Effect of phasing exhaust valve timing on combustion metrics including CA10, CA50 and BD

Figures 3.23 and 3.24, show the trend of combustion metrics for changes in EVO timing, 
(a)

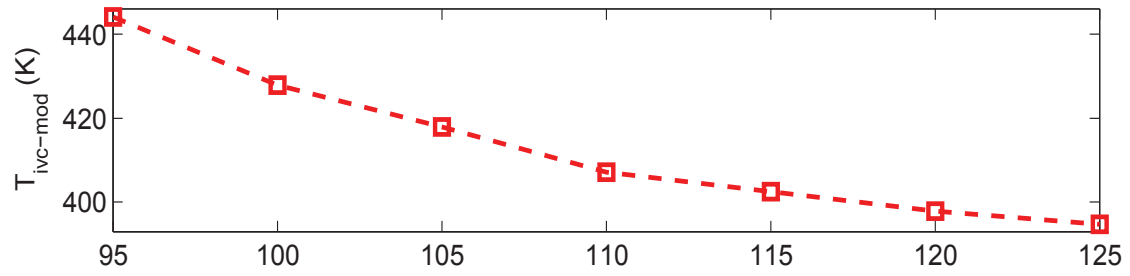

(b)

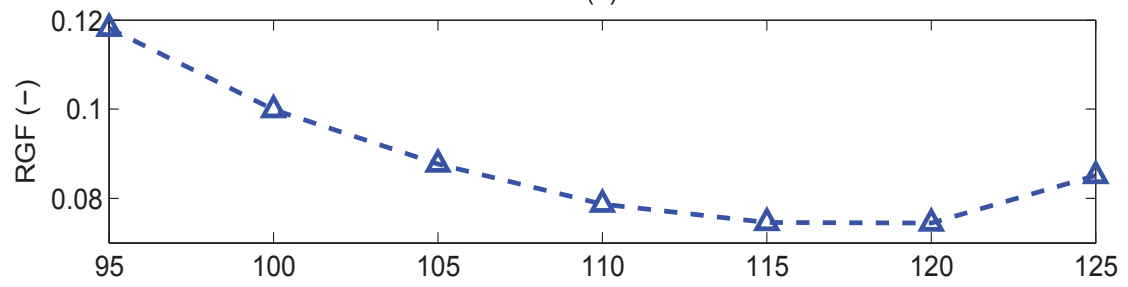

(c)

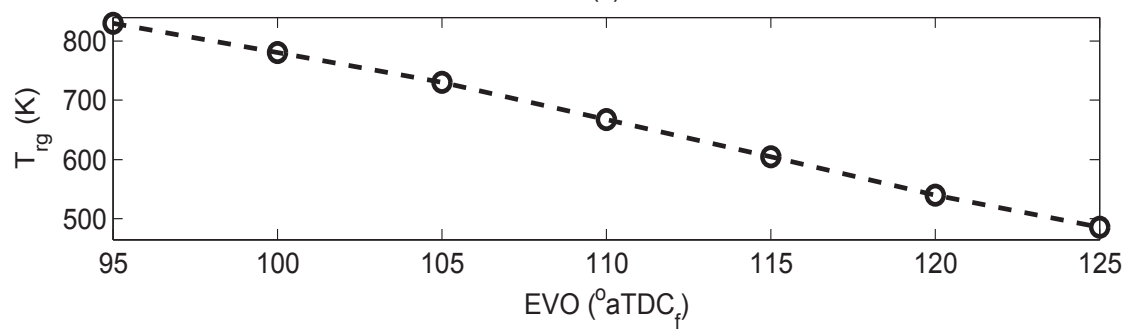

Figure 3.24: Effect of phasing EVO timing on (a): gas temperature at IVC, (b): RGF quantity, (c): temperature of trapped residual gases.

while Figures 3.25 and 3.26 show the trend of performance metrics for HCCI combustion.

For the case of advancing EVO timing from $125^{\circ}$ to $95^{\circ}$ auto-ignition steadily advances as seen by the changes in CA10 (Figure 3.23). CA50 also advances along with a decrease in the burn duration when the EVO occurs early. This can be explained by looking at Figure 3.24 which shows the $\mathrm{T}_{\mathrm{ivc}-\bmod }$ along with the RGF and the corresponding temperature of residual gases $\left(\mathrm{T}_{\mathrm{rg}}\right)$.

Residual gas amount is an important metric in controlling HCCI combustion phasing primarily by adjusting $\mathrm{T}_{\mathrm{ivc}-\bmod }$ in HCCI combustion. In addition, residual gases also contribute to the required dilution in making the combustion chamber environment 
(a)

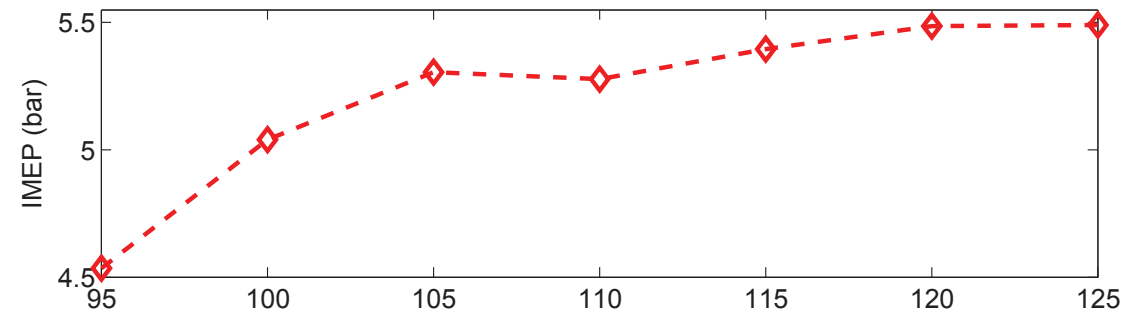

(b)

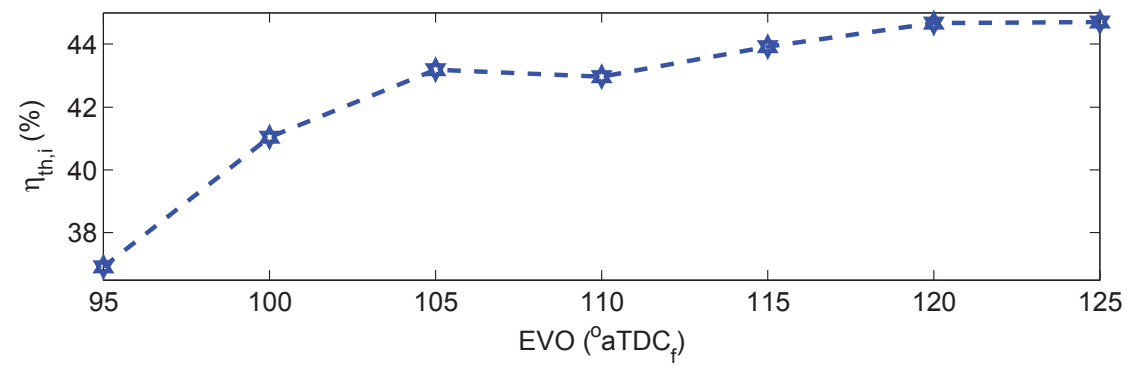

Figure 3.25: Variation of IMEP and indicated thermal efficiency $\left(\eta_{\mathrm{th}, \mathrm{i}}\right)$ as a function of exhaust valve phasing

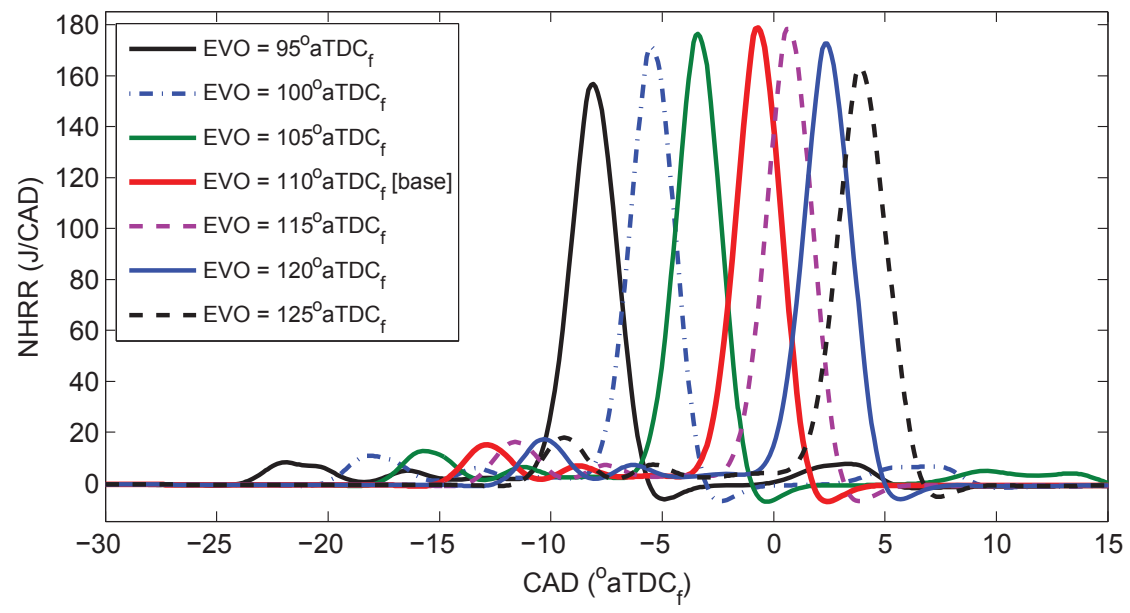

Figure 3.26: Net heat release rate (NHRR) versus CAD as a function of exhaust valve phasing

excessively fuel lean. Dilution by residual gases also helps in achieving stoichiometric HCCI combustion [60]. One primary aim of changing exhaust valve timing is to modulate the RGF quantity. As seen in Figure 3.24, the RGF amount generally increases when the EVO is advanced. Variation in RGF (Figure 3.24) provides about $50 \mathrm{~K}$ control over 
$\mathrm{T}_{\mathrm{ivc}-\mathrm{mod}}$ and can be used to control combustion phasing in the HCCI engine. The case with $\mathrm{EVO}=110^{\circ} a T D C_{f}$ corresponds to zero Negative Valve Overlap (NVO). NVO is an important factor in determining RGF quantity. It is expected that a longer NVO can trap the maximum amount of residual gases and at a higher temperature as compared to the re-breathing strategy used in HCCI engines [60].

The temperature at IVC $\left(\mathrm{T}_{\mathrm{ivc}-\bmod }\right)$ for the next engine cycle is dependant on the RGF temperature from the previous engine cycle. As more energy is being supplied at the start of the cycle with higher $\mathrm{T}_{\mathrm{ivc}-\bmod }$, the combustion occurs earlier and the burn duration is reduced (Figure 3.23). The presence of a higher amount of residual gases increases the mixture specific heat since composing diluents have higher specific heats than the air-fuel gas mixture. Hot internal EGR (i.e., residual gases) causes the mixture reactivity to decrease due to the presence of exhaust diluents, while high temperature of residual gases causes the mixture reactivity to increase, causing the combustion phasing to advance. Hence changing RGF causes an overall counteracting effect where temperature effects are generally prominent [8]. This temperature dominance is confirmed from Figure 3.22 where higher peak temperatures are observed for the cases with most advanced EVO which have high amounts of hot residual gases. Thus, increasing RGF causes the combustion phasing to advance.

For the case with $\mathrm{EVO}=125^{\circ} \mathrm{TDC}_{\mathrm{f}}$, RGF increases but the temperature of residual gases is lower than its previous case of $\mathrm{EVO}=120^{\circ} \mathrm{aTDC}_{\mathrm{f}}$. This causes the rate of $\mathrm{T}_{\mathrm{ivc}-\mathrm{mod}}$ drop 
(i.e., $\frac{\Delta \mathrm{T}_{\mathrm{ivc}-\mathrm{mod}}}{\Delta E V O}$ ) to reduce as seen in Figure 3.24. BD is affected by the presence of lower temperature $\left(\mathrm{T}_{\mathrm{rg}}\right)$ residual gases causing the BD to increase as EVO is delayed. Thus, as the EVO timing is delayed, CA50 retards and occurs at or after $\mathrm{TDC}_{\mathrm{f}}$ causing the IMEP and $\eta_{\mathrm{th}, \mathrm{i}}$ to increase. This is because useful energy released from combustion is during the piston's travel from $\mathrm{TDC}_{\mathrm{f}}$ to $\mathrm{BDC}$. For the cases where CA50 occurs before $\mathrm{TDC}_{\mathrm{f}}$, energy released due to $50 \%$ of fuel burnt is during the piston's upward motion from BDC and may cause negative work. This is confirmed from Figure 3.25 where IMEP and $\eta_{\text {th,i }}$ are decreasing as CA50 is advanced.

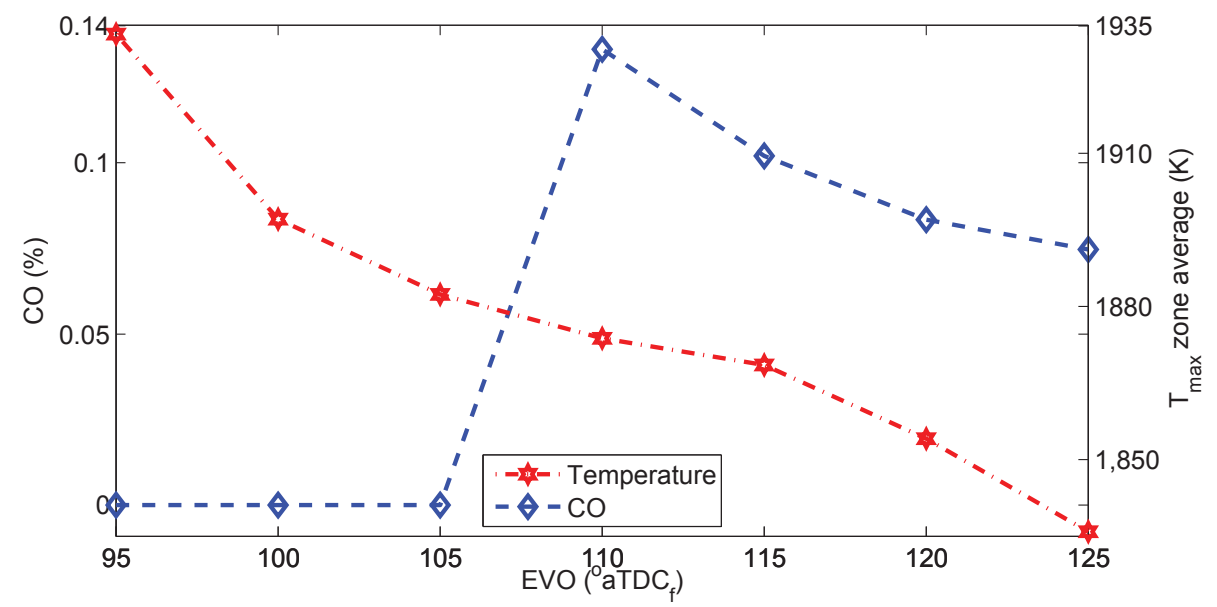

Figure 3.27: $\mathrm{CO}$ emissions and maximum zone averaged gas temperature as a function of exhaust valve phasing

Figures 3.27 and 3.28 show the trend of $\mathrm{CO}$ and $\mathrm{uHC}$ concentrations for variations in EVO timing. A similar explanation as that of Figure 3.17 can be given for the $\mathrm{CO}$ trend seen in Figure 3.27. uHC concentrations are largely temperature dependant and increase as the peak temperature reduces (Figure 3.28). The hot diluents can increase the local 


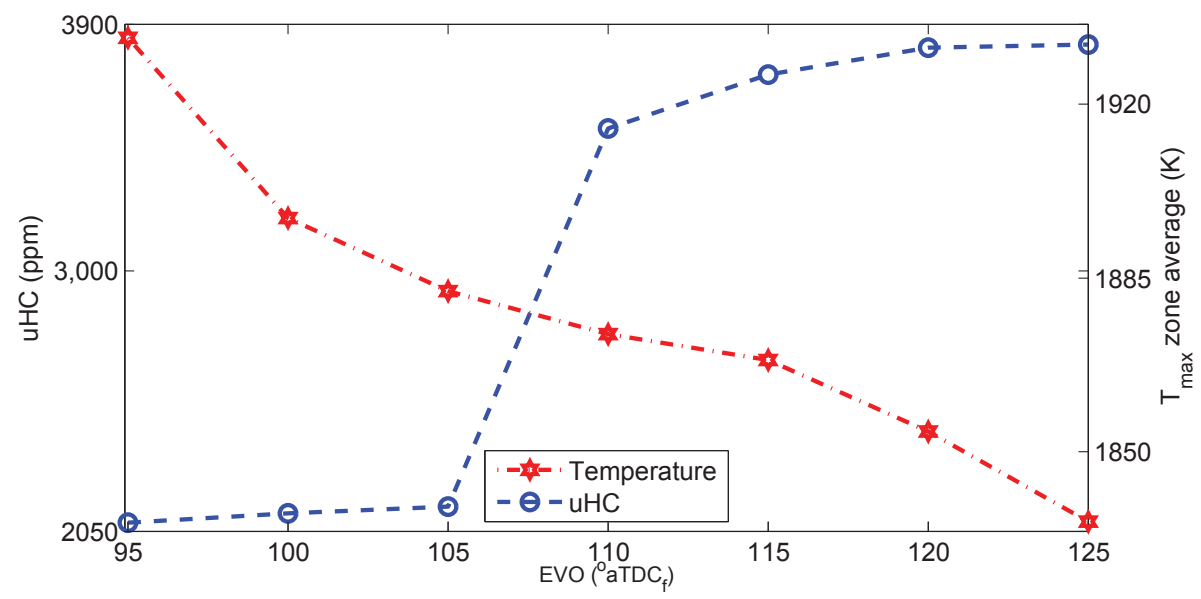

Figure 3.28: uHC emissions and maximum zone averaged gas temperature as a function of exhaust valve phasing

temperatures near the walls to burn more fuel. For $\mathrm{EVO}=110^{\circ} \mathrm{aTDC}$, a low $\mathrm{T}_{\mathrm{ivc}-\bmod }$ (Figure 3.24) and low gas temperature for zone \#1 to 4 can lead to high uHC emissions for cases with late EVO timing as seen in Figure 3.28.

\subsubsection{Virtual Engine Test Bed for Controller Design}

The SMRH is used as a virtual engine to create an engine efficiency map as a function of valve timing for the Ricardo HCCI engine. The simulation results can be used to design effective VVT strategies for HCCI combustion control. The schematic of the "Virtual Engine Test Bed" is shown in Figure 3.29.

HCCI engine performance is gauged in terms of a new index defined as Fuel Efficiency and 
Emission (FEE) index:

$$
F E E=\frac{R E I+\frac{\eta_{t h, i}}{\eta_{t h, i-\max }}}{2}
$$

where REI is a Raw Emission Index (REI) consisting of CO and uHC emissions normalized by their maximum values and then averaged [61] (note that $\mathrm{NO}_{\mathrm{x}}$ is ultra low in $\mathrm{HCCI}$ operating conditions). In Equation (3.18), both parameters of $\eta_{\mathrm{th}, \mathrm{i}}$ and REI are normalized with their respective maximum values, and a higher value of FEE index signifies better engine performance. $\eta_{\text {th,i }}$ is used to assess the combustion/engine performance in terms of fuel economy, while emissions are evaluated using the REI.

Two cases are studied to illustrate the FEE index. The first case includes constant load engine operating conditions where, equivalence ratio (hence fuel quantity) is varied to achieve constant IMEP $=5.5 \pm 0.2$ bar. The second case includes constant fuel engine operating conditions. Thermal efficiency and REI contour plots for constant load case study are shown in Figures 3.30 and 3.31. Contour plots are created by forming matrices of IVC and EVO timings.

Figures 3.30 and 3.31 show the contour plots of $\eta_{\text {th,i }}$ and REI as a function of IVC and EVO timings. It is clear that, $\eta_{\text {th,i }}$ is high for the regions with low $\mathrm{NVO}$ or those regions with PVO. This region is comprised of IVC timings of $-135^{\circ}$ and $-140^{\circ} \mathrm{aTDC}_{\mathrm{f}}$ and $\mathrm{EVO}$ timings from $110^{\circ}$ to $125^{\circ}$ aTDC . On observing the CA50 plot in Figure 3.32, the regions 


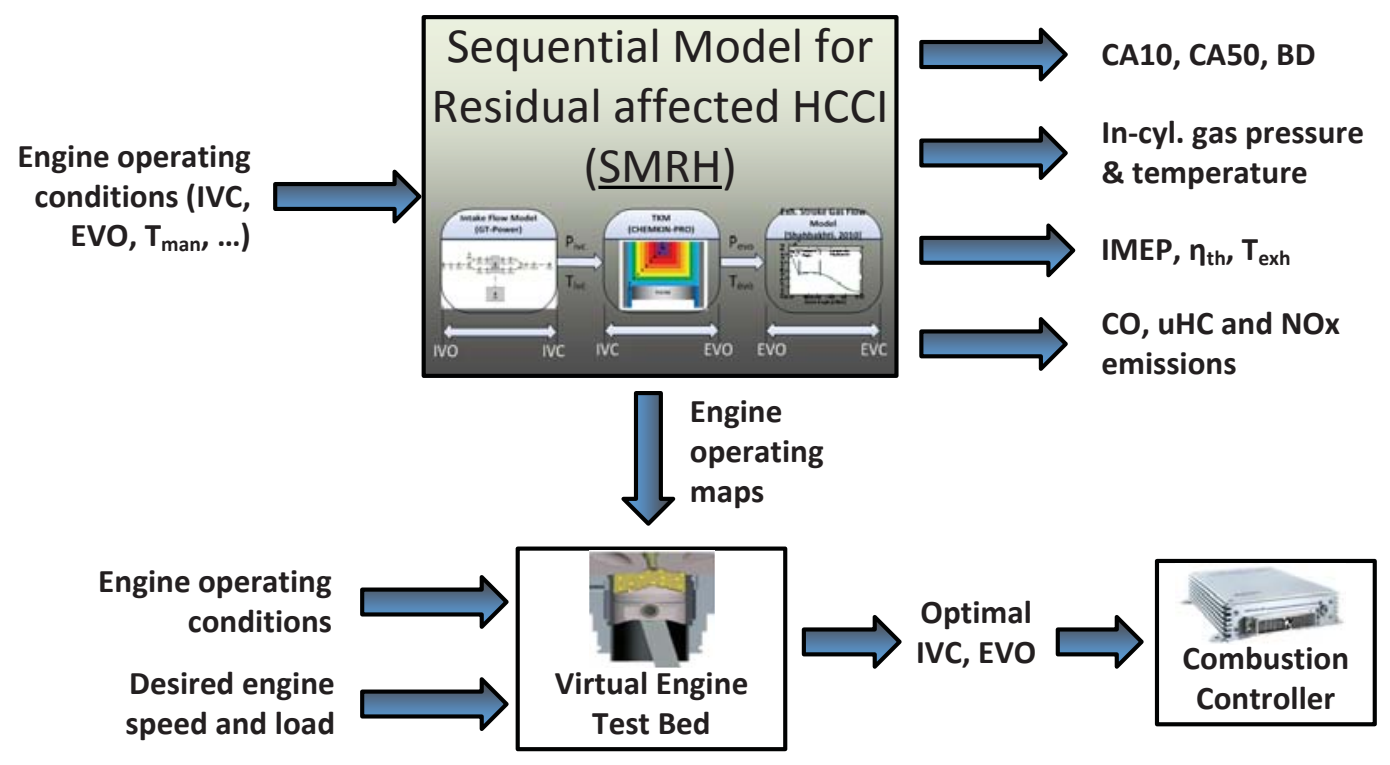

Figure 3.29: Schematic of SMRH based virtual engine test bed for HCCI combustion controller design

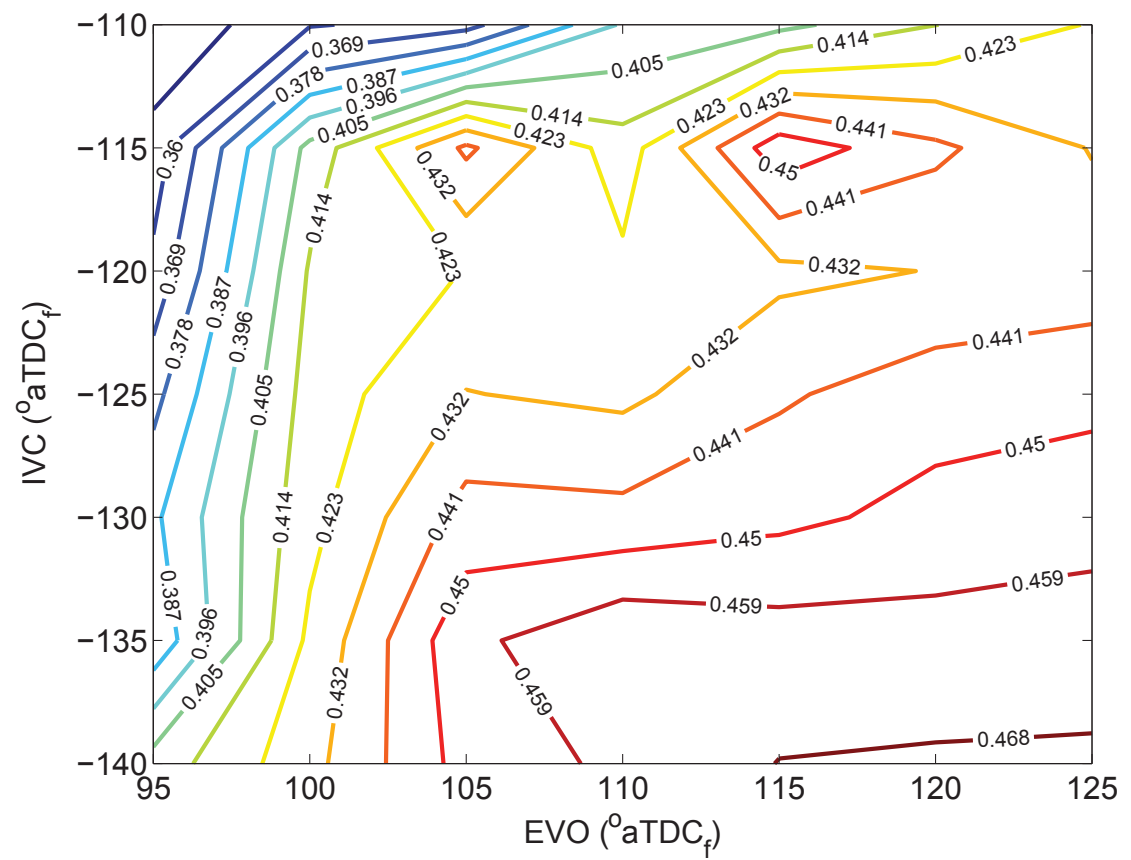

Figure 3.30: Contour plot of engine indicated thermal efficiency $\left(\eta_{\mathrm{th}, \mathrm{i}}\right)$ as a function of valve timing for the constant load case study. (IMEP $=5.5 \pm 0.2$ bar) 


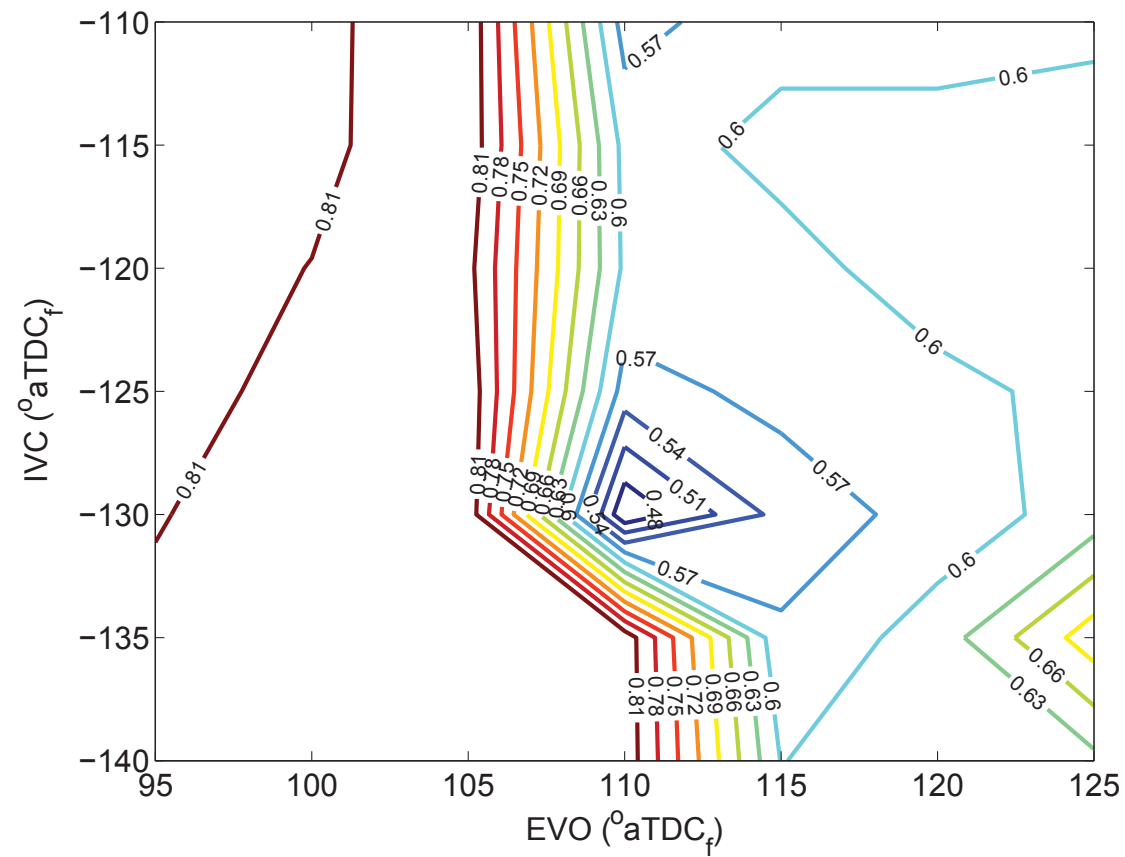

Figure 3.31: Raw emission index (REI) contour plot as a function of valve timings for the constant load case study. (IMEP $=5.5 \pm 0.2$ bar)

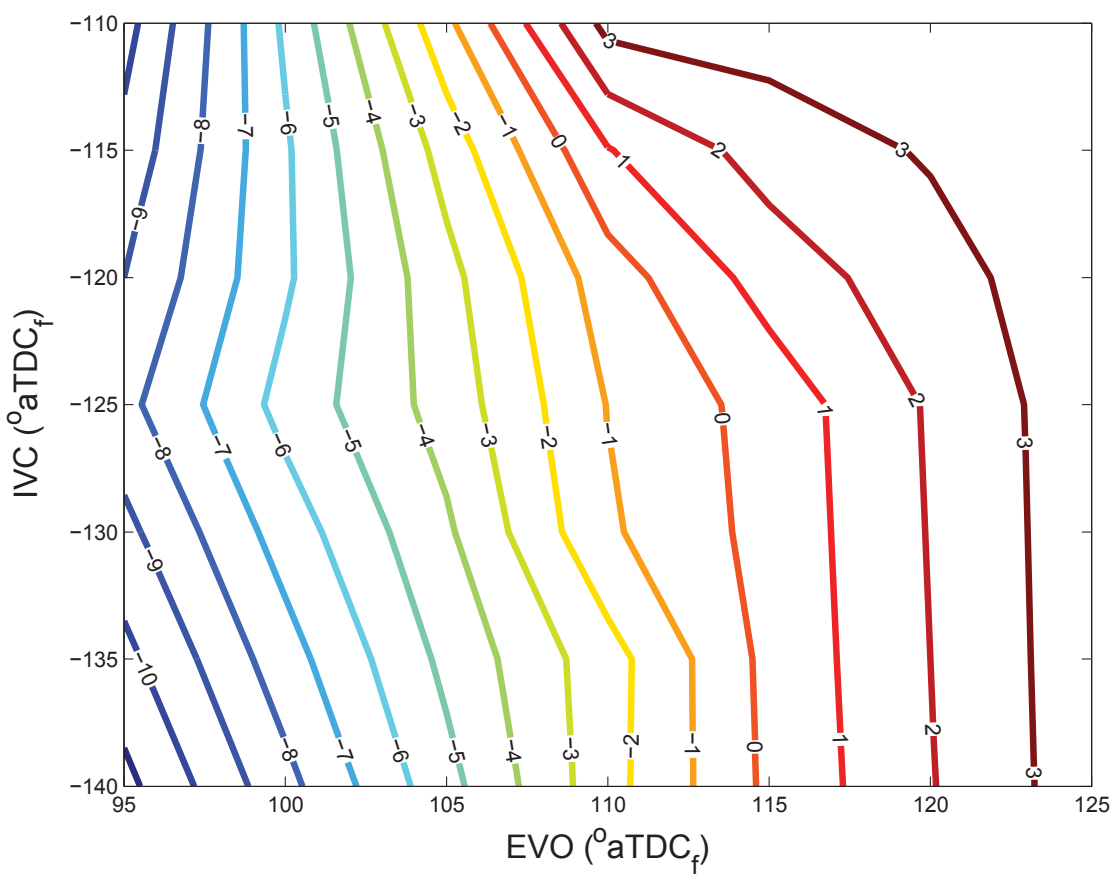

Figure 3.32: CA50 contour plot as a function of valve timings for the

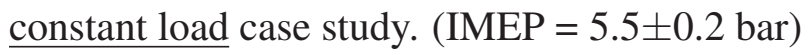




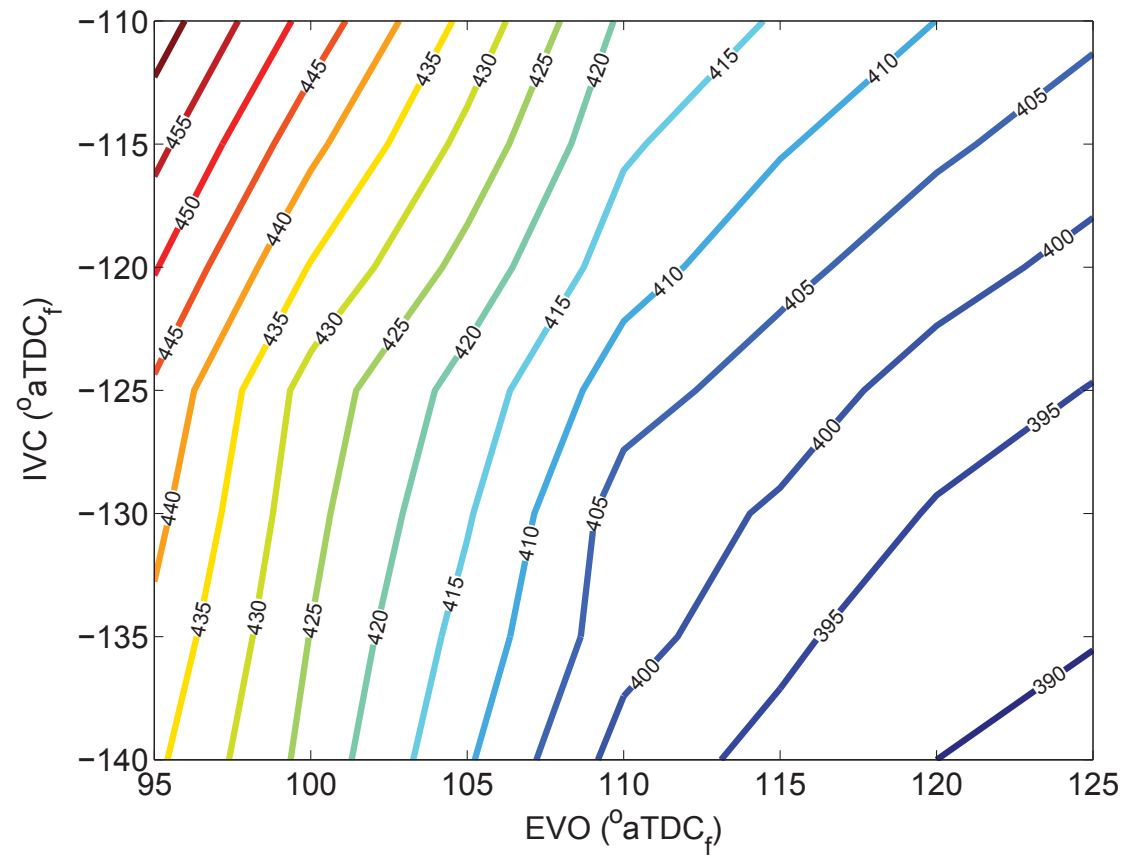

Figure 3.33: $\mathrm{T}_{\mathrm{ivc}-\bmod }$ contour plot as a function of valve timings for the

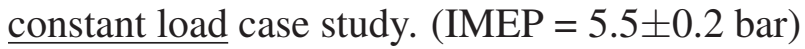

where CA50 is slightly after $\mathrm{TDC}_{\mathrm{f}}$ are the regions showing higher thermal efficiencies. This observation is in agreement with experimental results in [62] for the Ricardo HCCI engine. The effect of NVO is to advance combustion phasing while PVO retards combustion phasing. On the other hand, the REI contour plot (Figure 3.31) indicates that emissions are low for the regions where the thermal efficiency is high. $\mathrm{CO}$ and $\mathrm{uHC}$ emissions are dependant on in-cylinder gas temperatures as previously discussed in Section 3.2.2.1. A higher $\mathrm{T}_{\mathrm{ivc}-\text { mod }}$ would generally help in reducing $\mathrm{uHC}$ and $\mathrm{CO}$ emissions. This can be seen from Figure 3.33 where the regions having higher $\mathrm{T}_{\mathrm{ivc}-\bmod }$ show a higher value of REI which signifies lower emissions. Figures 3.30 and 3.31 show a tradeoff between fuel economy and emissions. The results in Figures 3.30 and 3.31 show SMRH is of utility to determine optimal IVC and EVO timings to achieve the desirable trade-off depending on 
which fuel economy target and minimum emissions levels are required for engine controller calibration.

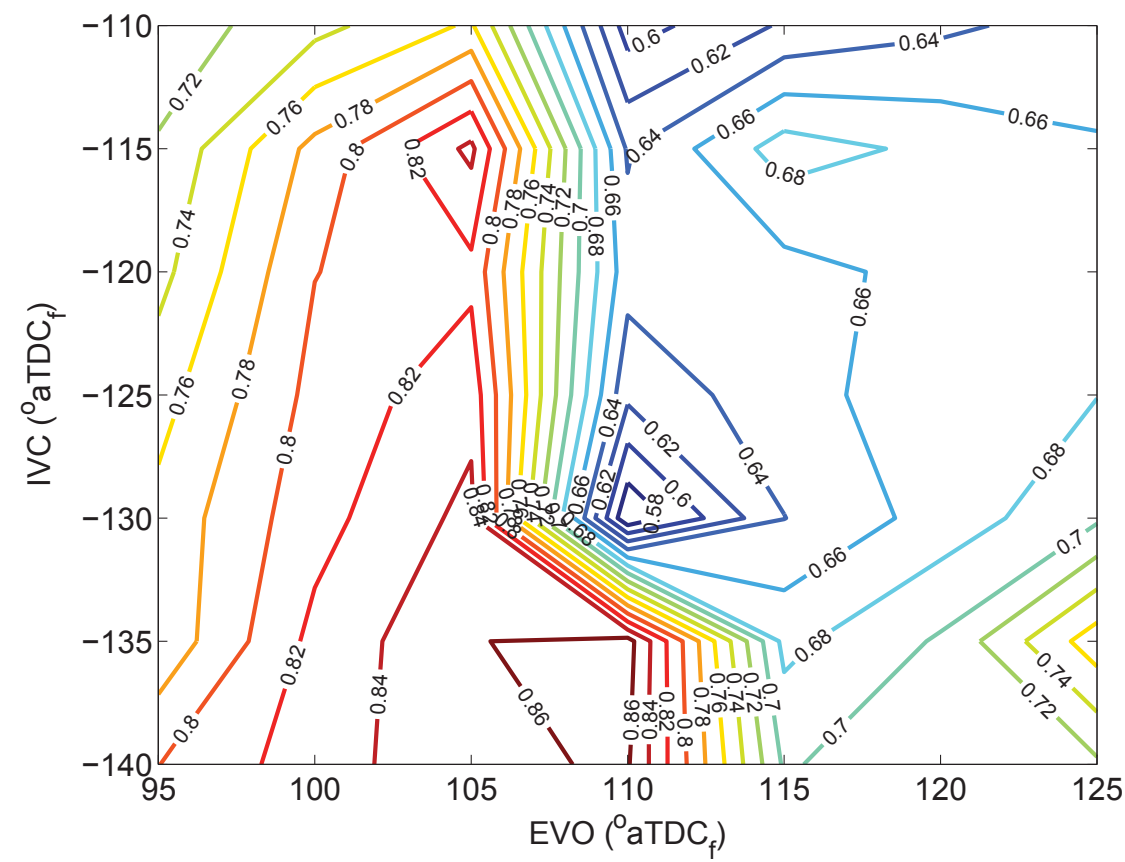

Figure 3.34: Contour plot of fuel efficiency and emissions (FEE) index for the constant load case study. (IMEP $=5.5 \pm 0.2$ bar)

For the operating regions studied, the engine must operate such that the IVC is most advanced while the EVO can be anywhere from the baseline to the most advanced condition. These valve timings correspond to nearly zero NVO. An advanced IVC in this case means that compression of the in-cylinder mixture will begin earlier and adjusting the EVO timing ensures optimum temperature at IVC due to residual gas effects.

In a particular case where a high thermal efficiency is the desired output, a high PVO can be chosen by disregarding emission values and vice versa. For increasing PVO, IVC timing 


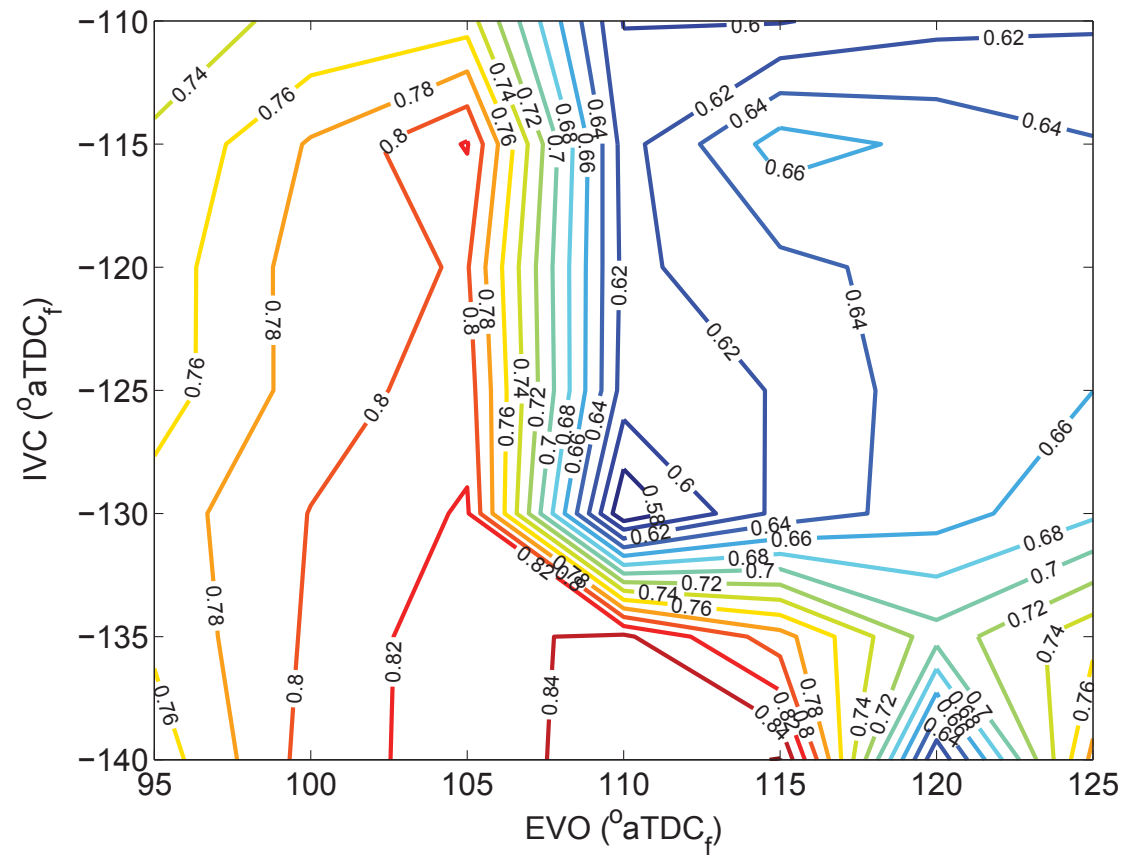

Figure 3.35: Contour plot of fuel efficiency and emissions (FEE) index for the constant fuel case study. $\left(\dot{m}_{\mathrm{f}}=0.3752 \mathrm{~kg} / \mathrm{hr}\right)$

has to be advanced along with retarding EVO timing. Advancing IVC would also advance IVO and the intake valve would begin to open around the intake TDC which is where the chance of piston to valve contact is the maximum. To avoid this contact, exact knowledge of the valve profile along with the locus of piston movement is necessary to analyze the room available for phasing.

For a particular case which requires the engine operation to have low emissions, EVO timing needs to be advanced from the baseline condition, while the IVC timings have a high flexibility for phasing. In this case, the possibility of piston to valve contact for an advanced IVC still exists. Thus, a high NVO is the best possible operating condition for the Ricardo HCCI engine. This engine has a fairly low geometric CR (10:1) and a high 
NVO would aid in achieving auto-ignition due to the higher temperature at IVC. Thus, referring to Figure 3.35 , the region comprising IVC timing of $-115^{\circ}$ to $-130^{\circ} \mathrm{aTDC}_{\mathrm{f}}$ and EVO timings from $96^{\circ}$ to $105^{\circ}$ aTDC f are the best feasible valve timings for operation of this HCCI engine, to obtain low fuel consumption and low emission levels.

The FEE plots for the constant fuel and constant load case studies are similar in nature (Figures 3.34 and 3.35). The regions where a high FEE index is observed is the same for both case studies. Slightly higher values of FEE index are observed for the constant load case study where fuel quantity is adjusted to get a fixed engine load. Higher FEE value in constant load case indicates the importance of using a combination of VVT and fuel quantity (e.g., $\phi$ ) to achieve optimum operation (high FEE) of the HCCI engine. 


\section{Chapter 4}

\section{Summary and Conclusion}

Two areas are focussed upon, which are considered to be the core of this thesis. First is the experimental setup of an HCCI engine for the test cell at Michigan Tech with a particular contribution to the setup of intake air handling (heating and boost) and valve timings along with compression ratio measurements. The second area is the SMRH modeling platform for simulating residual affected HCCI combustion and engine performance as a function of valve timing. 


\subsection{Summary of thesis contributions}

* This thesis has the contribution in further developing the HCCI engine test setup at Michigan Technological University. Contributions were made in the areas of air heater setup and its control. This will help to operate the engine in HCCI mode and also obtain large HCCI operating range. Valve profile along with piston to valve clearance were measured. New piston were procured which have a compression ratio of 12.1:1. In addition, a boosting station was designed and tested at different supercharger speeds.

* A sequential model called as SMRH was developed and validated against experimental data from a single cylinder HCCI engine [4]. The SMRH was validated for in-cylinder gas pressure, combustion phasing (CA10, CA50), performance metrics (IMEP and $\eta_{\mathrm{th}, \mathrm{i}}$ ) and $\mathrm{CO}$ emission. Effects of VVT were studied for both intake and exhaust valve variations. The SMRH was then used to find engine maps for a newly defined Fuel Efficiency and Emissions (FEE) index which shows the overall engine operation. Using the FEE index, optimum valve timings for engine operation were determined.

* SMRH is the first model in HCCI literature to characterize VVT effects on residual affected HCCI based on a simplified multi zone combustion model and intake and exhaust flow models. SMRH is of utility for HCCI control community to develop advanced VVT strategies to control HCCI engines in optimum operating regions. 


\subsection{Future Work}

* For the HCCI experimental setup, a mode switching control strategy needs to be developed for starting the engine in SI mode using the dSPACE controller, and switch back and forth to HCCI mode when necessary.

* The new pistons can be installed and checked for piston to valve contact to ascertain the phasing ability. The engine can be run in HCCI mode using the air heater to heat the intake air to a desired temperature. The boosting station can be used to provide the desired amount of boost for achieving HCCI mode at higher engine loads.

* Maps of the FEE index from the SMRH can be further analyzed to develop a systematic methodology to minimize calibration of HCCI engines.

* Combustion controller design can be carried out using the SMRH as the plant model. Such a controller would have the advantage of being more robust by incorporation of physical relations for engine variables and mitigating physical disturbances by using proper engine control variables. 



\section{References}

[1] EATON. M62 Performance Map. http://www.eaton.com/ecm/groups/public/ @pub/@eaton/@per/documents/content/ct_128484.gif, accessed September 30, 2014.

[2] Omega Inc. Process Air \& Duct Heaters. http://www. omega.com/Heaters/pdf/ AHF_HEATER.pdf, accessed September 30, 2014.

[3] Ray Franco. E-motor insulation classes. http://www.electrical-forensics. com/Motors/MotorClasses .html, accessed September 30, 2014.

[4] M. Shahbakhti and C. Koch. "Characterizing the Cyclic Variability of Ignition Timing in A Homogeneous Charge Compression Ignition Engine Fuelled with n-heptane/iso-octane Blend Fuels". International Journal of Engine Research, 9(5):361-397, 2008.

[5] S. Aceves, D. Flowers, C. Westbrook, J. Smith, W. Pitz, R. Dibble, M. Christensen, and B. Johansson. "A Multi-Zone Model for Prediction of HCCI Combustion and 
Emissions". 2000. SAE Technical Paper 2000-01-0327.

[6] John B Heywood. “Internal combustion engine fundamentals”. Mcgraw-hill New York, 1988.

[7] H. Anders, M. Christensen, B. Johansson, A. Franke, M. Richter, and M. Aldén. “A Study of The Homogeneous Charge Compression Ignition Combustion Process by Chemiluminescence Imaging”. 1999. SAE Technical Paper 1999-01-3680.

[8] S. Saxena and I. Bedoya. "Fundamental Phenomena Affecting Low Temperature Combustion and HCCI Engines, High Load Limits and Strategies for Extending These Limits". Progress in Energy and Combustion Science, 39(5):457-488, 2013.

[9] L. Koopmans, R. Ogink, and I. Denbratt. "Direct Gasoline Injection in The Negative Valve Overlap of A Homogeneous Charge Compression Ignition Engine”. 2003. SAE Technical Paper 2003-01-1854.

[10] A. Fuerhapter, W. Piock, and G. Fraidl. "CSI-Controlled Auto Ignition-The Best Solution for The Fuel Consumption-Versus Emission Trade-Off?”. 2003. SAE Technical Paper 2003-01-0754.

[11] P. Caton, H. Song, N. Kaahaaina, and C. Edwards. "Residual-Effected Homogeneous Charge Compression Ignition with Delayed Intake-Valve Closing at Elevated Compression Ratio". International journal of engine research, 6(4):399-419, 2005. 
[12] M. Christensen, B. Johansson, and P. Einewall. "Homogeneous Charge Compression Ignition (HCCI) Using Isooctane, Ethanol and Natural Gas-A Comparison with Spark Ignition Operation”. 1997. SAE Technical paper 972874.

[13] J. Yang, T. Culp, and T. Kenney. "Development of A Gasoline Engine System Using HCCI Technology-The Concept and The Test Results”. 2002. SAE Technical Paper 2002-01-2832.

[14] J Hyvönen, G Haraldsson, and B Johansson. Supercharging HCCI to Extend the Operating Range in a Multi-Cylinder VCR-HCCI Engine. 2003. SAE Technical Paper 2003-01-3214.

[15] R. Stanglmaier, T. Ryan, and J. Souder. "HCCI Operation of A Dual-Fuel Natural Gas Engine for Improved Fuel Efficiency and Ultra-Low NOx Emissions at Low to Moderate Engine Loads”. 2001. SAE Technical Paper 2001-01-1897.

[16] J. Tuttle. “Controlling Engine Load by Means of Late Intake-Valve Closing”. 1980. SAE Technical Paper 800794.

[17] J. Ma, X. Lü, L. Ji, and Z. Huang. “An Experimental Study of HCCI-DI Combustion and Emissions in A Diesel Engine with Dual Fuel". International Journal of Thermal Sciences, 47(9):1235-1242, 2008.

[18] H. Zhang, J. Chiu, and J. Bartel. "Late Intake Valve Closing with Throttle Control at Light Loads for a Lean-Burn Natural Gas Engine”. 1999. SAE Technical Paper 1999-01-3485. 
[19] M. Yao, Z. Zheng, and H. Liu. "Progress and Recent Trends in Homogeneous Charge Compression Ignition (HCCI) Engines". Progress in Energy and Combustion Science, 35(5):398-437, 2009.

[20] J. Zhang, X. Qiao, Z. Wang, B. Guan, and Z. Huang. "Experimental Investigation of low-temperature combustion (LTC) in an engine fueled with dimethyl ether (DME)". Energy \& Fuels, 23(1):170-174, 2008.

[21] E. Silke, H. Curran, and J. Simmie. "The influence of fuel structure on combustion as demonstrated by the isomers of heptane: a rapid compression machine study". Proceedings of the Combustion Institute, 30(2):2639-2647, 2005.

[22] C. Westbrook. "Chemical kinetics of hydrocarbon ignition in practical combustion systems". Proceedings of the Combustion Institute, 28(2):1563-1577, 2000.

[23] P. Dagaut, M. Reuillon, and M. Cathonnet. "Experimental Study of the Oxidation of n-heptane in A Jet Stirred Reactor from Low to High Temperature and Pressures Up to 40 atm". Combustion and Flame, 101(1):132-140, 1995.

[24] H. Curran, W. Pitz, C. Westbrook, G. Callahan, and F. Dryer. "Oxidation of automotive primary reference fuels at elevated pressures". International Symposium on Combustion, 1998.

[25] L. Cancino, M. Fikri, A. Oliveira, and C. Schulz. "Autoignition of gasoline surrogate mixtures at intermediate temperatures and high pressures: Experimental 
and numerical approaches". Proceedings of the Combustion Institute, 32(1):501-508, 2009.

[26] C. Westbrook, W. Pitz, and H. Curran. "HCCI and CAI Engines for the Automotive Industry”. CRC, 2007.

[27] P. Dagaut, C. Daly, J. Simmie, and M. Cathonnet. "The oxidation and ignition of dimethylether from low to high temperature (500-1600 K): Experiments and kinetic modeling”. International Symposium on Combustion, 1998.

[28] C. Westbrook, H. Curran, W. Pitz, J. Griffiths, C. Mohamed, and S. Wo. "The effects of pressure, temperature, and concentration on the reactivity of alkanes: Experiments and modeling in a rapid compression machine". International Symposium on Combustion, 1998.

[29] J. Warnatz, U. Maas, and R. Dibble. "Combustion: Physical and Chemical Fundamentals, Modeling and Simulation, Experiments, Pollutant Formation”. Springer, 2006.

[30] E. Hellström, A. Stefanopoulou, J. Vavra, A. Babajimopoulos, D. Assanis, L. Jiang, and H. Yilmaz. "Understanding The Dynamic Evolution of Cyclic Variability at The Operating Limits of HCCI Engines with Negative Valve Overlap”. 2012. SAE Technical Paper 2012-01-1106. 
[31] P. Borgqvist, P. Tunestal, and B. Johansson. "Investigation And Comparison of Residual Gas Enhanced HCCI Using Trapping (NVO HCCI) or Rebreathing of Residual Gases”. 2011. SAE Technical Paper 2011-01-1772.

[32] N. Milovanovic, R. Chen, and J. Turner. "Influence of The Variable Valve Timing Strategy on The Control of A Homogeneous Charge Compression (HCCI) Engine". 2004. SAE Technical Paper 2004-01-1899.

[33] P. Caton, A. Simon, J. Gerdes, and C. Edwards. "Residual-Effected Homogeneous Charge Compression Ignition at A Low Compression Ratio using Exhaust Reinduction. International Journal of Engine Research, 4(3):163-177, 2003.

[34] F. Agrell, H. Ångström, B. Eriksson, J. Wikander, and J. Linderyd. “Transient control of HCCI through combined intake and exhaust valve actuation”. 2003. SAE Technical Paper 2003-01-3172.

[35] US EPA. 2011 News Releases. http://yosemite.epa.gov/opa/admpress.nsf/ 1e5ab1124055f3b28525781f0042ed40/0019c092ccae8ac2852578dc0056ded0! OpenDocument, accessed September 30, 2014.

[36] V. Thakkar. "Experimental setup of an HCCI engine". Master's thesis, Michigan Technological University, 2014.

[37] D Kothari. "Experimental Setup And Controller DesignN For An HCCI Engine". Master's thesis, Michigan Technological University, 2014. 
[38] R Ferraz. LHU Engine. http://www.fmsrperformance.com/test/index.php? route=product/category\&path=20_70, accessed September 30, 2014.

[39] Crane Cams. Degreeing the Camshaft. http://www.cranecams.com/bulletins_ listview.php?s_id=5, accessed September 30, 2014.

[40] Jade, S. "Transient Load-Speed Control in Multi-Cylinder Recompression HCCI Engines". PhD thesis, The University of Michigan, USA, 2014.

[41] Shahbakhti, M. "Modelling and Experimental Study of An HCCI Engine for Combustion Timing Control”. PhD thesis, University of Alberta, Canada, 2009.

[42] J. Dec and M. Sjöberg. "A Parametric Study of HCCI Combustion-The Sources of Emissions at Low Loads and The Effects of GDI Fuel Injection". 2003. SAE Technical Paper 2003-01-0752.

[43] P. Kirchen, M. Shahbakhti, and C. Koch. "A Skeletal Kinetic Mechanism for PRF Combustion in HCCI Engines. Combustion Science and Technology, 179(6):1059-1083, 2007.

[44] S. Aceves, J. Smith, C. Westbrook, and W. Pitz. "Compression Ratio Effect on Methane HCCI Combustion". Journal of Engineering for Gas Turbines and Power, 121(3):569-574, 1999. 
[45] S. Kong, C. Marriott, R. Reitz, and M. Christensen. "Modeling and Experiments of HCCI Engine Combustion using Detailed Chemical Kinetics with Multidimensional CFD”. 2001. SAE Technical Paper 2001-01-1026.

[46] S. Kong, C. Marriott, C. Rutland, and R. Reitz. "Experiments and CFD Modeling of Direct Injection Gasoline HCCI Engine Combustion”. 2002. SAE Technical Paper 2002-01-1925.

[47] A. Agarwal and D. Assanis. "Multi-Dimensional Modeling of Ignition, Combustion and Nitric Oxide Formation in Direct Injection Natural Gas Engines”. 2000. SAE Technical Paper 2000-01-1839.

[48] S. Kong, R. Reitz, M. Christensen, and B. Johansson. "Modeling the Effects of Geometry Generated Turbulence on HCCI Engine Combustion”. 2003. SAE Technical Paper 2003-01-1088.

[49] Z. Wang, J. Wang, S. Shuai, and F. Zhang. "Numerical Simulation of HCCI Engine with Multi-Stage Gasoline Direct Injection using 3D-CFD with Detailed Chemistry”. 2004. SAE Technical Paper 2004-01-0563.

[50] A. Patel, S. Kong, and R. Reitz. "Development and Validation of A Reduced Reaction Mechanism for HCCI Engine Simulations”. 2004. SAE Technical Paper 2004-01-0558.

[51] S. Aceves, D. Flowers, F. Espinosa-Loza, A. Babajimopoulos, and D. Assanis. "Analysis of Premixed Charge Compression Ignition Combustion with a Sequential 
Fluid Mechanics-Multizone Chemical Kinetics Model”. 2005. SAE Technical Paper 2005-01-0115.

[52] I. Bedoya, C. Francisco, S. Saxena, R. Dibble, S. Aceves, and D. Flowers. "A Sequential Chemical Kinetics-CFD-Chemical Kinetics Methodology to Predict HCCI Combustion and Main Emissions”. 2012. SAE Technical Paper 2012-01-1119.

[53] R. Seiser, H. Pitsch, K. Seshadri, W. Pitz, and H. Curran. "Extinction and Autoignition of n-heptane in Counterflow Configuration". Proceedings of the Combustion Institute, 28(2):2029-2037, 2000.

[54] D Flowers, S Aceves, J Martinez-Frias, and R Dibble. "Prediction of Carbon Monoxide and Hydrocarbon Emissions in iso-octane HCCI Engine Combustion Using Multizone Simulations". Proceedings of the Combustion Institute, 29(1):687-694, 2002.

[55] Reaction Design: San Diego, CA. CHEMKIN-PRO theory manual, 2008.

[56] J Chang, O Güralp, Z Filipi, D Assanis, T-W Kuo, P Najt, and R Rask. "New Heat Transfer Correlation for an HCCI Engine Derived From Measurements of Instantaneous Surface Heat Flux”. 2004. SAE Technical Paper 2004-01- 2996.

[57] R. Lupul. "Steady State and Transient Characterization of a HCCI Engine with Varying Octane Fuel”. Master's thesis, University of Alberta, Canada, 2008. 
[58] A. Bhave, M. Kraft, L. Montorsi, and F. Mauss. "Sources of CO Emissions in An HCCI Engine: A Numerical Analysis". Combustion and flame, 144(3):634-637, 2006.

[59] S Tanaka, F Ayala, and JC Keck. A reduced chemical kinetic model for hcci combustion of primary reference fuels in a rapid compression machine. Combustion and Flame, 133(4):467-481, 2003.

[60] H. Yun, N. Wermuth, and P. Najt. "High Load HCCI Operation Using Different Valving Strategies in a Naturally-Aspirated Gasoline HCCI Engine”. 2011. 2011-01-0899, SAE Technical Paper.

[61] M. Bidarvatan and M. Shahbakhti. "Integrated HCCI Engine Control Based on a Performance Index". Journal of Engineering for Gas Turbines and Power, 136(10):101601, 2014.

[62] M. Shahbakhti, A. Ghazimirsaied, and C. Koch. "Experimental study of exhaust temperature variation in a homogeneous charge compression ignition engine". Proceedings of the Institution of Mechanical Engineers, Part D: Journal of Automobile Engineering, 224(9):1177-1197, 2010.

[63] P. Kirchen. "Thermokinetic Modeling of the HCCI Cycle:Predicting the Ignition Timing”. Master's thesis, University of Alberta, Canada, 2004. 
[64] N. Komninos, D. Hountalas, and D. Kouremenos. "Description of In-Cylinder Combustion Processes in HCCI Engines Using a Multi-Zone Model”. 2005. SAE Technical Paper 2005-01-0171.

[65] M. Sjöberg and J. Dec. "Combined Effects of Fuel-Type and Engine Speed on Intake Temperature Requirements and Completeness of Bulk-Gas Reactions for HCCI Combustion”. 2003. SAE Technical Paper 2003-01-3173.

[66] R. Ogink and V. Golovitchev. "Gasoline HCCI Modeling: Computer Program Combining Detailed Chemistry and Gas Exchange Processes”. 2001. SAE Technical Paper 2001-01-3614.

[67] R. Ogink and V. Golovitchev. "Gasoline HCCI Modeling: An Engine Cycle Simulation Code with A Multi-Zone Combustion Model”. 2002. SAE Technical Paper 2002-01-1745.

[68] L. Young and Young T. Camshaft Basics and Terminology. http://www . tildentechnologies.com/Cams/CamBasics.html, accessed September 30, 2014.

[69] L. Koopmans, R. Ogink, and I. Denbratt. "Direct Gasoline Injection in the Negative Valve Overlap of a Homogeneous Charge Compression Ignition Engine". SAE Technical Paper 2003-01-1854.

[70] G. Kontarakis, N. Collings, and T. Ma. "Demonstration of HCCI Using a Single Cylinder Four-Stroke SI Engine with Modified Valve Timing”. 2000. SAE Technical Paper 2000-01-2870. 
[71] D. Law, D. Kemp, J. Allen, G. Kirkpatrick, and T. Copland. "Controlled Combustion in an IC-Engine with a Fully Variable Valve Train”. 2001. SAE Technical Paper 2001-01-0251.

[72] M. Christensen, B. Johansson, P. Amnéus, and F. Mauss. "Supercharged Homogeneous Charge Compression Ignition". 1998. SAE Technical Paper 980787. 


\section{Appendix A}

\section{Calculations for cam timing}

\section{determination}

The following equations from [68] are used to determine the valve timing metrics, provided required values are known. Once IVO (bTDC), IVC (aBDC), EVO (bBDC) and EVC 
(aTDC) are known, then:

$$
\begin{array}{r}
\text { Intake Centerline }(I C)=\frac{(I V C-I V O+180)}{2} \\
\text { Exhaust Centerline }(E C)=\frac{(E V O-E V C+180)}{2} \\
L S A=\frac{I C+E C}{2} \ldots \text { In cam angle degrees } \\
A=E C-L S A \\
\text { Overlap }(O)=E V C+I V O
\end{array}
$$

The following are the definitions for the parameters in Equations (A.1) to (A.5) and also related terms that need to be known before calculating valve timing profile.

Advance (A): Crank angle degree location of the midpoint of the LSA.

Lobe separation angle (LSA): The angle between the exhaust and intake cam lobes measured in cam angle degrees.

Rocker Arm Ratio: It is defined as the ratio of the distance between the valve side to the center or pivot point and the distance between the lash adjuster to the pivot point of the rocker arm.

Valve lash: The maximum distance between the cam lobe and its point of contact with the rocker arm. 
Valve overlap: The crank angle duration for which intake and exhaust valve are simultaneously open.

Lobe centerline: The crank angle degree at which maximum lobe lift occurs. 


\section{Appendix B}

\section{MSc Publications}

$\dagger$ H. Saigaonkar, M. Nazemi, M. Shahbakhti, "Sequential Model for Residual Affected HCCI with Variable Valve Timing", Abstract has been accepted, 14 page manuscript will be submitted to 2015 SAE World Congress by Oct. 15, 2014.

$\dagger$ M. Nazemi, H. Saigaonkar, M. Shahbakhti, “Thermo-kinetic Modeling of Variable Valve Timing Effects on HCCI Engine Combustion”, Int. Conference on Advanced Technology \& Sciences, 6 pages, August 12-15, 2014, Antalya, Turkey. 


\section{Appendix C}

\section{Thesis files summary}

Following files were used for this thesis. Data is arranged in form of tables.

Table C.1

Experimental data files

\begin{tabular}{ccc}
\hline \hline Sr. \# & File Name & Description \\
\hline \hline 1 & Ricardo_ExpData_HCCI_Texh & Experimental data for fuel mass flow rate \\
2 & ExhValveProfile & Exhaust valve profile \\
3 & ExpData_Oct22_Test12 & Experimental data for EFR model \\
4 & ExpData_DynamicModeling & Experimental data for EFR model \\
\hline
\end{tabular}


Table C.2

Matlab script files for HCCI simulation

\begin{tabular}{ccc}
\hline \hline Sr. \# & File Name & Description \\
\hline \hline 1 & CA50DynamicModeling_VO & HCCI physical model \\
2 & CA50DynamicModeling_Cyclic & Function call for physical model \\
3 & GetHeatRelease & Script to calculate NHRR \\
4 & HCCI_loadsiconvert & Volume calculator from CA \\
5 & HCCIResearch_IMEPCalc_bothvalves.m & IMEP calculator \\
6 & FigFile_DataExtractor & Extract axis data from fig files \\
7 & HCCIResearch_plotgenerator_MZM & To process data in form of plots \\
\hline
\end{tabular}

Table C.3

GT - POWER ${ }^{\circledR}$ and CHEMKIN ${ }^{\circledR}$ - PRO files

\begin{tabular}{ccc}
\hline \hline Sr. \# & File Name & Description \\
\hline \hline 1 & GT_HCCImodel_all & GT-POWER ${ }^{\circledR}$ model file \\
2 & MZM_CHEMKINPRO & CHEMKIN ${ }^{\circledR}-$ PRO model file \\
3 & heptanesymp159_mec.inp & $\begin{array}{c}\text { Input file (chemical mechanism) for } \\
\text { CHEMKIN }\end{array}$ \\
& heptanesymp_thermo.dat & Input file (thermodynamic) for \\
4 & CHEMKIN ${ }^{\circledR}-$ PRO model \\
\hline
\end{tabular}

Table C.4

Matlab figure (.fig) files for Chapter 2

\begin{tabular}{ccc}
\hline \hline Sr. \# & File Name & Description \\
\hline \hline 1 & LHUValveProfile & Figure 2.5(a) \\
2 & PistonToValveClearance & Figure 2.6 \\
3 & EmotorSpeed_voltage_map & Figure 2.17 \\
4 & BoostPressData_5Vinput & Figure 2.18 \\
5 & BoostPress_Motoring & Figure 2.19 \\
\hline
\end{tabular}


Table C.5

Image files for Chapter 2

\begin{tabular}{ccc}
\hline \hline Sr. \# & File Name & Description \\
\hline \hline 1 & EngineTestSetup & Figure 2.2 \\
2 & ValveProfileMeasurementProcedure & Figure 2.3 \\
3 & PistonStop & Figure 2.4 \\
4 & PistonToValveClearance & Figure 2.6 \\
5 & Piston_Geom_Volume & Figure 2.7 \\
6 & PistonComparison & Figure 2.9 \\
7 & AirHeaterControlEnclosure & Figure 2.11 \\
8 & AirHeaterLabView & Figure 2.12 \\
9 & SuperchargingStation & Figure 2.13 \\
10 & SuperchargerPlenum & Figure 2.14 \\
11 & EatonMap & Figure 2.15 \\
12 & BoostPress_TestSetup & Figure 2.16 \\
\hline
\end{tabular}


Table C.6

Matlab figure (.fig) files for Chapter 3

\begin{tabular}{ccl}
\hline \hline Sr. \# & File Name & Description \\
\hline \hline 1 & PressVal117 & Figure 3.5 \\
2 & PressVal108 & Figure 3.6 \\
3 & PressVal920 & Figure 3.7 \\
4 & IntValveProfile & Figure 3.8 \\
5 & ExhValveProfile & Figure 3.9 \\
6 & PressureIVC & Figure 3.10 \\
7 & TemperatureIVC & Figure 3.11 \\
8 & ca10ca50bdIVC & Figure 3.12 \\
9 & TivcmodRGFTrg_IVC & Figure 3.13 \\
10 & TempZoomed_IVC & Figure 3.14 \\
11 & Imep_TE_IVC & Figure 3.15 \\
12 & NHRR_IVC & Figure 3.16 \\
13 & CO_IVC & Figure 3.17 \\
14 & uHC_IVC & Figure 3.18 \\
15 & TzoneIVC15 & Figure 3.19 \\
16 & CO_LateOxidn_IVC15 & Figure 3.20 \\
17 & PressureEVO & Figure 3.21 \\
18 & TemperatureEVO & Figure 3.22 \\
19 & ca10ca50bdEVO & Figure 3.23 \\
20 & TivcmodRGFTrg_EVO & Figure 3.24 \\
21 & Imep_TE_EVO & Figure 3.25 \\
22 & NHRR_EVO & Figure 3.26 \\
23 & CO_EVO & Figure 3.27 \\
24 & uHC_EVO & Figure 3.28 \\
25 & VirtTestBedSchematic & Figure 3.29 \\
27 & TE_CL & Figure 3.30 \\
28 & REI_CL & Figure 3.31 \\
29 & CA50_CL & Figure 3.32 \\
30 & Tivcmod_CL & Figure 3.33 \\
31 & FEE_CL & Figure 3.34 \\
\hline & FEE_CF & Figure 3.35 \\
\hline & &
\end{tabular}


Table C.7

Visio figures

\begin{tabular}{ccc}
\hline \hline Sr. \# & File Name & Description \\
\hline \hline 1 & VVTStrategies & Figure 1.1 \\
2 & ThesisOrganization & Figure 1.2 \\
3 & Test setup schematic & Figure 2.1 \\
4 & ValveTimingDiagram & Figure 2.5(b) \\
5 & PistonTopGeometry & Figure 2.8 \\
6 & TKMLitSurvey & Figure 3.1 \\
7 & ModelSchematic & Figure 3.2 \\
8 & MultiZoneTempDist & Figure 3.4 \\
9 & VirtualEngineTestBed & Figure 3.29 \\
\hline
\end{tabular}




\section{Appendix D}

\section{Permissions}

1. This permission is for Figure 2.10.

Hi Sue and Vic,

We had purchased four pistons for our research project at Michigan Technological

University from Wiseco. I am requesting permission to include the datasheet (attached) in my thesis for educational purpose.

I would really appreciate if you could grant me the permission.

P.S: Keith's auto reply suggested your email addresses to contact.

Regards,

Hrishikesh

$\cdots$

Good day, 
We grant permission to use the print for your thesis. Good luck with the program and thank you for using Wiseco Products!

Victor Ellinger

vellinger@wiseco.com 
2. This permission is for Figure 2.15.

Dear Brent Bussell,

I am a graduate student at Michigan Technological University and my research involved the use of a Eaton M62 supercharger. For educational purposes, I want to include its performance map (found on your website) in my thesis. I am requesting permission to use it. I would really appreciate your help in this matter.

Regards,

Hrishikesh

$\cdots$

Please read the FAQ it contains all the info I have, feel free to use what you need.

Brent Bussell

Customer Support

Technical Specialist 
3. This permission is for Figure 2.12.

Hi Dave,

I am a graduate student at Michigan Tech and had met you for a short while on campus before. I am currently using a screenshot (attached) from a LabView VI showing some temperature data. I want to request permission for using it. Can you tell me if it is alright to use this screenshot for my thesis ?

Regards,

Hrishikesh

Hi Hrishikesh,

That would be great if it helps you to display that in your thesis. Did you develop the VI? I only ask because we would have no issue with you sharing screenshots of the program, and the only issue that I might forsee would be if someone else had done the development and wanted a credit for that in the publication.

Best of luck, please let me know if there's anything else I can assist with.

Regards,

Dave 
Dave Collins

Academic Field Engineer - Midwest

National Instruments 